Portland State University

PDXScholar

1981

\title{
Isolation and characterization of frullanolide from Frullania franciscana (Howe)
}

Marshall Stuart Sass

Portland State University

Follow this and additional works at: https://pdxscholar.library.pdx.edu/open_access_etds

Part of the Environmental Chemistry Commons, and the Physical Chemistry Commons Let us know how access to this document benefits you.

\section{Recommended Citation}

Sass, Marshall Stuart, "Isolation and characterization of frullanolide from Frullania franciscana (Howe)" (1981). Dissertations and Theses. Paper 3093.

https://doi.org/10.15760/etd.3087

This Thesis is brought to you for free and open access. It has been accepted for inclusion in Dissertations and Theses by an authorized administrator of PDXScholar. Please contact us if we can make this document more accessible: pdxscholar@pdx.edu. 
AN ABSTRACT OF THE THESIS OF Marshall Stuart Sass for the Master of

Science in Chemistry presented March 1, 1981

Title: Isolation and Characterization of Frullanolide from Frullania franciscana (Howe).

APPROVED BY MEMBERS OF THE THESIS COMMITTEE:

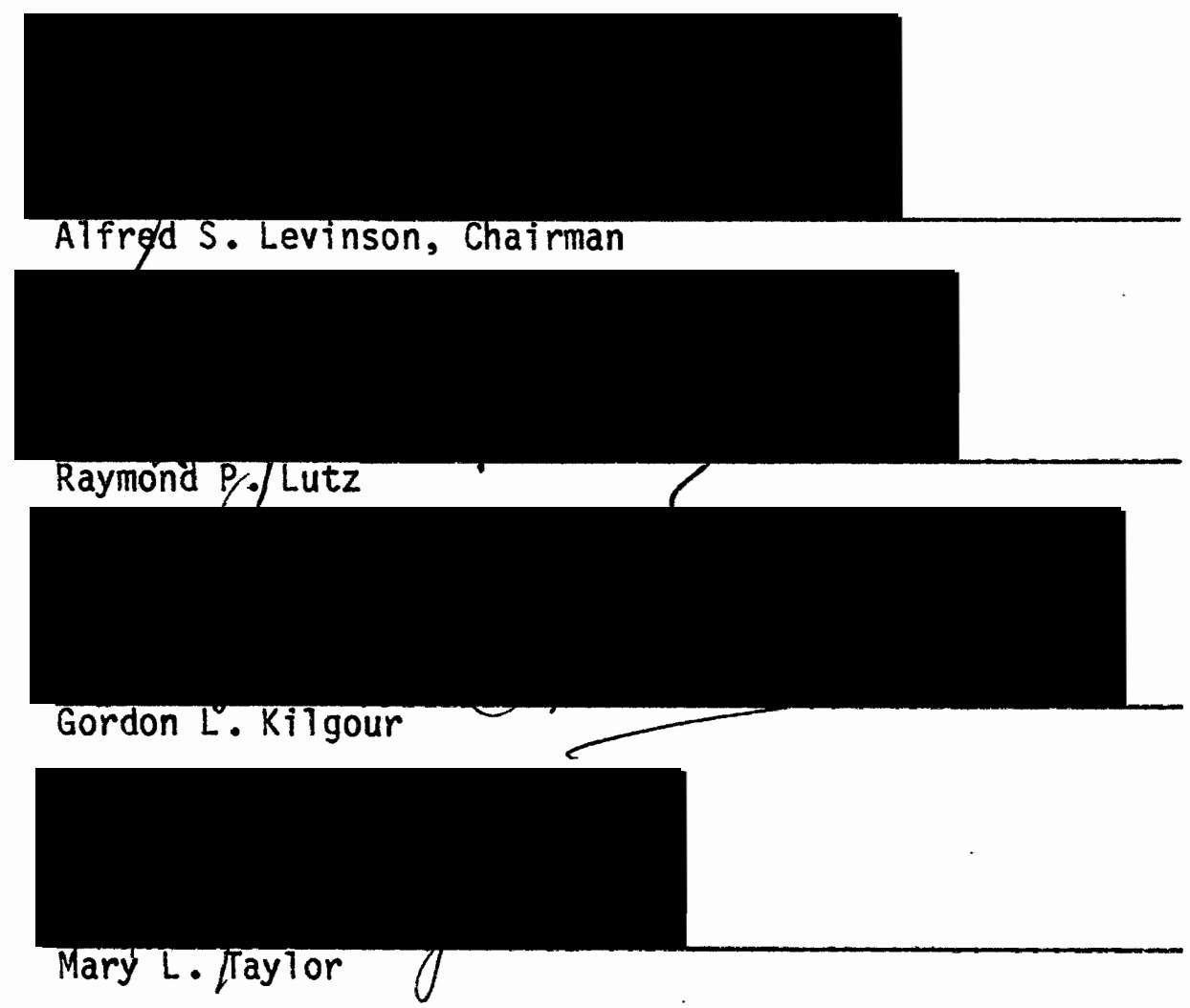

Investigation of the ether extract of the liverwort Frullania franciscana (Howe) resulted in the isolation of the sesquiterpene lactone frullanolide. The separation techniques of thin-layer chromatography, dry column chromatography, and liquid column chromatography were evaluated. Only liquid column chromatography was found usefut . Fractions from alumina liquid column separations had infrared spectra 
which resembled the published spectrum of frullanolide. The identity of the compound obtained from F. franciscana (Howe) was established after extensive purification by comparision of its infrared and nuclear magnetic resonance spectra with published spectra of frullanolide. The method of isolation that was perfected for frullanolide from F. franciscana (Howe) was tested on another species of Frullania reported to contain frullanolide, F. nisquallensis (Sul1). Frullanolide from this source was identified by infrared spectroscopy and melting point determination. Thus the isolation method developed with F. franciscana (Howe) was demonstrated to be applicable in at least one other species of Frullania. 


\section{ISOLATION AND CHARACTERIZATION OF}

FRULLANOLIDE FROM FRULLANIA franciscana (HOWE)

by

MARSHALL STUART SASS

A thesis submitted in partial fulfillment of the requirements for the degree of

MASTER OF SCIENCE

in

CHEMISTRY

Portland State University 
TO THE OFFICE OF GRADUATE STUDIES AND RESEARCH:

The members of the Committee approve the thesis of Marshall Stuart Sass presented March 1, 1981

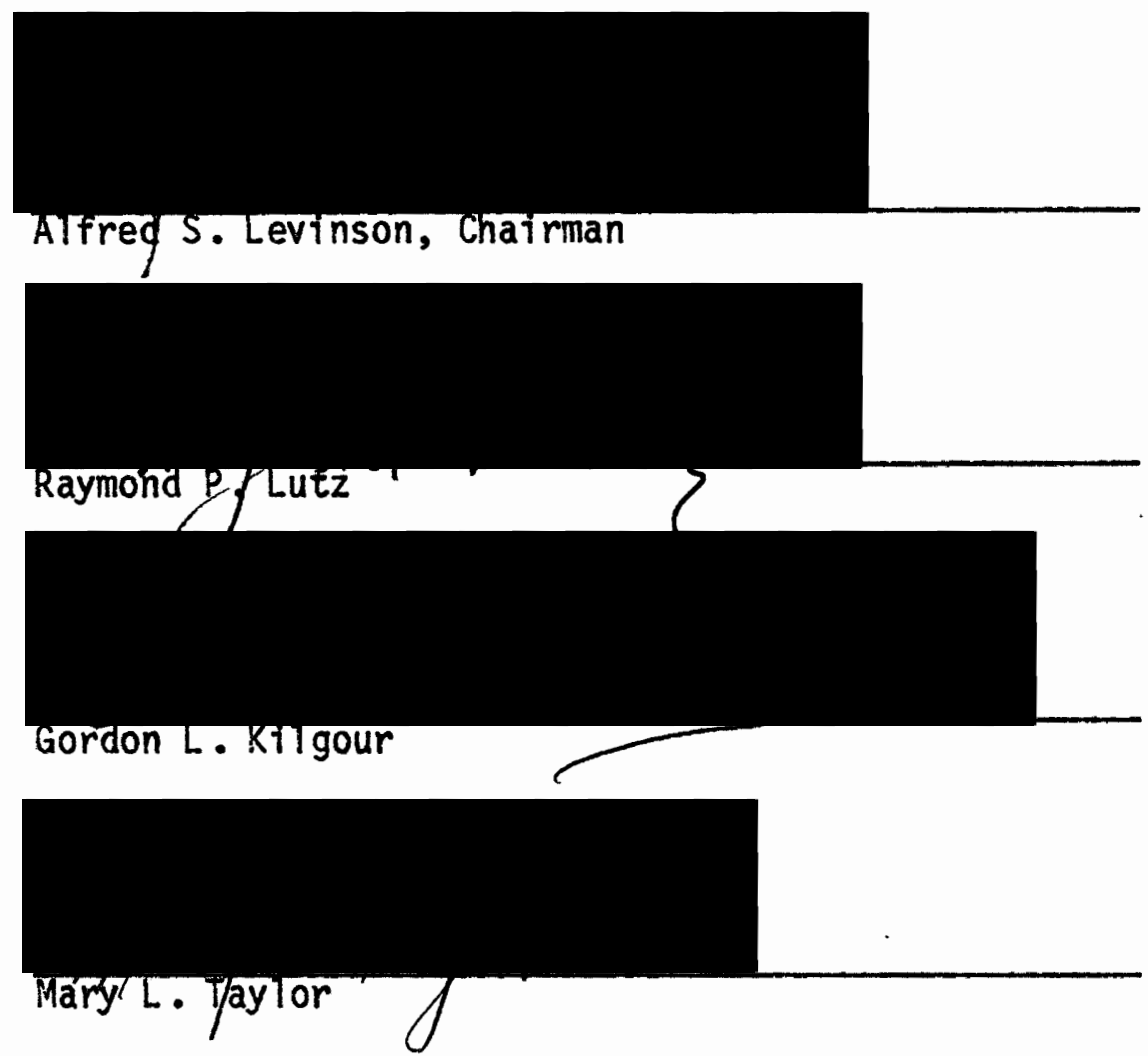

APPROVED:

David W. McClure, Chairman, Department of Chemistry 


\section{ACKNOWLEDGEMENTS}

I wish to thank Dr. Alfred Levinson for many stimulating discussions and for much valuable instruction.

I wish to thank Jim Cronin of the Biology Department, Portland State University, for hìs assistance in collecting and identifying $F$. franciscana (Howe).

I wish to thank Peter Paquet, Biology Department, Portland State University, for his assistance in identifying F. nisquallensis (Sul1).

I wish to thank Dr. Byron E. Lippert, Biology Department, Portland State University, for assistance in identification of liverworts, and for interesting discussions.

I wish to thank Dr. R.G. Kelsey and Dr. F. Shafizadeh, Wood Chemistry Lab, University of Montana, for providing an infrared spectrum of arbusculine $B$.

This thesis is dedicated to my parents, Mr. Harry L. Sass, and Mrs. Bernice C. Sass. Their love and encouragement made this work possible. 
TABLE OF CONTENTS

PAGE

ACKNOWLEDGMENTS ...............................

LIST OF TABLES ......................... vi

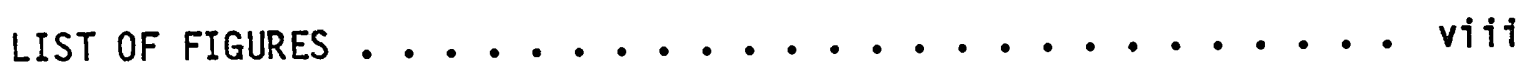

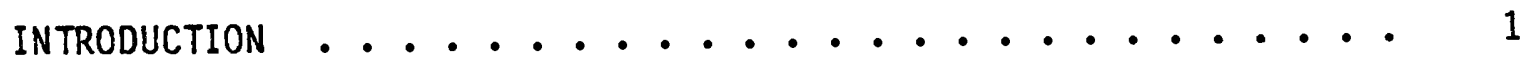

REVIEW OF PERTINENT LITERATURE . . . . . . . . . . . . 4

DISCUSSION .................................... 11

Problems Encountered in the Course of the Research .... 15

Choice of Separation System

Choice of Adsorbant

Choice of Solvent System

Removal of Silicon Lubricant Impurity

Dealing with the Instability and Allergenicity of Frullanolide

Detection of Frullanolide as it was Eluted from the Column

Determining Where to Start and Stop the Collection of Fractions

Investigating the Contents of Each Fraction

Limited Availability of Plant Material

Evaluating the Ability of a Solvent. or Adsorbant to Produce a Clean Fraction

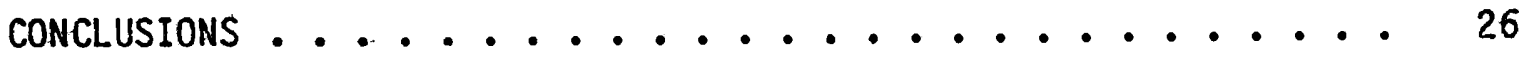

SUGGESTIONS FOR FUTURE RESEARCH . . . . . . . . . 28

Finish Characterization of Frullanolide

Further Development of the Method of Isolation

Find and Study Other Species of Liverwort

Application of the Method to Higher Plants

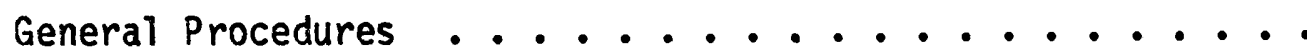

Instruments and Materials

Collection and Identification of Plants

Preparation of the Extract

Putting the Extract on the Column 
Column Chromatography on Alumina of $F$. franciscana (Howe) Extract ....... .........

Initial Chromatograph of $F$. franciscana (Howe) Extract Notes on the Initial Chromatograph

First Rechromatograph of $F$. franciscana (Howe) Extract Notes on the First Rechromatograph

Second Rechromatograph of F. franciscana (Howe) Extract Notes on the Second Rechromatograph

Column Chromatography on Alumina of F. nisquallensis

(Sull) Extract ................

Initial Chromatograph of F. nisquallensis (Sul1) Extract Notes on the Initial Chromatograph

First Rechromatograph of $F$. nisquallensis (Sul1) Extract

Second Rechromatograph of $\vec{F}$. nisqualiensis (Suil) Extract

The Determination of the Sequence of Solvent Elution . .

Introduction

Initial Chromatograph on Alumina

Notes on the Initial Chromatography

Purification of the Frullanolide Containing Fraction by Recrystallization

Use of TLC to Determine an Optimum Purification Solvent

Further Work with Benzene

Scale-up Using Benzene-First Rechromatograph

Search for a Different Purification Solvent that Benzene

\section{BIBLIOGRAPHY} APPENDIX

I. Examination of the $n$-hexane Fractions in Search of a New Alkene

New Alkene

II. Spectra

Notes on the Spectra 


\section{LIST OF TABLES}

TABLE

PAGE

I Separation Methods for a Variety of Plants ...... 5

II Initial Chromatograph of F. franciscana

(Howe) Extract ............ 37

III Data for First Rechromatograph F. franciscana

(Howe) Extract ............ 39

IV Data for Second Rechromatograph F. franciscana

(Howe) Extract ............ 39

$\checkmark \quad$ Initial Chromatograph of F. nisquallensis

(Su11) Extract ............. 40

VI First Rechromatograph of $F$. nisquallensis

(Sul1) Extract ............. 43

VII Second Rechromatograph of F. nisquallensis

(Su11) Extract ............ 43

VIII Initial Chromatography of F. franciscana

(Howe) Extact ............. 45

IX Thin Layer Chromatography of Material from the Initial

Chromatograph .............. 46

X Chromatography of Mixture A Using Benzene . . . . . 4 48

$X I$ Scale-Up of the Experiment Using Benzene-Initial

Chromatograph . . . . . . . . . 48

XII Scale-Up Using Benzene-First Rechromatograph ..... 49

XII Chromatography with a Variety of Solvents . . . . . 50 
PAGE

XIV Examination of the Hydrocarbon Fractions of Frullania - 54

XV Guide to the Spectra ............ 57 


\section{LIST OF FIGURES}

FIGURE

PAGE

1 Summary of Procedure for Isolation of Frullanolide

$$
\text { from F. franciscana (Howe) ....... } 12
$$

2 Summary of Procedure for Isolation of Frullanolide

from F. nisqualiensis $(S u 11) . . . . . .13$

3 Classification of Frullania Species Found in Oregon ... 33

4 Summary of the Procedure for the Determination of the

Sequence of Solvent Elution ........ 44 


\section{INTRODUCTION}

The liverwort Frullania franciscana (Howe) is a plant found in western Oregon $(1,2)$. Liverworts are members of the division Bryophyta, as are mosses. Bryophyta is placed in an intermediate position between the algae and the higher plants. F. franciscana (Howe) is one of five species of the genus Frullania growing in Oregon. Frullania are usually found near sources of water, such as streams, waterfalls that give off spray, or the ocean. The Bryophyta themselves are easy to recognize as they form a carpet of plant material on the trees, rocks and logs on which they grow.

Some species of Frullania are believed to be occupational hazards to workers in the forest products industry (3). Contact with the plant is most likely when the bark of a tree on which Frullania grows is handled. Contact with the plant can lead to the development of an allergy so severe that the worker must abandon any aspect of his profession that involved contact with the bark of trees that have been in contact with Frullania (4). It has been shown that, in most cases, it is Frullania, not the tree bark itself, that causes the allergy $(4,5)$. Some of the species that have been investigated are $F$. nisquallensis (Su11) (3), F. tamarisci $(6,7), F_{-}$brittonia (Evans) $(7,8)$, and $F_{\text {. }}$ dilatata $(7,8)$. These plants were subjected to chemical separation and analysis. Isolated compounds were applied separately to the skins of sensitive patients to determine if each could cause the allergy $(3,7,8)$. Each Frullania species mentioned yielded the compound 
frullanolide (I) as at least one of the allergy causing compounds. Frullanolide was found to be the most allergenic sesquiterpene lactone found in Frullania (3). It was thus of interest to see if frullanolide was present in $F$. franciscana (Howe). Demonstration of frullanolide in F. franciscana (Howe) would establish the basis of the plant's hazardous character.

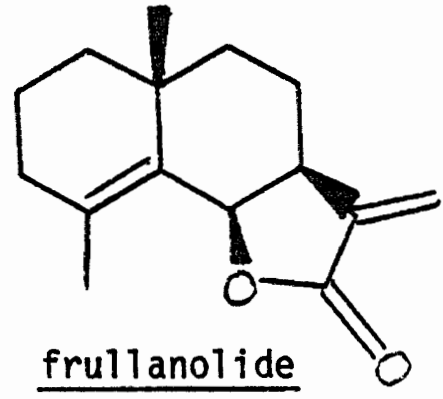

(I)

Frullanolide is a member of the class of sesquiterpene lactone compounds. There are approximately 924 sesquiterpene lactones known (9). The sesquiterpene lactones have been found to have profound and varied biological activities. Not all of the sesquiterpene lactones produce all of the biological effects to the same degree. Thus, it is of interest when a compound such as frullanolide produces a distinct and powerful biological effect. Among the range of biological effects seen with the sesquiterpene lactones are tumor cell and normal cell killing $(10,11)$, inhibition of the germination of seeds of plants (12), inhibition of bacterial growth (10), inhibition of the growth of higher plants (10), prevention of parasitic infection (10), deterrence of insect feeding (10), poisoning of vertebrates (10), and, of interest here, the ability to cause allergy (3). The concurrence of allergenicity and tumor cell killing has evoked surprise in the literature (13). Thus, this research was motivated in part because of the diverse 
biological activity shown by sesquiterpene lactones.

Efforts to obtain frullanolide from $F$. franciscana (Howe) by A. Levinson (14) were partially successful. An infrared spectrum of a fraction from silica column chromatography (Spectrum \#25) was very similar to the literature infrared spectrum of frullanolide (Spectrum $\# 30$ ). The work was continued by T. Huang (15) who experimented with silica column chromatography. He found it ineffective for routinely separating frullanolide from a $\underline{F}$. franciscana (Howe) extract by a single pass of the extract through the column. Better results were obtained with alumina liquid column chromatography. A fraction was obtained that demonstrated a very strong $1760 \mathrm{~cm}^{-1}$ absorption in its infrared spectrum, characteristic of a lactone ring with five carbons (16). The column was eluted with (in order) $\underline{n}$-hexane, benzene, ethy] ether, and methanol. The lactone fraction emerged with a benzene fraction. Another factor of interest is that the lactone fraction's infrared spectrum did not show the frullanolide fingerprint (7) (especially the $910 \mathrm{~cm}^{-1}$ absorption) to the degree that was seen in the previous work of Dr. Levinson.

The extract of Huang also produced a hydrocarbon which was partially characterized as a sesquiterpene hydrocarbon. The hydrocarbon was found to be present in a relatively large amount.

The primary goal of the research described herein was to isolate pure frullanolide from F. franciscana (Howe). 


\section{REVIEW OF PERTINENT LITERATURE}

The chemical literature is rich with accounts of the isolation of sesquiterpene lactones from a variety of plants. A survey will be made of some papers pertinent to this problem. A summary is given in Table I. Following this will be a discussion of the characterization of frullanolide.

A leader in the field of sesquiterpene lactone isolation is W. Herz. His methods represent a high state of development of the isolation of sesquiterpene lactones from plant extracts. A representative example (17) of his approach is discussed below.

Herz first powdered the wood of Eremanthus goyazensis and then extracted the $22 \mathrm{~kg}$ of powder with hot ethanol. The residue from evaporation of the polar solvent was chromatographed using a benzene packed silica column. The column was eluted with solvent mixtures of increasing polarity, and 273 fractions were collected in all. Each fraction was analyzed by thin layer chromatography; similar fractions were then combined. Preparative thin layer chromatography of similar fractions produced pure compounds. The amounts of the compounds of interest that were finally obtained were $60 \mathrm{mg}$ and $50 \mathrm{mg}$.

G.W. Perold, J.C. Muller, and G. Ourisson $(7,18)$ described two methods for the isolation of frullanolide from F. tamarisci (L.) Dum. The first method used unmilled whole plant material for the extraction. In the second method, the plant material that had been extracted once was milled and the powder obtained was then extracted. 
TABLE I

SEPARATION METHODS FOR A VARIETY OF PLANTS

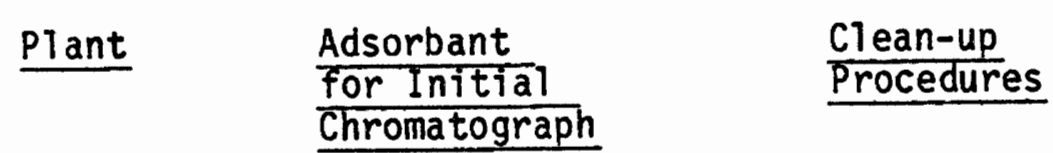

$\underline{\text { Reference }}$

Chromatograph

F. tamarisci

silica

TLC

7

(L) (Dum)

F. tamarisci

silica

fractional crystallization

fractional distillation

F. nisquallensis silica

several silica columns (sult) fractional sublimation

F. tamarisci

a)umina

TLC

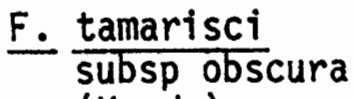

silica

TLC

(Verd.)

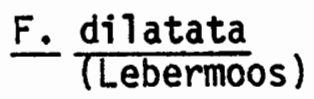

silica

several silica columns

8

Artemisia

silica

TLC

21

arbuscula

(Nutt) subsp

arbuscula

F. franciscana

a) umina

TLC

15

F. franciscana

a) umina

more alumina columns

this thesis 
In the first method of Perold, et al, 203 grams of air dried F. tamarisci (L.) Dum. was extracted with ether in a Soxlet extractor. (The residue (200 grams) was used in the second method.) The extract (2.22 grams) was chromatographed on silica ge1. A dark green fraction eluted with benzene-ethyl acetate $9: 1(\mathrm{v} / \mathrm{v})$. This fraction eventually produced 23 milligrams of impure frullanolide which was purified by a complex process: 1 . removal of another compound by crystallization with hot benzene. 2. distillation of the mother 1iquor. 3. crystallization of the frullanolide out of the distillate.

The second method of Perold began with the milling of the 200 grams of whole plant residue of the previous method. The powder was then extracted with ethyl ether in a Soxlet extractor. The extract (4.3 grams) obtained was chromatographed on silica ge1, and material from the green band was vacuum distilled. A crystalline product 11.33 grams) was obtained from the distillate. Recrystallization three times gave $440 \mathrm{mg}$. of suspected frullanolide.

Another early paper of the isolation of frullanolide from Frullania was by J.C. Mitchell et al. in 1970 (3). Mitchell started with 500 grams of dried F. nisquallensis (Sul1) which was extracted with several different organic solvents. The concentrated extracts were applied to the skin of patients known to be sensitive to Frullania. Ether was found to produce the extract with the most allergic response. The 500 grams of plant material was milled and extracted with ethyl ether several times. Because of this experiment by Mitche11, ether was used in the F. franciscana (Howe) research for extraction. Additionally, some work in the laboratory of A. Levinson indicated that 
ethyl ether was the extraction solvent of choice (19). Mitchell chromatographed the ether extract on silica gel. Ether and petroleum ether mixtures were used to elute the column and repetition of the process was necessary for purification.

Frullania tamarisci (L.) Dum. was investigated for sesquiterpene lactones by J.D. Connoly (6). His procedure differed in a number of ways from the above methods. Chloroform was used to prepare the extract instead of ether. A7so, alumina, rather than silica, was used in the initial chromatography. The sesquiterpene lactones were purified further by preparative thin-layer chromatography, a fairly common method.

Frullania tararisci subsp. obscura (verd.) (Hattori) was investigated by $Y$. Asakawa $(20)$. The procedure was similar to previous procedures: extraction with ether, initial chromatography on silica gel with n-hexane-ethyl acetate as elutant, and further purification with thin-layer chromatography. Frullanolide was not isolated, but other sesquiterpene lactones with similar structures were isolated.

The absence of detectable amounts of frullanolide from F. tamarisci subsp. obscura (verd.) (Hattori) lends interest to the investigation of F. franciscana (Howe) for the presence of frullanolide. It is never known whether frullanolide will be present in a particular species until that species has been properly investigated. However, if many species had been investigated and all possessed frullanolide, it would be less interesting if "yet another" species contained the compound. In two other species of Frullania, frullanolide was not detected (7). These are F. atrata from Guadeloupe, and F. ecklonii 
from South Africa. Allergic activity was attributed to these two plants nonetheless. The question of the presence of frullanolide in F. franciscana (Howe) is therefore made more interesting by the apparent absence of the compound in these three species of Frullania.

One attempt at the isolation of frullanolide from Frullania proved very successful for yielding large amounts of frullanolide. Frullanolide was found by $Y$. Asakawa (8) as the major sesquiterpene lactone constituent of $F$. dilatata (Lebermoos). Ether extraction of 1500 grams of the plant produced 71 grams of extract. The extract was chromatographed on silica, yielding a lactone fraction that weighed 28 grams. Details of solvents used for elution were not given. The lactone fraction was rechromatographed on silica to yield 7.1 grams of frullanolide.

The positive identification of frullanolide has involved a comparision of the various characteristics of the compound with those described by Perold (7). Frullanolide is characterized by an infrared spectrum, a nuclear magnetic resonance spectrum, a melting point determination, a boiling point determination, and an optical rotation determination. Less. valuable are the $R f$ in thin layer chromatography and the intense blue color that is seen when frullanolide is sprayed with $50 \%$ sulfuric acid (3).

The infrared spectrum is often the easiest and most useful technique to employ in the identification of a known compound. A spectrum of frullanolide fortunately was published by Perold (7) and a reproduction of it appears in the spectra section (Spectrum \#30). A nuclear magnetic resonance spectrum of frullanolide also was published by 
Perold (7) (Spectrum \#31).

Comparision of melting points is a standard technique of identification in organic chemistry. For frullanolide, the reported melting points are: $74-76^{\circ} \mathrm{C}(6), 77^{\circ} \mathrm{C}(7)$, and $75-76^{\circ} \mathrm{C}(8)$. A boiling point at 0.1 torr is reported at $120-130^{\circ} \mathrm{C}(7)$. The optical rotation of frullanolide has been reported: $[\alpha]_{D}= \pm 114^{\circ}(7),[\alpha]_{D}= \pm 109^{\circ}(6)$, and $[\alpha]_{D}= \pm 94^{\circ}(8)$. Coptical rotation data is presented as seen in the literature.)

Arbusculine $B$ (II) is a diastereoisomer of frullanolide, differing

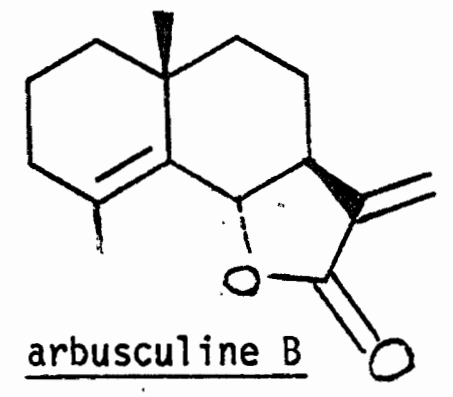

(II)

at one chiral center. Arbusculine $B$ has been isolated from Frullania species along with frullanolide $(6,8)$ as well as from a species of sagebrush (21). It is important therefore to distinguish between arbuscul ine $B$ and frullanolide. Infrared and NMR (Spectrum \#32) spectra of arbusculine $B$ are available; there are significant differences between the spectra of the two compounds $(21,22,23)$. The melting point of arbusculine $B$ is reported to be: $86-87^{\circ} \mathrm{C}(6), 86.5-88^{\circ} \mathrm{C}$ (21) and $85-86^{\circ} \mathrm{C}(8)$. The optical rotation of arbusculine $B$ has been reported as $[\alpha]_{D}=+27^{\circ}(6)$ and $[\alpha]_{D}=+22^{\circ}(21)$.

The properties of alantolactone (III), one of the few commercially available sesquiterpene 1actones, are often compared to the properties of other sesquiterpene lactones. Alantolactone is considered to be one 
of the most allergenic compounds known (3). The Rf values (thin layer chromatography, adsorbant unspecified) of frullanolide, arbusculine $B$ and alantolactone are all different (3). This fact may be useful in identifying the compounds. In the solvent system ethyl acetate-cyclohexane $(10 / 90(v / v))$, the respective Rf's are: frullanolide: 0.25 , arbusculine $B: 0.37$, and alantolactone: 0.22 .

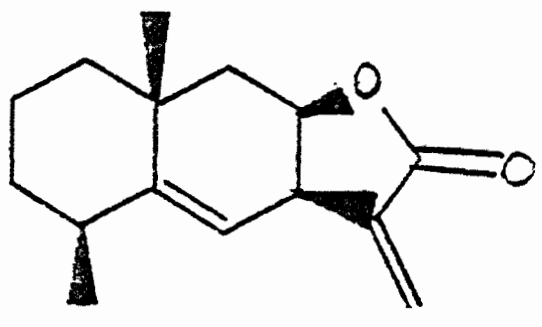

$$
\text { alantolactone }
$$

It is believed that the sesquiterpene lactones owe their biological activity to the reactivity of the $\alpha$-methylene $\gamma$-lactone group with nucleophiles (24). The generally accepted theory is that the $\alpha$-imethylene $\gamma-1$ actones combine by the Michael addition with cysteine or other nucleophlic amino acids present in proteins (25).
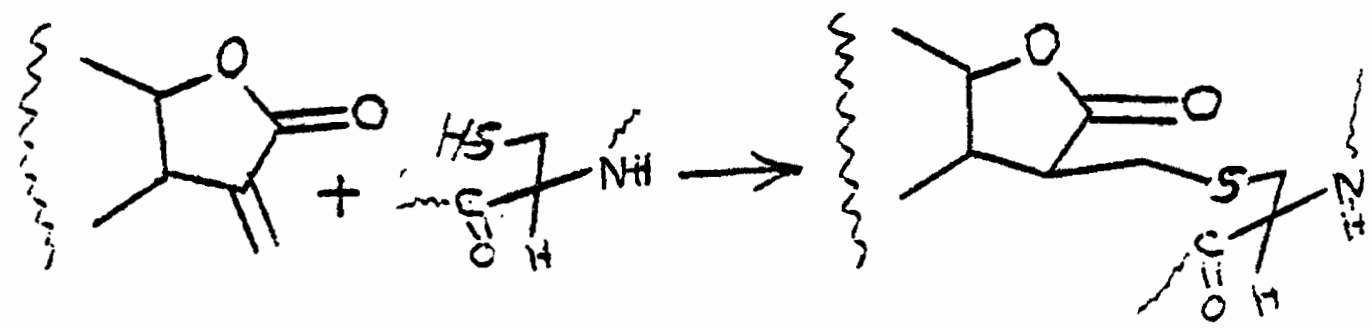

The exocyclic methylene group is a necessary, but not sufficient condition for immunologic activity. Some sesquiterpene lactones with the $\alpha$-methylene group are not immunologically active (26). It is not clear what other factors are involved. 


\section{DISCUSSION}

The point of this research is twofold: 1 . to attempt to isolate and characterize frullanolide from F. franciscana (Howe) and 2. to apply the method developed in 1. to another species of liverwort to test its generality. In the experimental section is described a set of experiments that led to the isolation and partial characterization of frullanolide from $F$. franciscana (Howe). In the experimental section there also is described a set of experiments that led to the isolation and partial characterization of frullanolide from F. nisquallensis (Sul1), a species known to contain this compound (3).

The method developed for the isolation used liquid column chromatography on alumina. The most sensitive part of this method is the sequence of solvent elution. The sequence of solvent elution was developed with a series of experiments that are described in the Experimental section.

The separation for each species is summarized in Figure 1 and in Figure 2. These procedures represent the highest state of the art and yield developed during this project.

A white, crystalline compound was obtained by chromatographic means from both F. franciscana (Howe) and F. nisqualiensis (Sul1). These compounds were subjected to a series of tests which identify the compounds as frullanolide.

The identification of the material obtained from chromatography was by an infrared spectrum (Spectrum \#27), a proton nuclear magnetic resonance spectrum (Spectrum $\# 29$ ) and a melting point determination. 


\section{Extract Preparation}

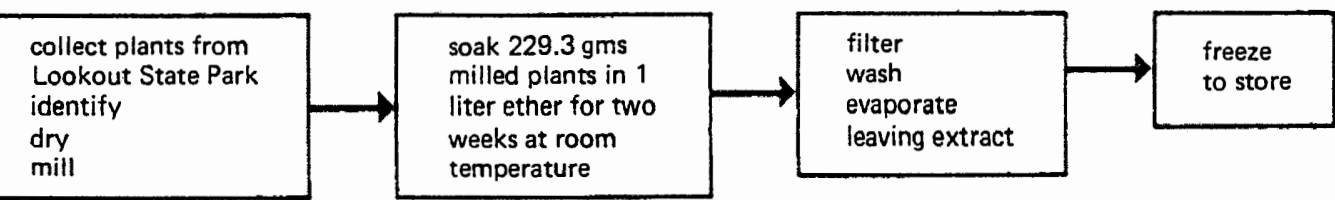

\section{Initial Chromatography}

wet pack in $n$-hexane a $25 \mathrm{ml}$ buret $24.5 \mathrm{gms}$ alumina

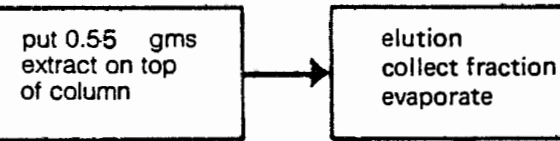

2.
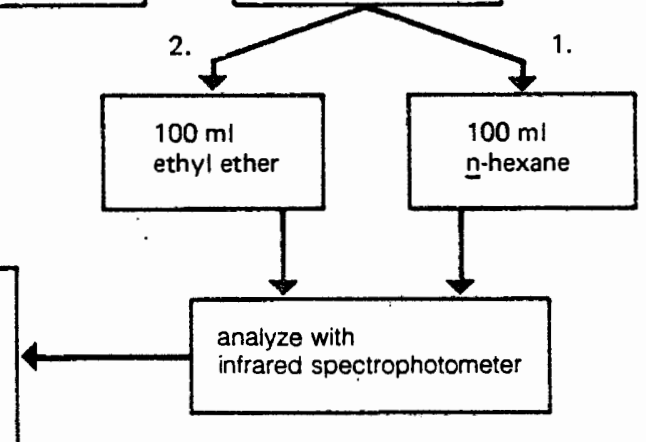

$1765 \mathrm{~cm}^{-1}$ absorbing

fractions; those

that eluted between

$15 \& 40 \mathrm{ml}$ ether

\section{2nd Chromatography}

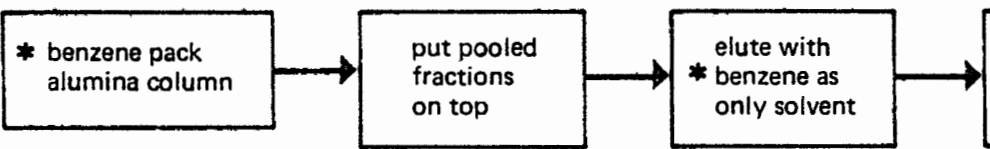

pool fractions

showing infrared

"frullanolide fingerprint'

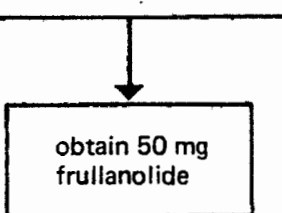

- $\mathrm{CCl}_{4}$ was subsequently found to be superior

to benzene for the rechromatograph.

\section{FIGURE 1}

\section{Summary of Procedure for Isolation of Frullanolide from F. franciscana (Howe)}




\section{Extract Preparation}

collect plants from

Young's River

identify

dry

mill

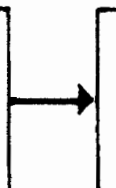

soak 139.2 gms milled

plant in $?$ liter ether

for two weeks at room

temperature

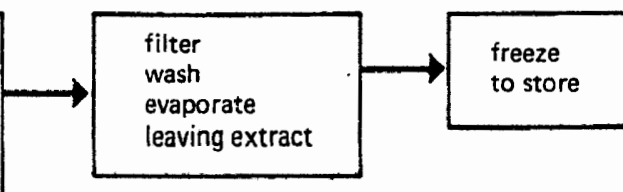

Initial Chromatography

wet pack in $\underline{n}$-hexane

50 gms alumina

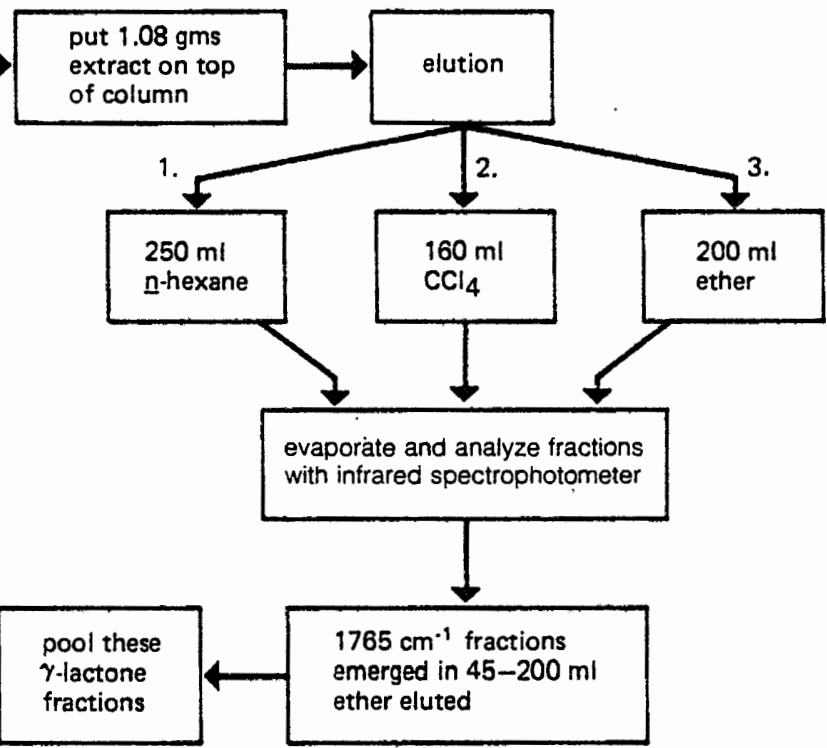

2nd Chromatography

wet pack in $\mathrm{CCl}_{4}$ and alumine column

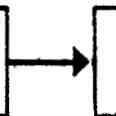

put pooled material

(64.2 mg) on column

elute with

$\mathrm{CCl}_{4}$

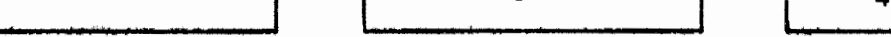

\begin{tabular}{|l|l|l|l|}
\hline $\begin{array}{l}\text { recrystallize } \\
\text { in n-hexane } \\
\text { air dry }\end{array}$ & $\begin{array}{l}\text { pool fractions } \\
\text { showing infrared } \\
\text { "frullanolide fingerprint" } \\
49.8 \mathrm{mg} \text { of material }\end{array}$
\end{tabular}

\section{FIGURE 2}

Summary of Procedure for Isolation of Frullanolide

from F. nisquallensis (Sull) 
The first two were done for material isolated from F. franciscana (Howe); the first and last were done for material isolated from $\mathrm{F}$. nisquallensis (Su11).

The means of preparation of the compound for taking the infrared spectrum differed from the means of preparation in the literature. This was done to prevent possible harm to the sample, and to facilitate recovery of the sample. In the literature (7), a $\mathrm{KBr}$ pellet was made, while in this work the sample was deposited on a $\mathrm{NaCl}$ plate in a thin film (see Experimental). The resulting spectrum is nonetheless a good match with the literature infrared spectrum (7).

A proton nuclear magnetic resonance spectrum was taken of the frullanolide from $F$. franciscana (Howe). This frullanolide was the combination of material obtained from several experiments. These nuclear magnetic spectra are reproduced in Spectrum \#28 and Spectrum \#29. A nuclear magnetic resonance spectrum of the compound isolated from $F$. nisquallensis (Sul1) was not taken.

A melting point determination of frullanolide from F. nisquallensis (Su11) gave $72-73^{\circ} \mathrm{C}$ and $73-74^{\circ} \mathrm{C}$. This material had been recrystallized in $n$-hexane once.

Tests that were not done for material from $F$. franciscana (Howe) are a melting point determination, an optical rotation, an Rf determination on TLC and a color test with $50 \% \mathrm{H}_{2} \mathrm{SO}_{4}$. Tests that were not done for material isolated from F. nisqualiensis (Sull) are: a nuclear magnetic resonance spectrum, an optical rotation and the TLC Rf and $\mathrm{H}_{2} \mathrm{SO}_{4}$ test.

The most sensitive characterization of the compound isolated from $F$. franciscana (Howe) was the proton nuclear magnetic resonance 
spectrum. Comparison of the spectrum obtained with the published spectra of frullanolide and arbusculine $B$ identify the compound as frullanolide. The observed NMR spectra (Spectra \#28 and \#29) show peaks at 7.2 de7ta, 6.1 delta and a doublet at 5.1 and 5.2 delta. The published spectrum (Spectrum \#31) shows the same peaks. The published spectrum of arbusculine B, on the other hand, has no doublet at 5.1 delta but has a doublet at 4.5 delta.

\section{PROBLEMS ENCOUNTERED IN THE COURSE OF THE RESEARCH}

A number of technical problems were encountered in the course of the research. These will be 1 isted and then discussed in turn. In some cases, no solution to the particular problem was found.

1. Choice of separation system.

2. Choice of adsorbant.

3. Choice of solvent system.

4. Removal of silicon lubricant impurity.

5. Dealing with the instability and allergenicity of frullanolide.

6. Detection of frullanolide as it was eluted from the column.

7. Determining where to start and stop the collection of fractions.

8. Investigating the contents of each fraction.

9. Limited availability of plant material.

10. Evaluating the ability of a solvent or adsorbant to produce a clean fraction. 
1. Choice of Separation System

A number of alternatives were tried: thin layer chromatography (analytical and preparative), dry column chromatography, recrystallization of the extract and liquid column chromatography. Only liquid column chromatography gave good results.

Thin layer chromatography of a F. nisquallensis (Sull) extract yielded a band that contained frullanolide (3). The same procedure was applied to a F. franciscana (Howe) extract, but streaking, not distinct bands or spots, was observed. It was hoped that a better separation would result by increasing the amount of adsorbant. To this end, dry column chromatography, a form of preparative thin-layer chromatography, was tried. The results were similar to the thin-layer work: no distinct separation was found with a variety of solvents.

Liquid alumina column chromatography next was tried because the method had demonstrated some promise in previous work by T. Huang (15). Huang obtained a fraction which absorbed relatively sharply at 1769 $\mathrm{cm}^{-1}$ (Spectrum \#26) . By comparison, the infrared absorption of fractions from dry column chromatography spanned the carbonyl region.

The ether extract of the dried plant material was chromatographed on a liquid alumina column. A fraction from this experiment gave a broad $1760 \mathrm{~cm}^{-1}$ absorption, characteristic of a lactone (Spectrum \#2). This fraction was chromatographed on a fresh liquid alumina column, and a sharp peak centered at $1765 \mathrm{~cm}^{-1}$ was obtained (Spectrum \#13). This was taken as an indication of improvement over the dry column or the thin-layer methods. Thin layer chromatography did give some valuable information (see experimental), but the technique was ineffective in purifying the lactone fraction. 
2. Choice of Adsorbant

The following adsorbants were tested: silica in thin layer chromatography, silica in dry column chromatography and two grades of alumina in liquid column chromatography. T. Huang (15) found silica in liquid column chromatography ineffective, so this was not tried. The cheaper grade of alumina was found to be the most effective of all the adsorbants tested.

\section{Choice of Solvent System}

The solvent system that was eventualiy devised is described in the experimental section. The solvents that were found usefur (in their order of elution) are: $\underline{n}$-hexane, $\mathrm{CCl}_{4}$, and ethyl ether. The choice of these solvents was determined emperically.

\section{Removal of Silicon Lubricant Inpurity}

No silicone lubricant was used, but silicon lubricant was seen in fractions that also contained frullanolide. For example, traces of silicone lubricant can be seen in Spectra \#1, \#2, \#4, and \#5. The presence of silicone lubricant is indicated by three characteristic peaks: two peaks are between $1000 \mathrm{~cm}^{-1}$ and $1100 \mathrm{~cm}^{-1}$, and one peak is at $800 \mathrm{~cm}^{-1}$. By comparison, examination of Spectum $\# 27$, a purified frullanolide spectrum, reveals a frullanolide peak at $820 \mathrm{~cm}^{-1}$. The problem was solved by using excessive $n$-hexane at the beginning of the elution and also a little $\mathrm{CCl}_{4}$ before the ether elution. As seen in Spectrum \#8, the silicon lubricant has been significantly removed. The removal of the silicone lubricant required at least two successive chromatographs starting with the extract. 
The silicone lubricant probably came from residue on glassware. Distillation apparatus and other glassware were rinsed with distilled ether before solvents were distilled, yet the silicon lubricant remained. Repeated evaporaton of solvents in the preparation of frullanolide could have led to the concentration of trace amounts of this impurity.

\section{Dealing with the Instability and Allergenicity of Frullanolide}

Frullanolide is known to be unstable because if left in the hood in an open container for a period of several months, the properties of the material would change. It would no longer be as soluble in ether, for example. Precautions were taken to prevent chemical change in the frullanolide once it was isolated from the extract. The frullanolide was stored under nitrogen in a sealed container in a freezer. Excessive heat was not applied to any solution containing frullanolide. Thus, a solution eluted from a column was left standing overnight in the hood at room temperature to evaporate. It is possible that some of the frullanolide from the $F$. nisquallensis (Su1l) experiment was destroyed during recrystallization. Little material remained after the approximateiy $50 \mathrm{mg}$ was recrystallized. This behavior is not unique, as recrystallization reduced the amount of material by one third in one case described in the literature (7). On the other hand, heat was used in the isolation of frullanolide from plant extracts: fractional sublimation (3), distillation (7) and Soxlet extraction (7). Yields of $0.005 \%$ (3) to $0.2 \%$ (8) of plant dry weight were reported, but $1-3 \%$ of dry weight was estimated. More studies are needed to determine if heat in the isolation process has any effect on the compound. Another problem related to the instability of frullanolide is the 
allergenicity of the compound, the piant and the extract. If a worker becomes allergic to the plant, further work with the plant or its products would be difficult $(4,6)$. It was found that the use of gloves and the use of the hood when handling the plants and the extract prevented any health problems. At the beginning of the research, these precautions were not taken, and allergy did indeed develop. However, when the precautions were taken, no health problems were then observed. The work continued for a period of two years without the symptoms of the allergy reappearing. Gloves were used when collecting plants, and care was taken not to breath directly the plants, extract, solutions or purified compounds.

6. Detection of Frullanolide As It Was Eluted from the Column

This was a problem that was not solved. Frullanolide is a colorless compound (7). It cannot be seen in a band in thin layer chromatography or in column chromatography. It is ultraviolet absorbing (7), but an ultraviolet spectrophotometer in line with a low pressure column was not available. The use of high pressure liquid chromatography with an ultraviolet detector remains unexplored.

Several unsuccessful attempts were made to detect frullanolide during liquid column, dry column, or thin-layer chromatography. In the latter two cases, the adsorbants contained a dye that glows in ultraviolet light. If a compound were present, the flourescence would be quenched at that spot. No useful results were obtained with ultraviolet light and adsorbants with dye.

Another attempt involved application of the $\mathrm{H}_{2} \mathrm{SO}_{4}$ test (3) to drops eluting off the column. The test worked with relatively pure and 
concentrated solutions of frullanolide in $\mathrm{CCl}_{4}$ or ether. The color change was from colorless to purple. The test was applied to similar solutions of alantolactone; the color change was from colorless to brown. The test did not work with fruilanolide in solution as frullanolide eluted from the column. The test was done for all of the fractions, one of which at least contained frullanolide, No color change was seen. The frullanolide solution was probably too dilute.

7. Determination of Where to Start and Stop the Collection of Fractions

Since frullanolide could not be detected as it eluted out of the column, this problem posed particular difficulty. As was mentioned above, heat was not used to evaporate the solvents from elution. Consequently, the results of the chromatography were not known until the next day. The choice of where to start and stop collection of fractions had therefore to be based on the accumulated experience of many chromatographs. Where frullanolide would emerge could then be predicted with some degree of accuracy for a given column bed size.

There are some loose relationships between bed size and the number of milliliters of $\mathrm{CCl}_{4}$ or ether that are needed to be collected before frullanolide appears. The column itself was usually a buret with milliter markings. The dry weight of the alumina in grams was nearly equal to the volume in milliters of the wet-packed alumina.

A rule of thumb for size of fractions when frullanolide was being eluted was developed. When $\mathrm{CCl}_{4}, \mathrm{CH}_{2} \mathrm{Cl}_{2}$, or ethyl ether was used as solvent, it was found most convenient to make the volume of each fraction equal to the volume of the wet-packed alumina. Deviation occured when it was desired to collect fractions according to color or 
according to the "solvent front" of ether (see below). The "one column volume" was not adhered to strictly, but most fractions were of that order. If some $\mathrm{CCl}_{4}$ were used in the initial chromatograph, three column volumes of this solvent would remove impurities but would not elute frullanolide to any great extent. More $\mathrm{CCl}_{4}$ than this would elute the compound, however.

Another indication of where frullanolide would elute was obtained from the observation of the movement of plant pigments in the chromatography column. Frullanolide was reported as being in a green fraction (7). In chromatography of F. franciscana (Howe) and F. nisquallensis (SUlT), frullanolide appeared between yellow and green colored bands. This was useful knowledge when work on the problem was beginning, because there was no other indication of where to collect fractions. However, erronous predictions were occasionality made. As more knowledge was gained, observation of colored bands was dispensed with as a useful indication of the location of frullanolide. It was of supreme value at the early stages of the research, however. It will be interesting to see if, in future chromatographs of Frullania species, the sesquiterpene lactones appear at the transition between yellow and green colored bands.

A very useful method of knowing where to stop and start fractions was discovered when sharp changes in elution solvents were made. In changing from $\mathrm{CCl}_{4}$ to ethyl ether, a color change was seen in the adsorbant. A sharp line of demarcation ("solvent front") was seen to move down the column as ether was added. Frullanolide was found to be in the eluted solvent immediately behind this line of demarcation. 
8. Investigation of the Contents of Each Fraction

Infrared spectra were used extensively to monitor the chromatography fractions. Analysis by thin layer chromatography was found to be of limited usefuiness. An indication of the quality of separation could be immediately seen by the extent to which the residual material was white and crystalline. However, a white and crystalline material often turned out not to be a lactone, but perhaps a wax, with an absorption at $1740 \mathrm{~cm}^{-1}$

\section{Limited Availability of Plant Material}

The limited availability of plant material resulted in limited amounts of extract being available. If small amounts of extract therefore were to be chromatographed, few fractions had to be taken to prevent the dilution of the compounds below detection limits. The collection of few fractions required the understanding of how frullanolide moved on alumina with a variety of solvents (see above), so that the compound would not be spread over too many fractions.

Once some frullanolide was made available by trial and error methods, it was found that on alumina, frullanolide will elute negligably with n-hexane, slowly with $\mathrm{CCl}_{4}$ and rapidly with ether. Relatively large amounts on $\underline{n}$-hexane followed by relatively small amounts of $\mathrm{CCl}_{4}$ would elute significant amounts of non-frullanolide material. Ether would then elute the lactones rapidly. Knowledge of volumes of solvent run through the column was not translatable to a scale-up. What was translatable was the knowledge of relative movement. In experiments performed with variable amounts of extract and adsorbant, frullanolide eluted in a consistent manner: negligably with n-hexane, 
slightly with $\mathrm{CCl}_{4}$, and rapidly with ethyl ether. Thus, the location of frulianolide could be pinpointed to within a few fractions. This is seen best in the $F$. nisquallensis (Su11) experiment described in the experimental section.

Complex mixtures were usually obtained when few fractions were taken, and recognition of frullanolide in an infrared spectrum from such fractions was sometimes difficult. The first column spectra are useful tools in recognizing frullanolide in a mixture. Spectrum \#1 to spectrum \#8 are fractions from initial chromatographs that eventually, upon cleanup, produced what was believed to be frullanolide. The $1760 \mathrm{~cm}^{-1}$ and $910 \mathrm{~cm}^{-1}$ absorptions are seen in each. These regions of Spectra \#1 to \#8 can be compared with the literature spectrum of frullanolide. Often other absorptions are more intense. Indeed, the $1760 \mathrm{~cm}^{-1}$ absorption may exist as a shoulder to another carbonyl absorption.

These techniques used with small amounts of $F$. franciscana (Howe) were successfully used with small amounts of F. nisquilensis (Sult). 10. Evaluating the Ability of a Technique to Produce Clean Fractions

The shape of a carbony 1 peak in an infrared spectrum of a fraction was used to evaluate how well a procedure or material purified frullanolide. A sharp carbonyl peak in an infrared spectrum le.g. Spectrum \#21) was considered a sign of purity in the fraction. The observations of peak shape found use in the following situations: finding the purest fraction in a 2nd rechromatograph, knowing if rechromatographs on alumina cleaned up the material from the initial chromatograph and finding optimal solvents and adsorbants.

The analysis of a set of infrared spectra from a second 
rechromatograph illustrates the change of shape of the carbonyl peak as elution proceeds. The Spectra \#19 to \#23 are of materiar in successive column fractions. It is expected that the purity of a compound in a chromatograph will change as the elution proceeds. Examination of the Spectra \#19 to \#23 reveals a change of sharpness of the carbonyl peak with elution. In fact, the sharpness is seen to rise to a maximum at spectrum \#21, then to decrease. These observations lead to the conclusion that a good separation had occured, and that the purest fraction was the one corresponding to Spectrum \#21.

Rechromatographs are an essential feature of the method of isolation of frullanolide from F. franciscana (Howe). Evidence is needed that shows that purification did indeed take place from one pass through a column to the next. Comparasion of spectra of initial chromatographs with first rechromatographs and with second rechromatographs provides this evidence. Spectra \#1 to \#8 are of initiai chromatographs. Spectra \#9 to \#18 are first rechrmatographs. Spectra \#19 to \#23 are second rechromatographs. In general, the carbonyl peaks of the initial chromatographic fractions seem less sharp than the carbonyl peaks of the first rechromatographs. The carbonyl peaks of the infrared spectra of second rechromatographs are sharper still. It was concluded that purification was indeed taking place from one separation stage to another and that the general scheme is worthwhile.

The decisions regarding selection of optimum solvents and adsorbants were based on observation of carbonyl peak shapes. Infrared spectra of fractions obtained when these materials were used contained carbonyl peaks which were sharper than any previously obtained. 
The materials and the associated spectra are:
alumina: Spectrum \#2
benzene: Spectrum \#13

$\mathrm{CCl}_{4}: \quad$ Spectrum \#33

Spectrum \#33 containes the sharpest carbonyl peak in the lactone region of any spectra taken in this research. Thus was made the decision to use $\mathrm{CCl}_{4}$ as the most important elution solvent in the rechromatographs. 


\section{CONCLUSIONS}

Some members of the liverwort genus Frullania that grow in North America and Europe are known to be occupational hazards to workers in forest areas. The compound frullanolide has been isolated from some Frullania, and the hazard of these liverworts has been, in the main, attributed to this substance. F. franciscana (Howe), found in western Oregon, has been identified as a source of allergic contact dermatitis (4). The goal of the research described herein was to attempt to isolate and identify frullanolide from F. franciscana (Howe).

To this end, F. franciscana (Howe) was collected, cleaned, identified, milled, and an ether extract was prepared. Of the several separation methods tried, only liquid column chromatography was found useful. The research focused on finding an optimal solvent system for chromatography. At the highest state of the art developed, the location of frullanolide could be pinpointed to within a few fractions. Extensive purification of the ether extract from $F$. franciscana (Howe) yielded a compound identified as frullanolide by comparison of its infrared and proton nuclear magnetic resonance spectra with published spectra of frullanolide and arbusculine B. Thus the species F. Franciscana (Howe) can be included in the group of allergic plants known to contain frullanolide.

The isolation method that worked successfully for $F$. franciscana (Howe) was tried with $F$. nisquallensis (Sull), a liverwort known to contain frullanolide. Material obtained from this plant was 
recrystallized; an infrared spectrum and a melting point determination identified the compound as frullanolide. Thus, the procedure that resulted in the isolation of frullanolide from F. franciscana (Howe) was found to apply successfully to one other species of Frullania. The lack of a melting point determination for material isolated from $F$. franciscana (Howe) weakens the proposition that this material is frullanolide. Infrared and nuclear magnetic resonance spectra by themselves are not sufficient for complete proof of structure.

The melting point of material from F. nisquallensis (Sul1) was within an acceptable range for frullanolide, and the infrared spectrum of this material matched that of the material isolated from F. franciscana (Howe). 
Finish Characterization of Frullanolide

The complete characterization of frullanolide from F. franciscana (Howe) was not done. The following need to be done with the compound if complete characterization is desired: a melting point determination, an optical rotation determination, the thin-layer chromatography test and the $\mathrm{H}_{2} \mathrm{SO}_{4}$ color test. For Mitchell's test to be accurate, authentic samples of frullanolide and arbusculine $B$ should be run alongside for comparasion. Unfortunately, these two compounds are not readily available.

Part of the characterization of frullanoide included proton nuclear magnetic resonance decoupling studies. These experiments may be of interest to repeat. Since the sample of frullanolide would be in the spectrometer, there would be the additional opportunity to lower the temperature and see if there is any difference in chemical shifts. The information gained may help in understanding the most stable configuration of the compound. This information may aid in understanding the Michael addition reaction in terms of the most stable transition state during reaction. Ultimately, this knowledge may be a small, yet significant part of a larger understanding of the mechanism of the allergenicity of the sesquiterpene 1actones.

Further Development of the Method of I solation

There are several areas in the isolation procedure that would 
benefit from further development. Putting the extract on the column in the initial chromatograph is quite messy and some material is lost sticking to the sides of containers. One possibility that was tried oniy once is to dissolve the extract to be used in ether, add the solution to some dry alumina and then allow the ether to evaporate. The powder so obtained could be simply added to the top of the column. Another possibility is the use of only $n$-hexane and ether as the solvents in the initial chromatograph. This is very simple and convenient, and it worked well the only time it was tried.

Find and Study Other Species of Liverwort

Several species of Frullania are present in the Pacific Northwest that have not been examined for the presence of frullanolide. These species are F. californica, F. asagrayana and F. bolanderi. Finding and identifying adequate amounts of pure species of these plants is no small task in itseif. Several hundred grams of each species will probably be required.

Arbusculine $B$ may be present in a number of Oregon Frullania species that have not been examined for this compound. These species are F. californica, F. asagrayana, F. bolanderi, F. franciscana (Howe) and F. nisquallensis (Sull).

The Pacific Northwest is a rich source of liverworts. Two hundred species are listed in one compilation (2). It remains to find out which species have not been examined, to find adequate amounts of these plants, to positively identify them and to examine them for interesting compounds.

One possible genus to examine would be Porella. P. navecalaris 
is a common Oregon liverwort (1). P. vernicosa, found in Hiroshima, Japan, contained 8 sesquiterpene lactones (27). None of these compounds had the frulianolide skeletal structure. The largest concentration of any one compound of a sesquiterpene lactone nature was $12 \%$ of the extract. Other compounds were present in varying amounts from $10 \%$ to $0.4 \%$. The value of such a screening program would be in the identification of plants that are potentially hazardous. This information would be useful to those who use the forest for occupation or recreation. Such information would also be useful to health professionals who wished to identify the source of allergic dermatitis in their patients.

Application of the Method to Higher Plants

The chrysanthemum is one of the most allergic plants known (28). Recently, gas chromatographic evidence for the presence of alantolactone in chrysanthemums has been obtained (29). Purified compounds were not isolated, however. The method for the isolation of frullanolide from Frullania described herein may prove useful if applied to the isolation of alantolactone from chrysanthemums. 


\section{EXPERIMENTAL}

\section{GENERAL PROCEDURES}

Instruments and Materials

Infrared spectra were taken with a Perkin-E7mer 467. Nuclear magnetic resonance spectra were taken with a Varian EM 390. Measurment of mass was done with a Mettler H1O balance. The plants were milled in a Thomas Wiley Mill using a \#40 screen.

All solvents were distilled before use. The adsorbants for column chromatography were: Mallinckrodt aluminAR, CC-10, 100-200 mesh, activity grade 4; Woelm neutral alumina, activity grade I, Lot \#11286. The adsorbant that was used for thin layer chromatography was: Mallinckrodt Silicar TLC-7gf, Lot ABD, dated March, 1974.

A sample was prepared for infrared spectroscopy by 1) dissolution in ether, 2) placement in solution on a $\mathrm{NaCl}$ plate and 3) evaporation of the solvent from the plate, leaving the sample in a thin film. A sample was prepared for nuclear magnetic resonance by dissolution in $\mathrm{CCl}_{4}$. A few drops of tetramethylsilane were added to the solution.

Collection and Identification of Plants

Frullania franciscana (Howe) was collected at Ecola State Park, Cannon Beach, Oregon, on July 15, 1976. The plants were found on alder trees located on cliffs near the ocean. The plants had a dark reddish brown color. Extraneous plant material was cleaned from the F. franciscana (Howe), yielding 126.1 grams of the desired material. F. franciscana (Howe) was also collected at Lookout State Park, Tillamook 
County, Oregon, on September 25, 1976. The plants were found on cedar trees on cliffs overlooking the ocean and on trees close to the sandy beach. The plant material was cleaned as before, yielding 229.3 grams. F. nisquallensis (Sull) was collected along Young's River near Astoria, Oregon. Plants were collected from trees, rocks, fallen logs, all near a waterfall that produced copious water spray. The plants were cleaned as before to yieid 139.2 grams.

Identification of the plant material as F. franciscana (Howe) was done with the assistance of Jim Cronin. Mr. Cronin was a graduate student in Biology at Portland State University, Portland, Oregon. Identification of the plant material as F. nisquallensis (Sul1) was done with the assistance of Peter Packet, a graduate student in Biology at Portland State University. The basis for identification was comparasion of the microscopic appearance of the plant material with published drawings of F. franciscana (Howe) and F. nisquallensis (Sul1) $(1,31$ ). These drawings are reproduced in Figure 3. Plants with a central row of paracysts and with wedge-shaped or rounded underleaves were considered F. franciscana (Howe). Plants without paracysts and with a pointed underlobe were considered F. nisquallensis (Sul1). Each batch of plants was subjected to approximately 50 spot checks to assure homogeniety of species. The plants from each location were allowed to air dry for a period of time: Ecola State Park-1.5 months, Lookout State Park -3 months and Young's River-1.5 months.

\section{Preparation of the Extract}

After air drying, an extract was made from each of the three batches in essentially the same manner. The plants were milled and the 


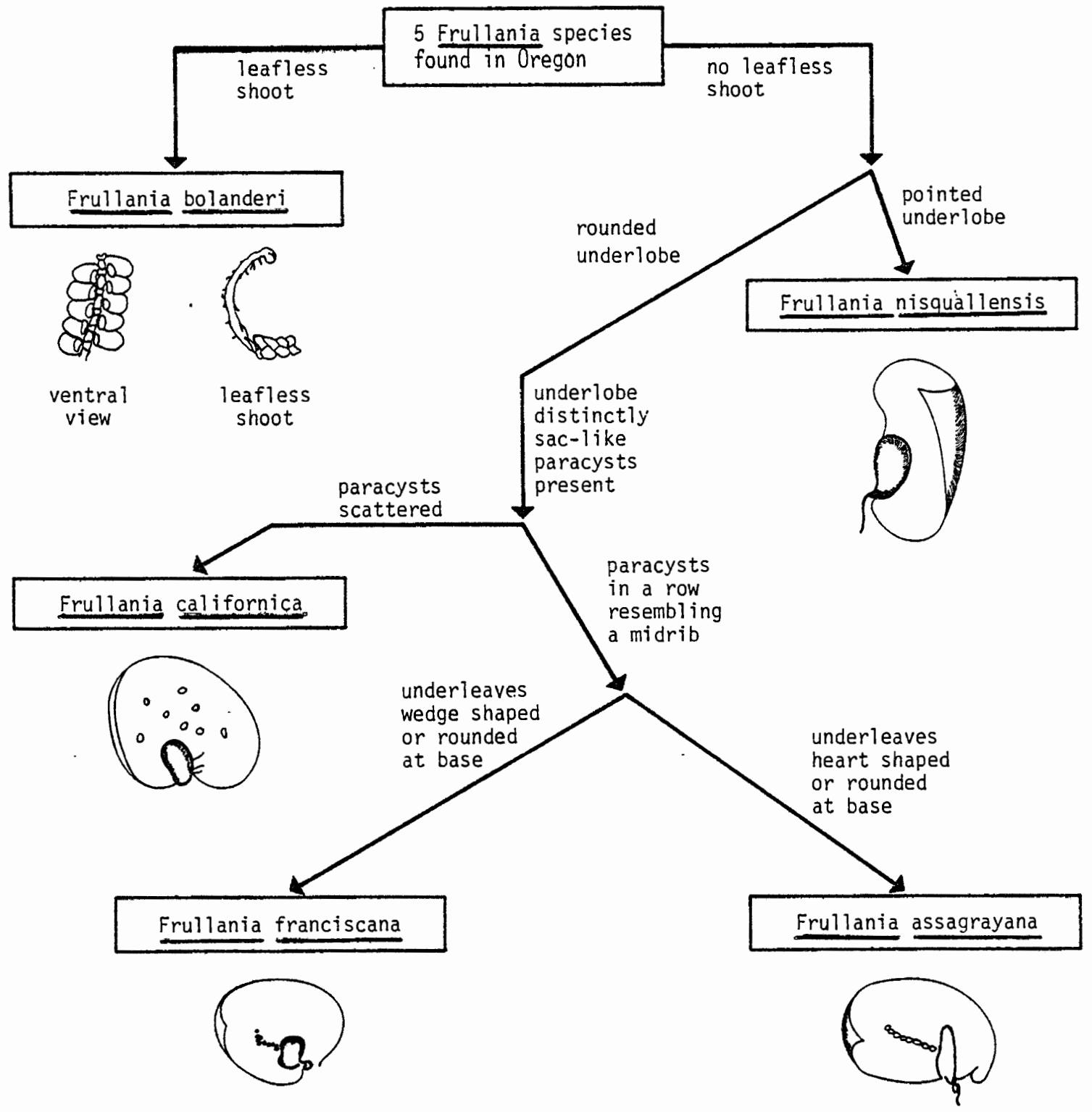

FIGURE 3

\section{Classification of Frullania Species}

Found in Oregon 
powder was mixed with $800 \mathrm{ml}$ of distilled ethyl ether. The mixture was left standing for 2 weeks at room temperature and gravity filtered leaving behind the powder in the extraction flask. The milled material had the consistency of wet powder. The wet powder was re-extracted with $200 \mathrm{ml}$ of ethyl ether three times. Each time, the powder was left standing with the ethyl ether for 10 minutes. After each extraction, the solution was poured into the same container through the same filter. Finally, $200 \mathrm{ml}$ of ethyl ether was added to the powder, and all of the mixture was poured into the filter as a slurry. The filtrate was concentrated to near dryness with a rotary evaporator. The flask containing the extract was sealed with aluminum foil and was stored in a freezer. The weights of the extracts obtained and the percentages of extracts of dry weights of the plants from the three batches are: Ecola State Park-3.3 grams, 2.6\%; Lookout State Park-not determined; Young's River 3.6103 grams, $2.6 \%$.

Rotary evaporation gives a non-homogenous extract, but evaporation by a gentle stream of nitrogen and immersion in a warm water bath gives a homogeneous extract. However, with the latter procedure, it is necessary to transfer the solution to successively smaller containers. It is also necessary to wash material off the sides of the container as evaporation proceeds. This entire alternative procedure makes unnecessary the redissolution of the extract in ether when the extract is taken out of the freezer to remove some extract for experiments.

In the preparation of the Ecola State Park extract, the flask was dropped in the water bath used with the rotary evaporator. The waterethyl ether mixture was extracted with more ether three times, and the solution was concentrated by rotary evaporation. 
Putting the Extract on the Column

The extract was put on the column by a variety of methods. In each case the extract was removed from the freezer and allowed to warm to room temperature in the hood. The extract at this point appeared to be either heterogeneous or homogeneous in color and texture. 1. If the extract was not homogeneous, the entire extract was dissolved in ether. A small amount of this solution was pipetted onto the top of the column. At times $\mathrm{CCl}_{4}$ was used to dissolve the extract. 2. If the extract was homogeneous, a small amount would be removed directly from the storage flask and put on the column. 3. An alternative to the usual method was to dissolve the small amount of homogeneous extract removed from the storage flask in ether or methylene chloride. This solution was then mixed with some alumina. The amount of alumina was sufficient to absorb the solution. The solvent was allowed to evaporate for ten minutes at room temperature to the consistency of a powder. The alumina-extract powder could then be easily poured onto the column. The container contained some residual extract which was removed by adding more ether and alumina. After evaporation, this additional powder was put on the column. 4. Some homogeneous extract was removed from the storage flask and mixed with some alumina without using solvents. The mixture was then put on the column. A large amount of alumina relative to the amount of alumina already on the column was required, often $50 \%$. 
COLUMN CHROMATOGRAPHY ON ALUMINA OF F. franciscana (Howe) EXTRACT Initial Chromatograph of $F$. franciscana (Howe) Extract

The extract prepared from F. franciscana (Howe) collected at Ecola State Park was used in this experiment. A small amount $(0.25 \mathrm{gram})$ of extract was removed from the storage flask by method \#2 above and put on a columm of 13 grams of adsorbant. The data for the experiment is given in Table II. The fractions were collected in beakers, and the solvents were allowed to evaporate in the hood overnight. The infrared spectrum of each fraction was taken. The presence of frullanolide in a fraction was suggested by the appearance of an infrared absorption at $1760 \mathrm{~cm}^{-1}$.

Notes on the Initial Chromatograph

The Mallinckrodt aluminAr was used. The six $\mathrm{ml}$ of Fraction \#5 was the remainder of the head of solvent above the column bed. This n-hexane had to be removed before the next solvent, $\mathrm{CCl}_{4}$, could be added. The same was the case for the $5 \mathrm{ml}$ of $\mathrm{CCl}_{4}$ collected in Fraction \#16. ${ }^{\dagger}$

First Rechromatograph of $F$. franciscana (Howe) Extract

The material in fractions \#15 and \#16 $(73 \mathrm{mg})$ from the initial chromatograph showed an infrared peak at $1760-1770 \mathrm{~cm}^{-1}$ and was pooled. This material was rechromatographed on alumina (4.5 grams). The material was put on the column by method \#1 described above. Carbon tetrachloride was used to dissolve the material. The data for the experiment

tother experiments indicate that nearly $100 \%$ recovery of material put on the column is possible if methanol is used as a final elution solvent. 


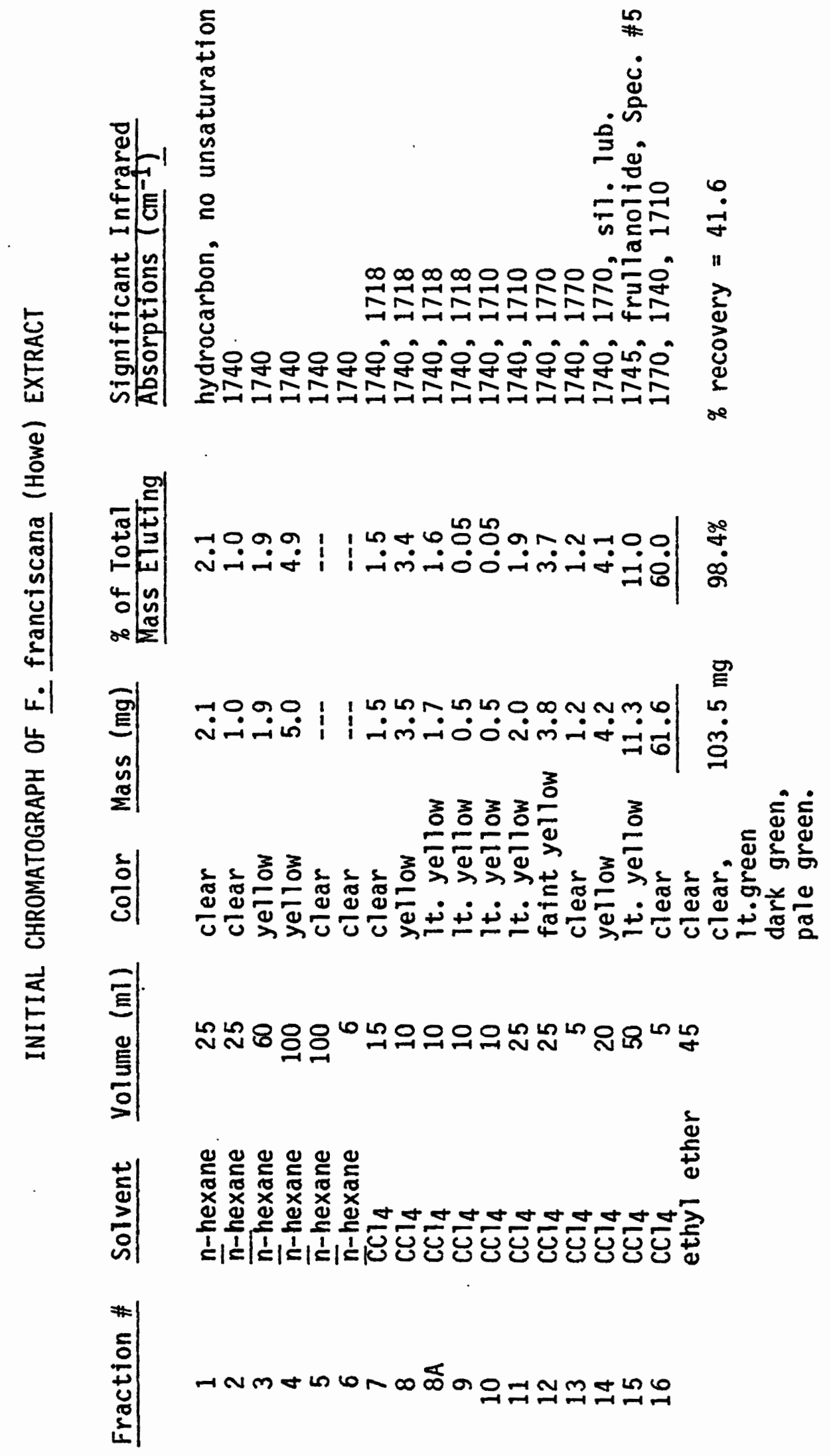


are given in Table III. Flow rates were determined by counting drops for 30 seconds. The total mass of frullanolide obtained was $12.6 \mathrm{mg}$ ( $5 \%$ of extract, $0.13 \%$ of dried plant material). The material at this point had a very good match with the literature infrared spectrum of frullanolide. It did contain some yellow color, requiring further purification.

Notes on the First Rechromatograph

There were other lactone fractions that had appeared after frullanolide had moved through the column. Experience has shown that when other material appears after frullanolide, no more frullanolide is seen to elute with the ethyl ether or methanol.

There is a separation between the frullanolide of Fractions \#3 to \#6 and the other $1760 \mathrm{~cm}^{-1}$ absorbing material. The separating fraction is Fraction \#7 in which essentially nothing appeared.

Second Rechromatograph of $F$. franciscana (Howe) Extract

The frullanolide containing fractions (\#3-\#6) from the first rechromatograph were pooled. This material was added to frullanolide containing fractions from second and third rechromatographs from other experiments with $F$. franciscana (Howe) $(35.6 \mathrm{mg}$ total), and was chromatographed on 5 grams of alumina. Table IV contains the data from this experiment. All of the fractions were clear in color. Upon evaporation in the hood, Fractions \#1 to \#5 yielded residue that appeared slightly yellow in color and oily. Fractions \#6 to \#10, upon evaporation in the hood, yielded residue that appeared white and crystalline. 
DATA FOR FIRST RECHROMATOGRAPH

F. franciscana (Howe) EXTRACT

Fraction \# Solvent $\frac{\text { Volume Mass }}{\underline{(\mathrm{ml})}} \frac{\% \text { of Total }}{\text { (mg) }} \frac{\text { Significant IR }}{\text { Mass Eluting }}$

\begin{tabular}{|c|c|c|c|c|}
\hline $\begin{array}{l}\text { n-hexane } \\
\text { CCI } \\
" \\
" \\
" \\
" \\
" \\
" \\
" \\
" \\
" \\
" \\
" \\
" \\
" \\
\text { ether }\end{array}$ & $\begin{array}{r}100 \\
10 \\
" 1 \\
" \\
" \\
" \\
" \\
" \\
" \\
" \\
" \\
" \\
100 \\
50\end{array}$ & $\begin{array}{l}2.8 \\
3.3 \\
8.5 \\
0.7 \\
2.4 \\
1.3 \\
-1 .- \\
1.2 \\
1.0 \\
-0.6 \\
0.6 \\
0.2 \\
0.2 \\
--- \\
1.8 \\
31.9 \\
\end{array}$ & $\begin{array}{r}5.0 \\
5.8 \\
15.0 \\
1.2 \\
4.2 \\
2.3 \\
--.-1 \\
2.1 \\
1.8 \\
-0.4 \\
1.4 \\
0.4 \\
0.4 \\
--.2 \\
36.0 \\
\end{array}$ & $\begin{array}{l}1740,1710, \text { sil . } 1 \text { ub. } \\
1770,1740 \\
\text { frullanolide spec. } \\
\text { " Spec. \#4 } \\
\text { frullanolide spec. } \\
\text { impure frullanolide } \\
1770,1740 \\
1760 \text { not frullanolide } \\
1760 \text { not frullanolide } \\
\text { no carbonyl } \\
\text { not taken } \\
" \\
" \\
" \\
" \\
" \\
"\end{array}$ \\
\hline & Total & $56.5 \mathrm{mg}$ & $99.6 \%$ & $\%$ recovery $=77$ \\
\hline
\end{tabular}

TABLE IV

DATA FOR SECOND RECHROMATOGRAPH

F. franciscana (Howe) EXTRACT

Fraction \# Solvent $\frac{\text { Volume }}{\underline{\text { (mI) }}} \frac{\text { Mass }}{\text { (mg) }} \frac{\% \text { of total }}{\text { mass eluting }} \frac{\text { Significant Infrared }}{\text { Absorptions }\left(\mathrm{cm}^{-1}\right)}$

\begin{tabular}{|c|c|c|c|}
\hline $\begin{array}{l}3 \\
4 \\
5\end{array}$ & $\begin{array}{l}\text { n-hexane } \\
\text { n-hexane } \\
\text { CCl } \\
" \\
" \\
" \\
" \\
" \\
\text { ether } \\
\text { methanol }\end{array}$ & $\begin{array}{r}50 \\
40 \\
5 \\
5 \\
5 \\
5 \\
15 \\
15 \\
35 \\
40 \\
35\end{array}$ & $\begin{array}{r}1.4 \\
1.1 \\
0.6 \\
0.4 \\
0.7 \\
2.8 \\
3.7 \\
3.1 \\
5.8 \\
8.3 \\
13.1\end{array}$ \\
\hline & & & $41.0 \mathrm{~m}$ \\
\hline
\end{tabular}


Notes on the Second Rechromatograph.

The material to be chromatographed was put on the column by method \#3 above. $\mathrm{CCl}_{4}$ was used to dissolve the impure frutlanolide.

COLUMN CHROMATOGRAPHY ON ALUMINA OF F. nisquallensis (SU11) EXTRACT Initial Chromatograph of $F$. nisquallensis (Sull) Extract

The extract prepared from the $F_{\text {. nisqualiensis (Sull) gathered at }}$ Young's River was used in this experiment. For this experiment, 1.1 gram of extract was chromatographed on a 50 gram alumina column. The data for this experiment are given in Table $V$. There is some uncertainty in the volume of fractions \#9 and \#16.

\section{TABLE V}

INITIAL CHROMATOGRAPH OF F. nisquallensis (Su11) EXTRACT

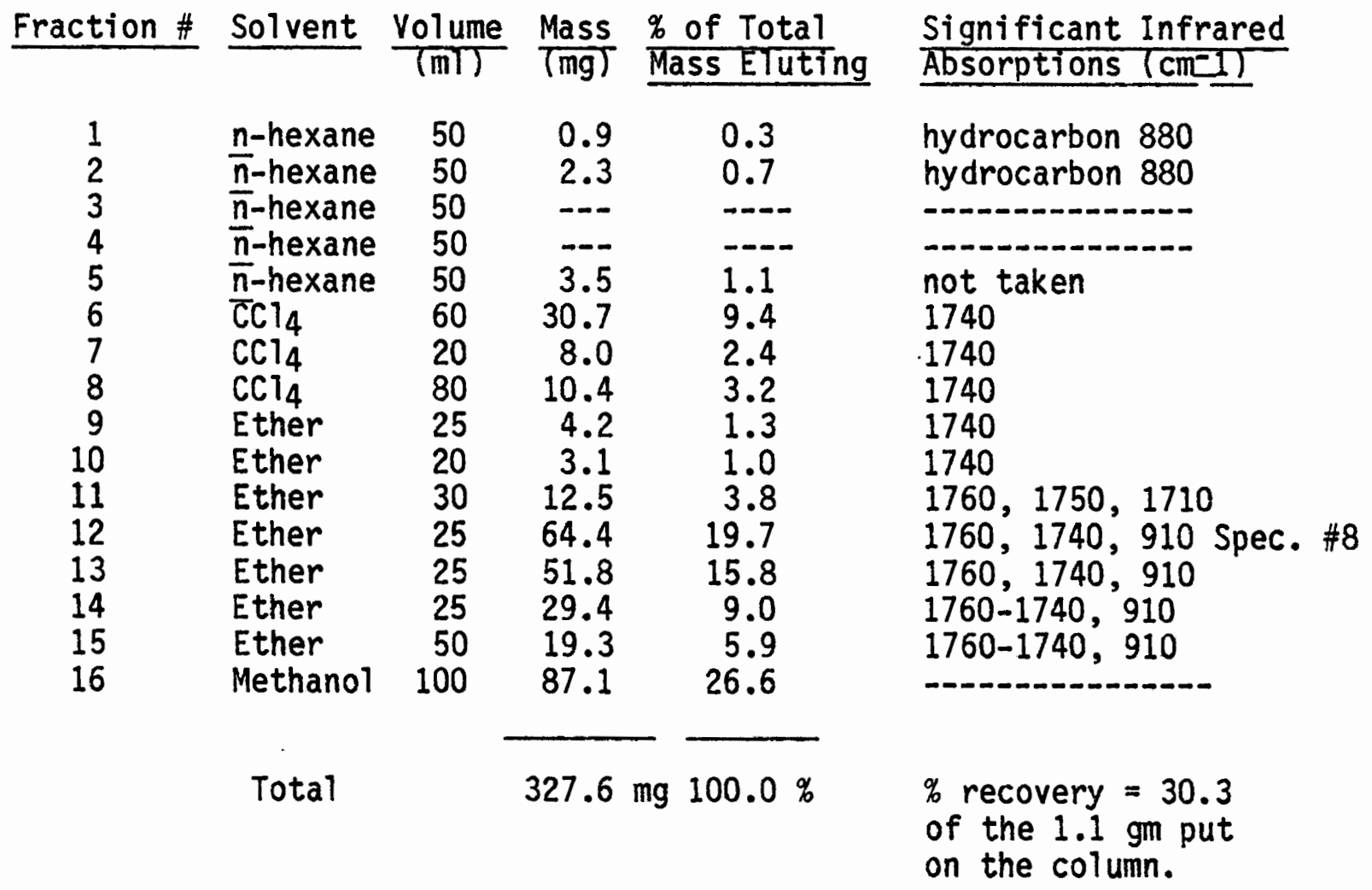


Notes on the Initial Chromatograph

The Mallinckrodt aluminAR was used in this experiment. The extract was put on the column by method \#2 described above. This experiment used less $\mathrm{CCl}_{4}$ than was used in the initial chromatograph of the F. franciscana (Howe) extract described above. No frullanolide appeared to elute with the $\mathrm{CCl}_{4}$, but $15 \%$ of the total mass eluting was eluted by the $\mathrm{CCl}_{4}$.

As ether was added to the column in this experiment, a line of demarcation was observed to move down the column. This line probably occured at the separation between the ether and the $\mathrm{CCl}_{4}$. The collection of fractions took this line of demarcation into account. In the first 25 milliliters collected with ether (Fraction \#9), the line of demarcation moved approximately half way down the column. (The total packed volume, measured with the buret markings on the glass, was about $50 \mathrm{ml}$.$) The next 20$ milliliters (Fraction \#10) was collected as the line of demarcation moved to the bottom of the column. As the first drops of the liquid behind the line of demarcation fell into the solution of Fraction \#10, a second phase was seen to form. Collection of Fraction \#10 was stopped at this point and collection of Fraction \#11 was begun. The volume of Fraction \#11 and each subsequent fraction was about $25 \mathrm{mr}$. Frullanolide appeared in the eluent behind the line of demarcation (in Fraction \#11 and in subsequent fractions). It appears that the majority of the frullanolide eluted with one full column volume of ether (Fractions \#11-\#14). There was also some frullanolide present in Fraction \#15. 


\section{First Rechromatograph of F. nisquallensis (Su11) Extract}

Fractions \#11 to \#15 (177.4 mg) of the initial chromatograph were pooled and rechromatographed on 8 grams of alumina. The data for this experiment are given in Table VI. A large amount of $\mathrm{CCl}_{4}$ was used; frullanolide appeared onty in $\mathrm{CCl}_{4}$ fractions. Purer material usualiy was obtained from $\mathrm{CCl}_{4}$ elution than from ether elution.

Second Rechromatograph of F. nisquallensis (SuI1) Extract

Fractions \#3 to \#7 $(64.2 \mathrm{mg})$ of the first rechromatograph were pooled and rechromatographed on 3.2 grams of alumina. The data for this experiment are given in Table VII. Fractions \#2 to \#10 were pooled to yield $49.8 \mathrm{mg}$ of frullanolide. This material was recrystallized once in n-hexane to yield approximately $1 \mathrm{mg}$ or about $2 \%$ recovery. Two melting point determinations gave $72-73^{\circ} \mathrm{C}$ and $73-74^{\circ} \mathrm{C}$.

\section{THE DETERMINATION OF THE SEQUENCE OF SOLVENT ELUTION}

\section{Introduction}

In the procedure for the isolation of frullanolide from F. tamarisci and F. dilatata (7), frullanolide eluted from silica in a green band ("Ia bande verte") (7). In an initial experiment to determine a solvent elution sequence that would eventually isolate frullanolide from $F$. franciscana (Howe) extract, attention was paid to any green band that might appear. A green band did indeed appear, and frullanolide was found in it. This was the starting point for a series of experiments to determine the sequence of solvent elution that was eventually used in the experiments perviously described. Figure 4 outlines this series of experiments. 
FIRST RECHROMATOGRAPH OF F. nisquallensis (Sul1) EXTRACT

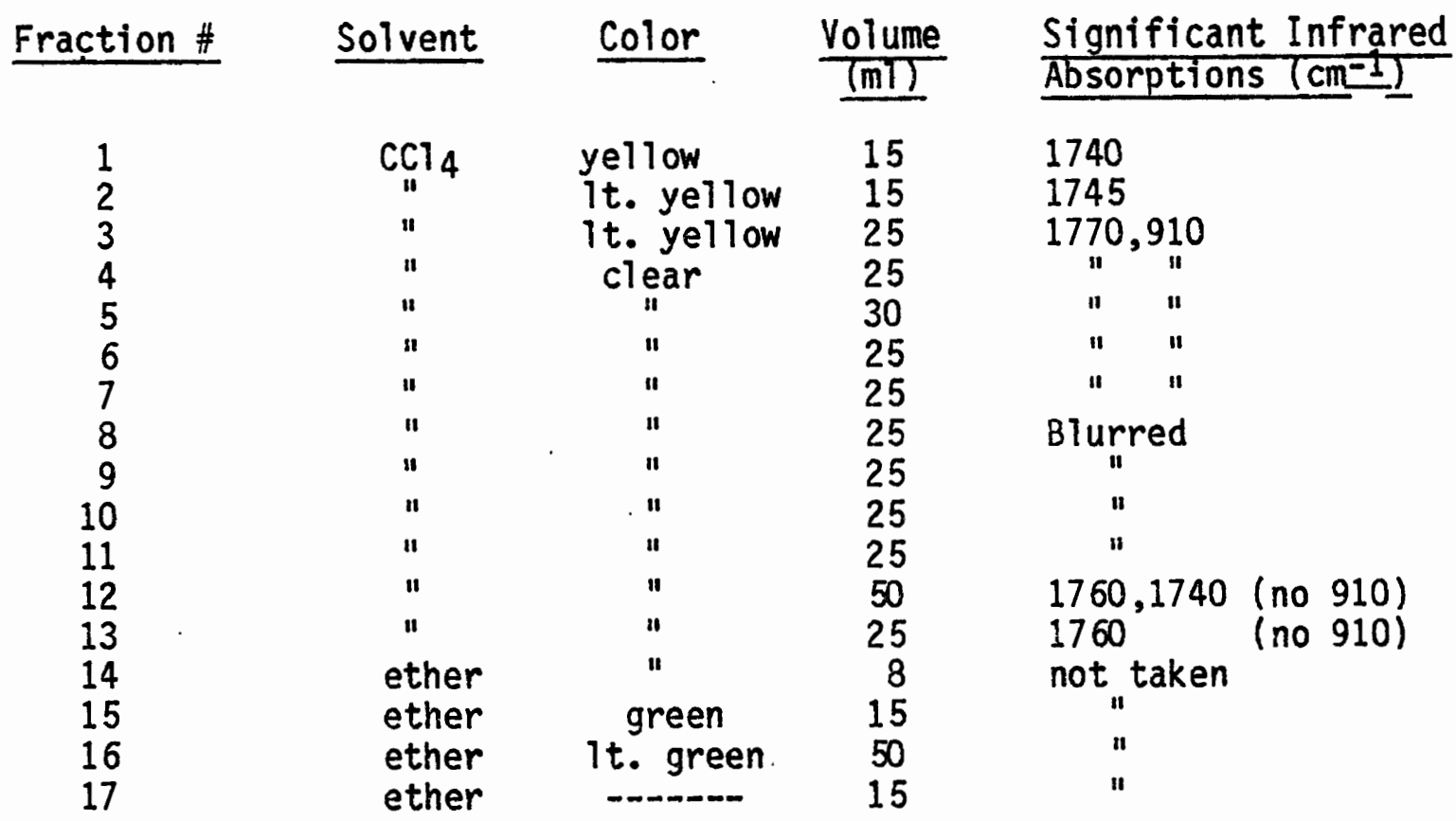

\section{TABLE VII}

SECOND RECHROMATOGRAPH OF F. nisquallensis (SU11) EXTRACT

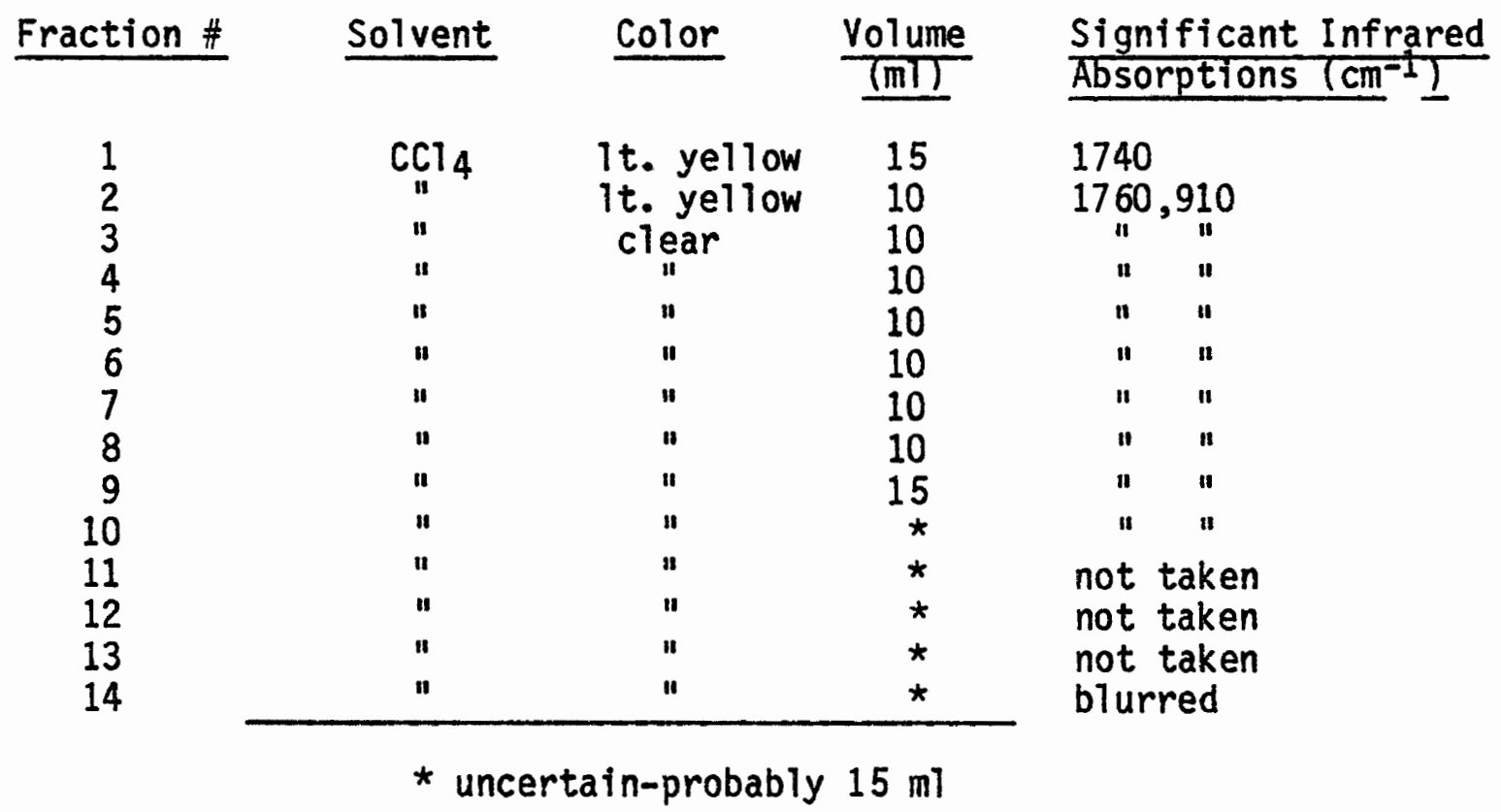


Initial Development of Solvent System

initial chromatograph of $F$. franciscana (Howe) extract from Lookout State Park on alumina

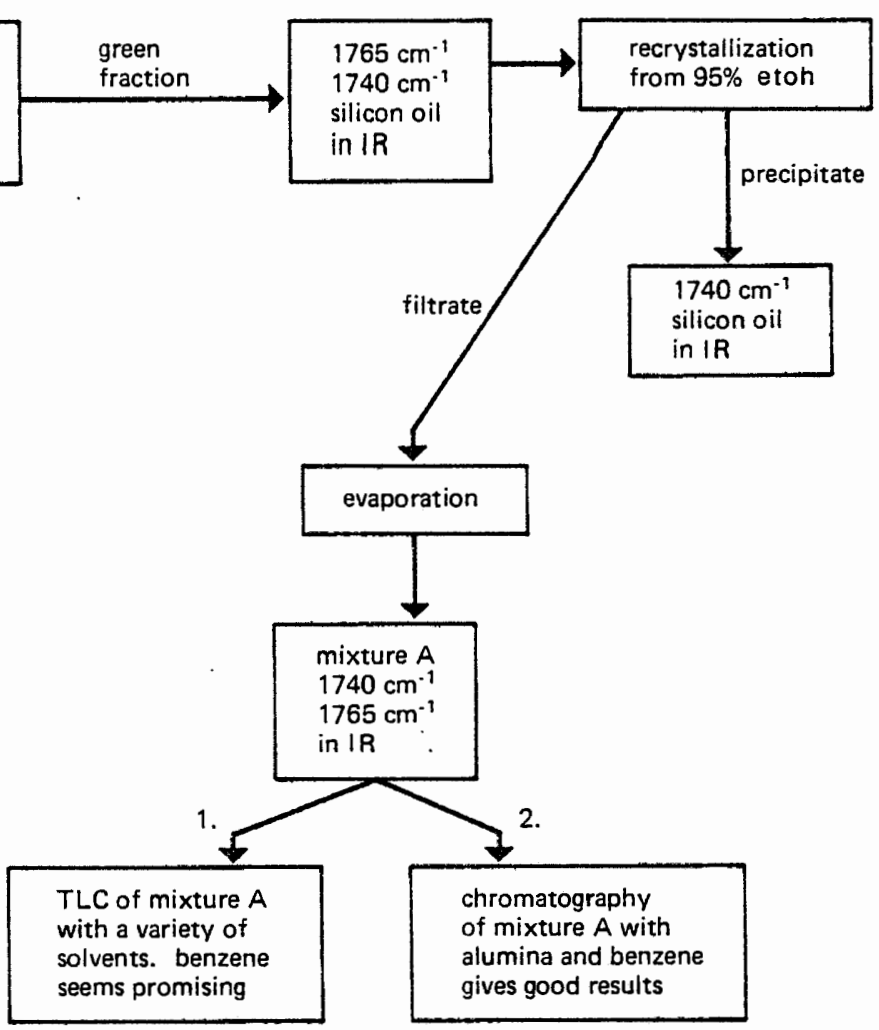

\section{Repeat of Method Starting with the Extract}

initial chromatograph of F. franciscana (Howe) extract from Lookout State Park on alumina

pooling of
$\begin{aligned} & 1760-1770 \mathrm{~cm}^{-3} \\ & \text { absorbing fractions }\end{aligned}$

pool

$1760-1770 \mathrm{~cm}^{-1}$ absorbing fractions

rechromatograph

on alumina

all elution with

benzene

FIGURE 4

Sunmary of the Procedure for the Determination 
Initial Chromatograph on Alumina

Two grams of the extract of $F$. franciscana (Howe) gathered at Lookout State Park was chromatographed on 60 grams of alumina (Woelm neutral). The data for this experiment are given in Table VIII. Masses were not taken.

\section{TABLE VIII}

INITIAL CHROMATOGRAPHY OF F. franciscana (Howe) EXTRACT

\begin{tabular}{|c|c|c|c|c|}
\hline Fraction \# & Solvent & Volume (ml) & Color & $\frac{\text { Significant Infrared }}{\text { Absorptions }\left(\mathrm{cm}^{-1}\right)}$ \\
\hline $\begin{array}{l}1 \\
2 \\
3 \\
4 \\
5 \\
6\end{array}$ & $\begin{array}{l}\frac{n-h e x a n e}{n-h e x a n e} \\
\frac{\pi}{\star} \\
\star \\
\star \\
\star\end{array}$ & $\begin{array}{r}100 \\
100 \\
40 \\
10 \\
20 \\
60\end{array}$ & $\begin{array}{l}\text { clear } \\
\text { clear } \\
\text { clear } \\
\text { yellow-orange } \\
\text { dark green } \\
\text { light green }\end{array}$ & $\begin{array}{l}\text { hydrocarbon } \\
\text { hydrocarbon } \\
\text { not taken } \\
1760,1740 \quad(\text { Spec. } \# 2) \\
1740 \\
1740\end{array}$ \\
\hline
\end{tabular}

\section{Notes on the Initial Chromatography}

Silicon lubricant was also seen in Fraction \#4. A sharp color change was seen while collecting Fraction \#4. Fraction \#4 was yellow orange in color, and a dark green band was collected as Fraction \#5. In this experiment, solvents were removed by distillation. The alumina was discarded even though some material appeared to have remained on the column, as indicated by the presence of color.

Purification of the Frullanolide Containing Fraction by Recrystallization

Fraction \#4 from the initial chromatograph was dissolved in hot 95\% ethanol and allowed to c001. Crystals formed which by infrared analysis were found to be silicon lubricant and material with strong infrared absorption at $1740 \mathrm{~cm}^{-1}$. The mother liquor was evaporated 
to dryness and the residue (termed Mixture A) showed infrared absorptions at 1740 and $1760 \mathrm{~cm}^{-1}$. Further work on Mixture $A$, which led to the isolation of frullanolide, is described below.

Use of TLC to Determine an Optimum Purification Solvent

Thin layer chromatography of Mixture A and Fraction \#4 was performed with a variety of solvents. The results of these experiments are given in Table IX.

The presence of streaking in all cases ruled out thin-layer chromatography as a method of purification at this stage. Comparatively little streaking occured with benzene; consequently this solvent was chosen for further experiments.

TABLE IX

THIN LAYER CHROMATOGRAPHY OF MATERIAL FROM THE INITIAL CHROMATOGRAPH

Source of spot Solvent Rf values

Fraction \#4

Mixture A

Fraction \#4

Mixture A

Fraction \#4

Mixture A
*

0.91
Denzene 0.90

benzene $0.90,0.55,0.36$
$\mathrm{CHCl}_{3}$

0.91

$\mathrm{CHCl}_{3}$
General Appearance

streak streak one spot, less streaking three spots, less streaking
Fraction \#4

Mixture A
$0.91,0.83,0.50,0.25$

streak

streak with dense areas
Fraction \#4 Mixture A
$\mathrm{CH}_{2} \mathrm{Cl}_{2} \quad 0.90$

$\mathrm{CH}_{2} \mathrm{CT}_{2} \quad 0.90,0.40$ streak

streak
$\mathrm{CCl}_{4} \quad 0.86$

$\mathrm{CCl}_{4} \quad 0.57,0.24,0.17$

* ethyl acetate one spot, some streaking several spots, steaking 
Further Work with Benzene

Five column chromatographs of Mixture A were performed using benzene as solvent. One of the five experiments that gave the best results will be described.

Mixture A was dissolved in benzene, and an amount of solution was removed that was equivalent to $168.0 \mathrm{mg}$ of mixture $A$. This solution was put on an alumina column (17.4 grams) and eluted with benzene as the only elution solvent. Table $X$ presents the data for this experiment. Silicone lubricant was eluted in the first $35 \mathrm{ml}$. Frullanolide eluted in the range 60-90 ml. Thus, this experiment was a success in separating the silicone Tubricant and the $1740 \mathrm{~cm}^{-1}$ absorbing impurity from frullanolide.

Scale-Up of the Experiment using Benzene-Initial Chromatograph

On an alumina (24.5 grams) column was p1aced $548.4 \mathrm{mg}$ extract of F. franciscana (Howe) gathered at Lookout State Park. The data for this experiment is presented in Table XI. The size of fractions was about one "column volume" $(25 \mathrm{ml})$. The mass of the impurities eluting with $\underline{n}$-hexane is seen to taper off, indicating that sufficient $\underline{n}$-hexane was used. Frullanolide was eluted by approximately one "column volume" of ether. The movement of the ether "solvent front" would require about one "column volume" of ether to pass through the column.

Mallincrodkt aluminAR was used in this experiment and in the rechromatograph. The spectrum of Fraction \#6 is remarkably close to the literature spectrum (6) of frullanolide, even though Fraction \#6 is a mixture. 
TABLE $X$

CHROMATOGRAPHY OF MIXTURE A USING BENZENE

Fraction \# Volume (m1) Mass (mg) \% of total $\frac{\text { Significant IR }}{\text { mass eluting }}$ absorptions (cm -1 )

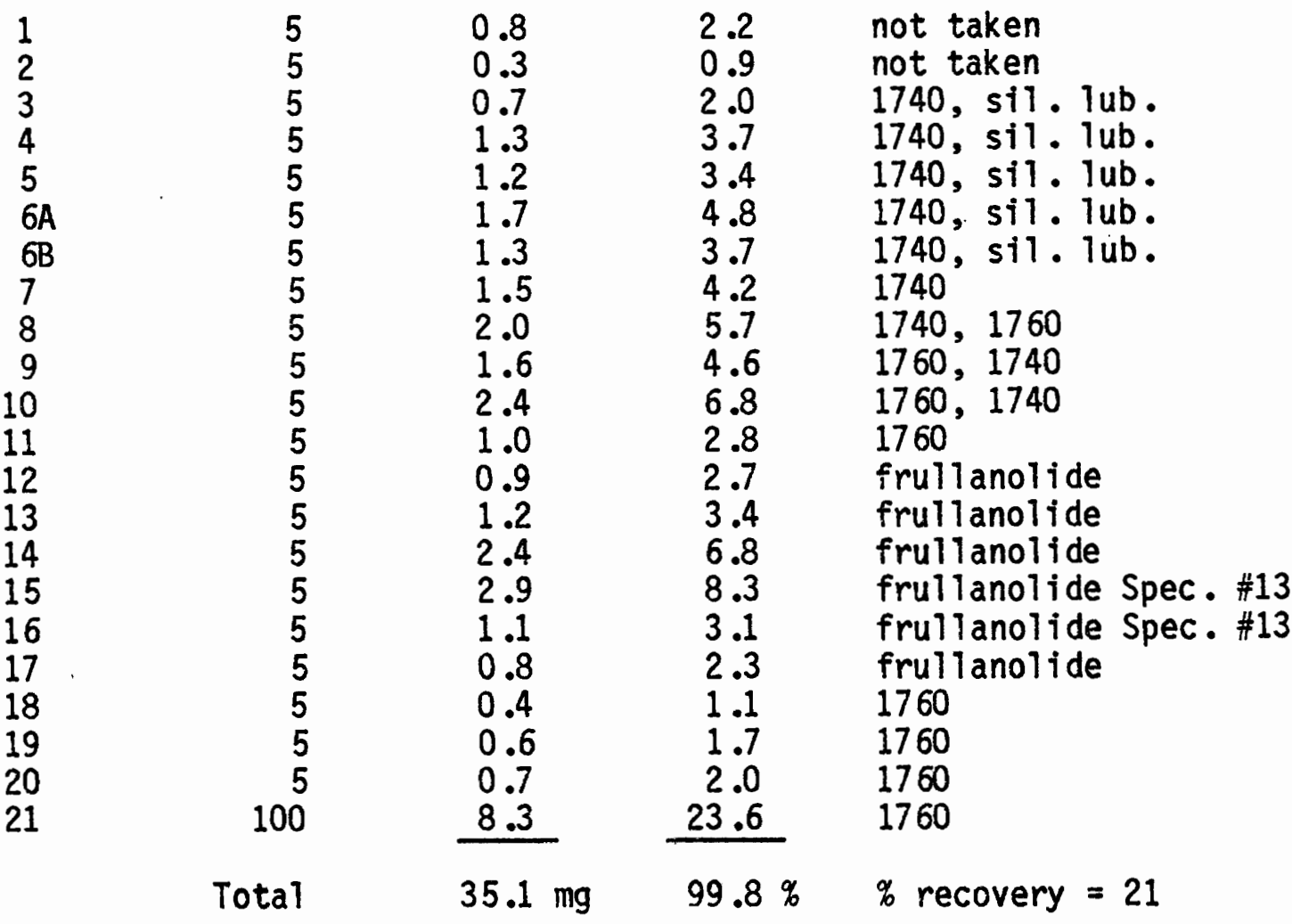

TABLE XI

SCALE-UP OF THE EXPERIMENT USING BENZENE INITIAL CHROMATOGRAPH

Fraction \# Sovent $\frac{\text { Volume }}{\underline{(\mathrm{ml})}} \frac{\text { Mass }}{(\mathrm{mg})} \frac{\% \text { of total }}{\text { mass eluting }} \frac{\text { Significant IR }}{\text { Absorptions }\left(\mathrm{cm}^{-1}\right)}$

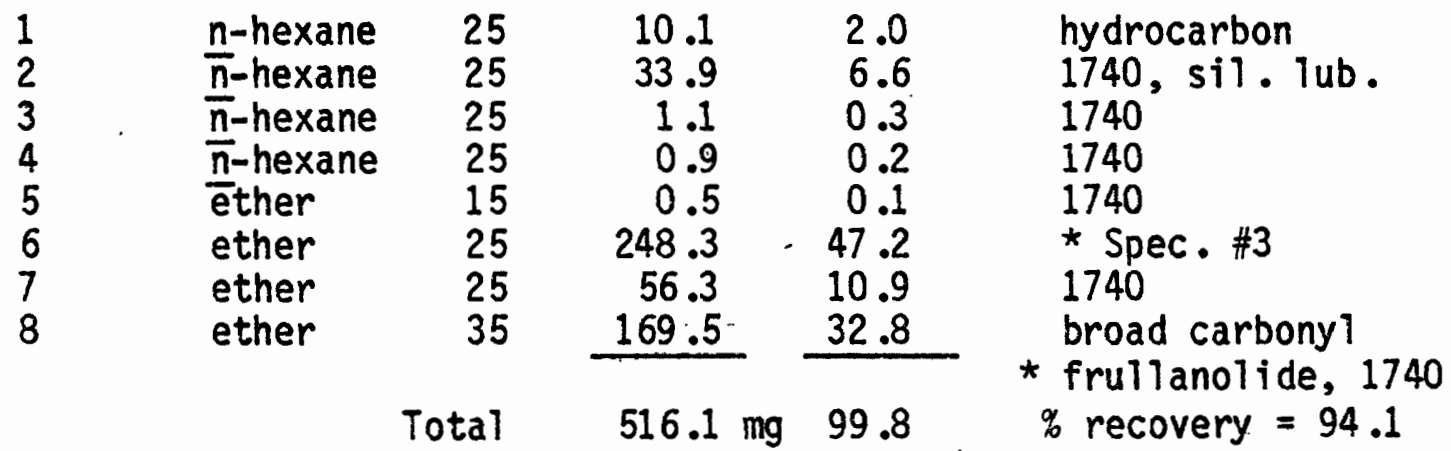


Scale-up using Benzene-First Rechromatograph

Fraction \#6 above was rechromatographed on 19 grams of alumina. The data for this experiment are presented in Table XII. Benzene was used as the solvent throughout. The volume of each fraction was $15 \mathrm{ml}$. Some impurities from the initial chromatograph were successfully removed by the chromatography with benzene. Frulianolide appeared at the junction between orange and green bands. Benzene separated nonfrullanolide $1760 \mathrm{~cm}^{-1}$ absorbing material from frullanolide.

TABLE XII

SCALE-UP USING BENZENE-FIRST RECHROMATOGRAPH

\begin{tabular}{|c|c|c|}
\hline Fraction \# & Color & Significant Infrared Absorptions $\left(\mathrm{cm}^{-1}\right)$ \\
\hline $\begin{array}{r}1 \\
2 \\
3 \\
4 \\
5 \\
6 \\
7 \\
8 \\
9 \\
10 \\
11 \\
12 \\
13 \\
14\end{array}$ & $\begin{array}{l}\text { clear } \\
\text { yellow-orange } \\
\text { yellow-green } \\
\text { pale green } \\
\text { pale green } \\
\text { light green } \\
\text { light green } \\
\text { light green } \\
\text { light green } \\
\text { light green } \\
\text { light green } \\
\text { light green } \\
\text { colorless } \\
\text { colorless }\end{array}$ & $\begin{array}{l}1740 \text {, sil. lub. } \\
1740 \text {, } 1760 \text {, frullanolide fingerprint } \\
\text { frulianolide spectrum } \\
\text { frullanolide spectrum spec. } \# 14 \\
\text { frullanolide spectrum } \\
1760 \text {, not frullanolide fingerprint } \\
1760 \text {, not frullanolide fingerprint } \\
1760 \text {, not frullanolide fingerprint } \\
1760 \text {, not frullanolide fingerprint } \\
1760 \text {, not frullanolide fingerprint } \\
1760 \text {, not frullanolide fingerprint } \\
\text { broad carbony } 1 \\
\text { broad carbonyl }\end{array}$ \\
\hline
\end{tabular}

Search for a Different Purification Solvent Than Benzene

Benzene elution on alumina produced colored compounds, a sign of impurity. A solvent was sought that would produce colorless compounds. Some impure frullanolide was at hand from the experiments of the chromatography of Mixture $A$ and the Lookout State Park extract of F. franciscana (Howe). Ten milligrams of impure fruilanolide was put on a 5 gram alumina (Mallincrodkt) column. The data for this 
experiment is given in Table XIII. The mass of fractions was not measured. The volume of each fraction was $25 \mathrm{ml}$.

The frullanolide put on the column had a yellow color, but Fractions \#6 to \#8 were white and crystalline in appearance and showed sharp peaks in their infrared spectra. The material from the toluene and ether elution was yellow and oily in appearance. These results indicated that $\mathrm{CCl}_{4}$ would be a good substitute for benzene. Subsequent experiments did use $\mathrm{CCl}_{4}$ as an elution solvent.

TABLE XIII

\section{CHROMATOGRAPHY WITH A VARIETY OF SOLVENTS}

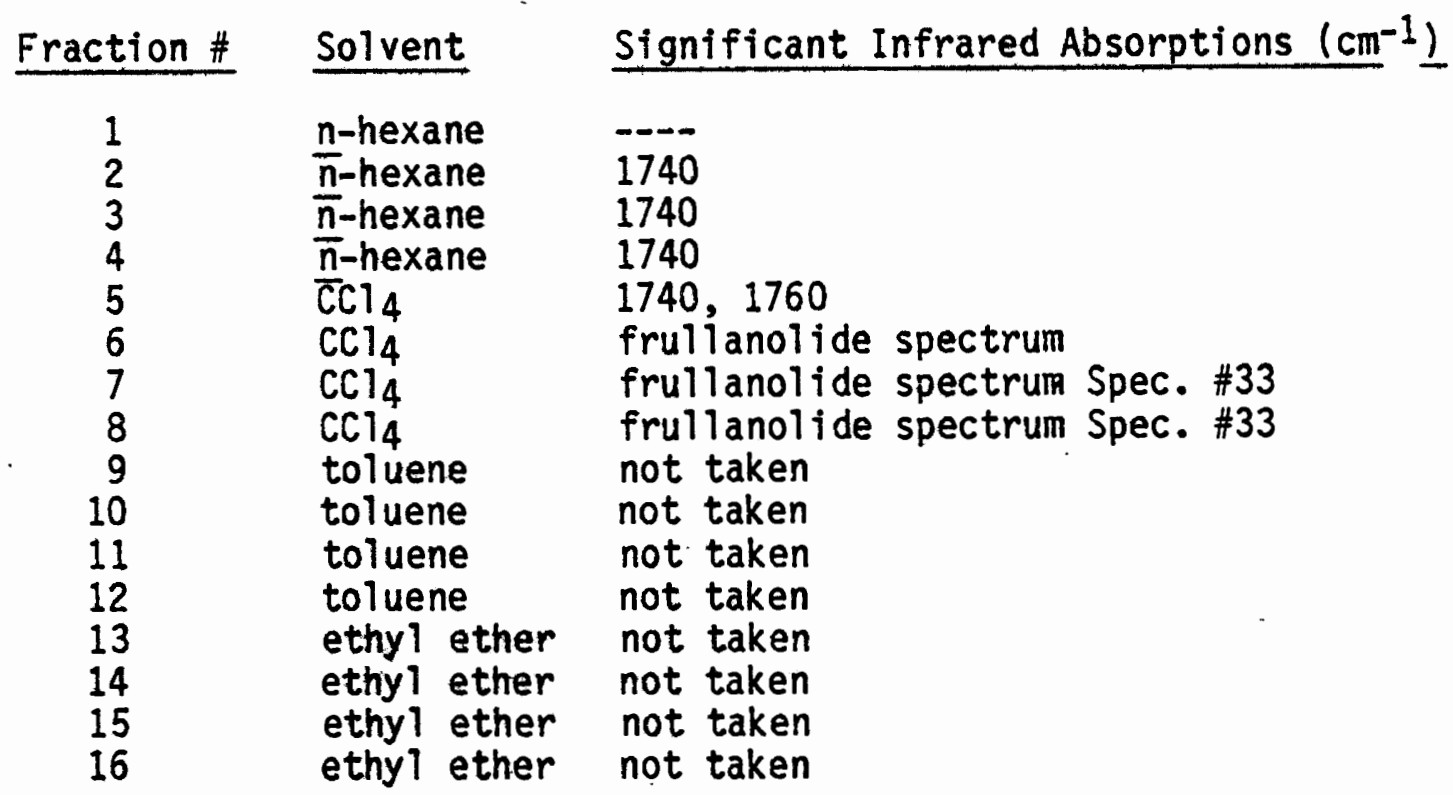

The pattern of solvent elution used in the $F$. nisquallensis (Sul1) experiment is the highest state of development of the elution sequence obtained during this project. Minimal amounts of $\mathrm{CCl}_{4}$ were used in the initial chromatograph so that all of the frullanolide would elute with ether, pinpointing the frullanolide containing fraction. In the rechromatograph, large amounts of $\mathrm{CCl}_{4}$ were used so that 
most of the frullanolide would elute with $\mathrm{CCl}_{4}$, the purification of frullanolide being desired. 


\section{BIBLIOGRAPHY}

1. Conard, H.S. How to Know the Mosses and Liverworts A.M.C. Brown (1972).

2. Clark, Lois; Frye, T.C. "The Liverworts of the Northwest" Publications of the Puget Sound Biological Station 6,1-194 (1928).

3. Mitche11, J.C.; Fritig, B.; Singh, B.;Towers, G.N.H. The J. of Invest. Dermatology 54,233 (1973).

4. Stores, F.J.; Mitche17, J.C.; Rasmussen, J.E. Cutis 18 (1976).

5. Bleumink, E.; Mitche11, J.C.; Nater,J.P. Br. J. Dermatol. 88,499 (1973).

6. Connol1y, J.D.; Thornton, M.S. Phytochemistry 12,631-632 (1973).

7. Perold, G.W.; Muller, J.C.; Ourisson, G. Tetrahedron 28, 5797-5803 (1972).

8. Asakawa, Y.; Ourisson, G. Bull. Soc. Chim. France, 1465 (1976).

9. Fischer, N.H.; OTiver, E.J.; Fischer, H.D. Progress in the Chemistry of Organic Natural Products 38,49 (1979).

10. Rodrigutz, E.; Towers, G.N.H.; Mitche11, J.C. Phytochemistry 15, $1573-1580$ (1976).

11. Dupuis, G.; Brisson, J. Chem. Biol. Interactions 15,205-217 (1976).

12. Dolve, L. Chemio. Biol. Interact. 3,13-18 (1971).

13. Mitche11, J.C. Recent Advances in Phytochemistry 9, 119-138

ed. V.C. Runeckles, PTenum Press, N.Y. (1975).

14. Levinson, A. Personal communication.

15. Huang, T. Masters Thesis, Portland State University (1974).

16. Conley, R.T. Infrared Spectroscopy Allyn and Bacon Inc. (1972).

17. Herz, W. J. Org. Chem. 42, 3910-3913 (1977).

18. Knoche, H.; Ourisson, G.; Perold, G.W. Science 166,240-241 (1969).

19. Haiverson, B. unpublished data. 
20. Asakawa, T.; Aratani, T., Tetrahedron Letters 45,3957-3960 (1975).

21. Irwin, M.A.; Geissman, T. Phytochemistry 8,2411 (1969).

22. Irwin, M.A. PHD Thesis, UCLA, (1971).

23. Kelsey, R.G.; Shafizadeh, F. Personal communication. Wood Chemistry Lab, University of Montana.

24. Mitche11, J.C. Geissman, T. J. Invest. Derm. 104,73 (1971).

25. Dupuis, G. Can. J. Bioch. 52, 575 (1974).

26. Mitche11, J.C. Arch. Derm. 110,871 (1974).

27. Asakawa, Y. et al, Phytochemistry 15,1929-1931 (1976).

28. Hausen, B.M.; Schultz, K.H. Archives of Dermatological Research 255,111-121 (1976).

29. Campolmi, P. et al, Contact Dermatitis 4,93-102 (1978).

30. Hattori, S. Hattori Botanical Journal 35, 202-251 (1972).

31. Shuster, R.M. The Hepaticae and Anthocerotae of North America East of the 100th Meridian VoT. I Columbia University Press N.Y. 1966. 


\section{APPENDIX I}

\section{EXAMINATION OF THE n-HEXANE FRACTIONS \\ IN SEARCH OF A NEW ALKENE}

An unsaturated hydrocarbon was isolated from $F$. franciscana

(Howe) extracts (15). This compound was the major component (97.33\%) of the first hexane fraction of an alumina chromatograph. Evidence for the presence of this compound was sought in the infrared spectra of the hexane fractions in the chromatographs with Frullania. Whenever a plant extract was chromatographed, hexane was the first solvent used. Thus was there opportunity to repeat T. Huang's procedure for the isolation of the hydrocarbon.

Table XIV lists chromatographs of two species of Frullania. The table shows the species, the location of the collection of the plants and what was significant in the infrared spectrum of the fraction.

TABLE XIV

EXAMINATION OF THE HYDROCARBON FRACTIONS OF FRULLANIA

Species Source

1 Cape Lookout

1 Cape Lookout

1 Cape Lookout

1 Cannon Beach

1 Cannon Beach

2 Young's River

1 Unknown *

\section{Significant Infrared Absorptions $\left(\mathrm{cm}^{-1}\right)$}

Hydrocarbon, no unsaturation

Hydrocarbon, no unsaturation

Hydrocarbon, 1640, 880

Hydrocarbon, no unsaturation

Hydrocarbon, no unsaturation

Hydrocarbon, 1640,880

Hydrocarbon, 1640,880

1 - F. franciscana (Howe)

2 - F. nisquallensis (Sul1)

* Prepared by Michael Clement 
The infrared spectrum of the hydrocarbon isolated by $T$. Huang had strong absorbances at $1640 \mathrm{~cm}^{-1}$ and $880 \mathrm{~cm}^{-1}$. The absorbance at 1640 $\mathrm{cm}^{-1}$ is correct for a carbon-carbon double bond. The absorbance at 880 $\mathrm{cm}^{-1}$ is due to an exocyclic double bond.

In Table XIV is seen the presence of these two characteristic infrared absorbances. Thus, the compound isolated by T. Huang may be present in the extracts examined. Some gas chromatographic work was done with the $\underline{n}$-hexane fraction from the first two column chromatographs mentioned in Table XIV. These gas chromatographs of first n-hexane fractions differed significantly from the gas chromatograph published by T. Huang. The infrared spectrum of the hydrocarbon fraction of an extract prepared by Michael Clement was very similar to the infrared spectrum of the unsaturated hydrocarbon of T. Huang's work. A gas chromatograph was not taken of the hydrocarbon fraction from Michael Clement's extract. Curiously, frullanolide was not isolated by the procedures described in the Experimental section from Michael Clement's extract.

These findings are consistent with the idea that variability of chemical constitution occurs in F. franciscana (Howe) depending on where and when the sample of plant was collected. This may be an example of the variability of the Bryophyta in general, a phenomena much discussed in the botanical literature $(30,31)$. It is also possible that the sample had deteriorated. 


\section{APPENDIX II}

\section{SPECTRA}

Notes on the Spectra

Unless otherwise indicated, the spectra were taken by the author. The samples were prepared for infrared and nuclear magnetic resonance spectroscopy as described in the experimental section.

Spectra 1-23 are from fractions from various chromatographs. In any chromatograph, a number of fractions are generated. Spectra (infrared) are taken of the evaporated fractions whenever possible. These spectra are compared with the published spectrum of frullanolide (7). One spectrum from the set of spectra from each chromatograph usually resembles the published frullanolide spectrum more than the others. Spectra \#1 to \#18 come from different chromatographs, and they were judged to be the most similar to the published spectrum of frullanolide (one spectrum from each chromatograph). Spectra 19-23 all come from the same chromatograph, a second rechromatograph. These are the infrared spectra of consecutive fractions. Spectrum \#21 was judged to be the closest to the published spectrum of frullanolide and was judged to be the best spectrum of frullanolide obtained. Spectrum \#21 was therefore enlarged as Spectrum \#27.

In some cases, the spectra of several fractions were taken on one sheet of recorder paper (e.g. Spectrum \#19). The fractions are in numerical order; the smallest numbered fraction is at the top of the paper. 
TABLE XV

GUIDE TO THE SPECTRA

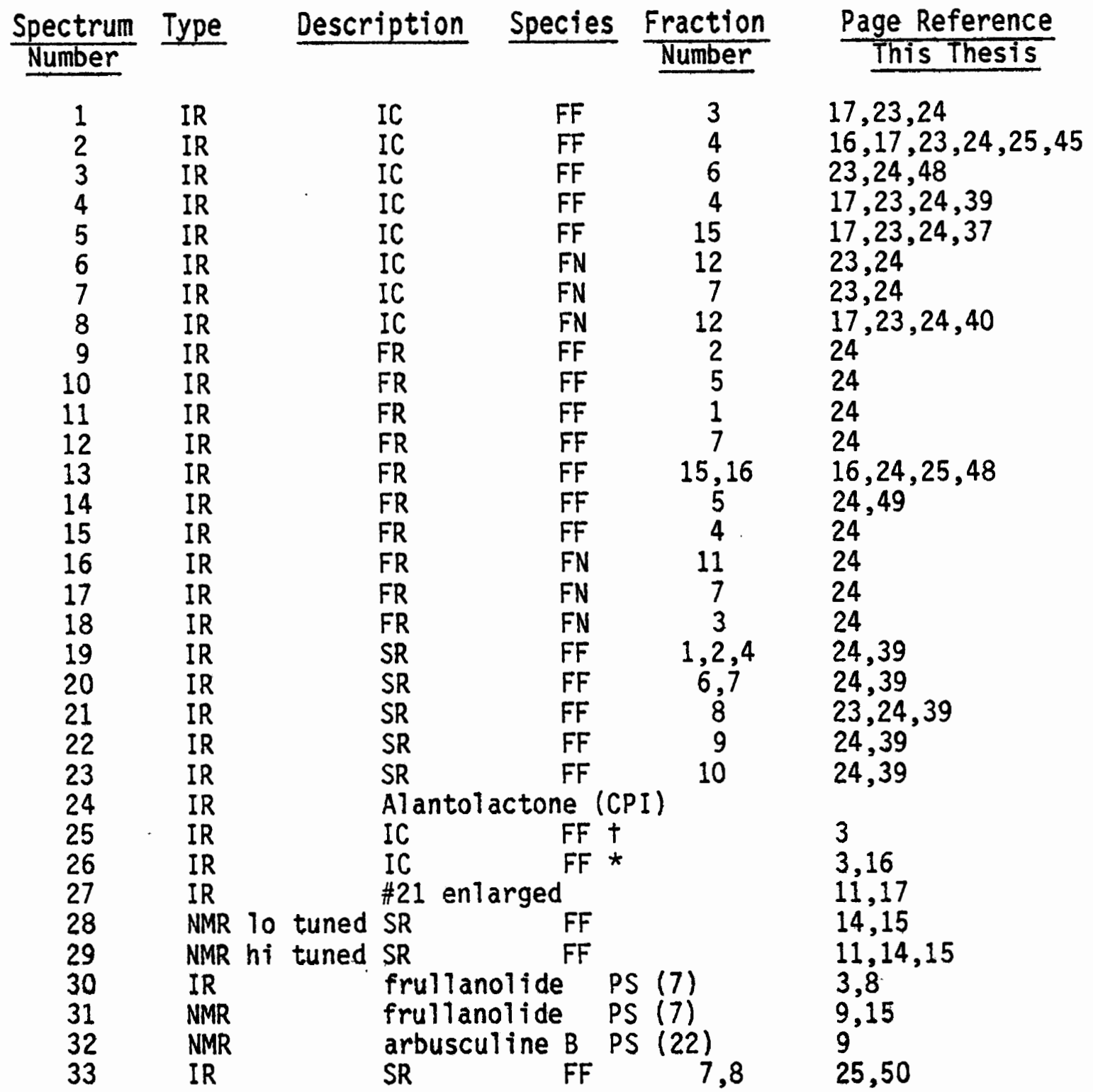

CODE

\begin{tabular}{ll|ll} 
IR & Infrared & IFN & F. nisquallensis (SuI1) \\
NMR & Nuclear Magnetic ResonancelPS & PubTished spectrum \\
IC & Initial Chromatograph & It & From Dr. Levinson \\
FR & First Rechromatograph & $*$ & From Tim Huang \\
SR & Second Rechromatograph & CPI & Chemicals Procurement \\
FF & F. franciscana (Howe) & & Laboratories, Inc.
\end{tabular}




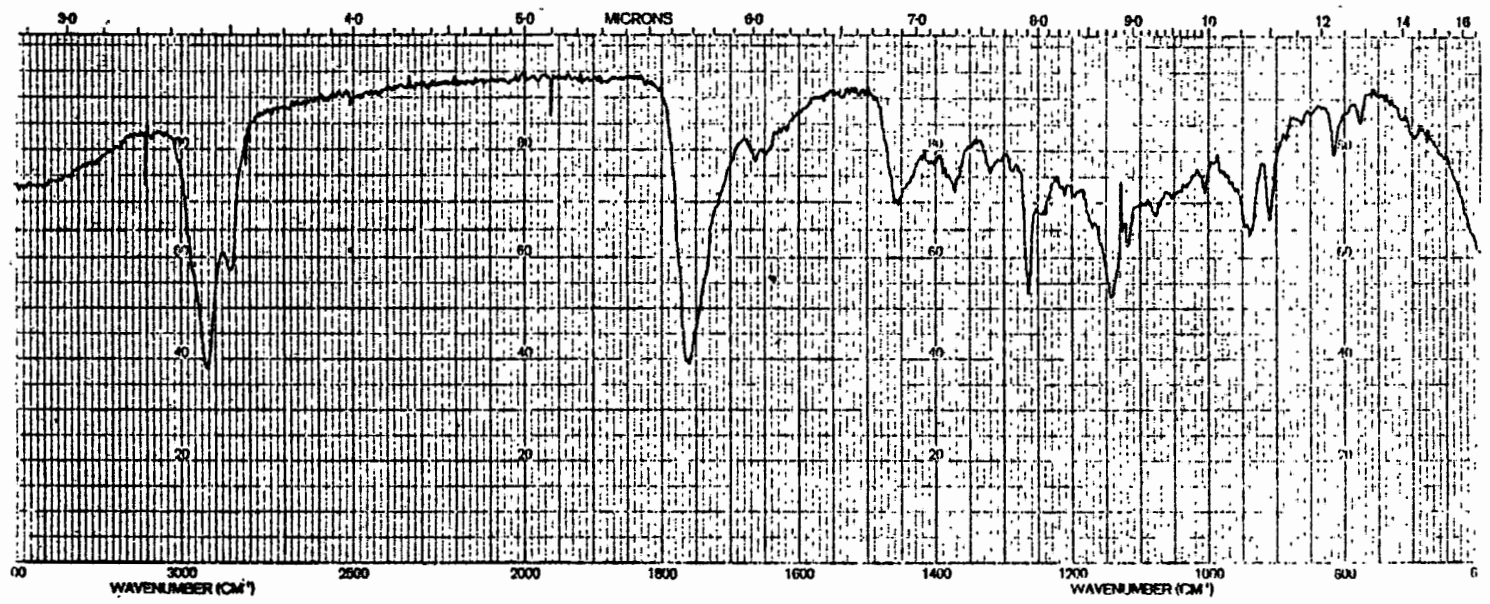

1. Infrared. Initial Chromatograph. F. franciscana (Howe) Fr. 3

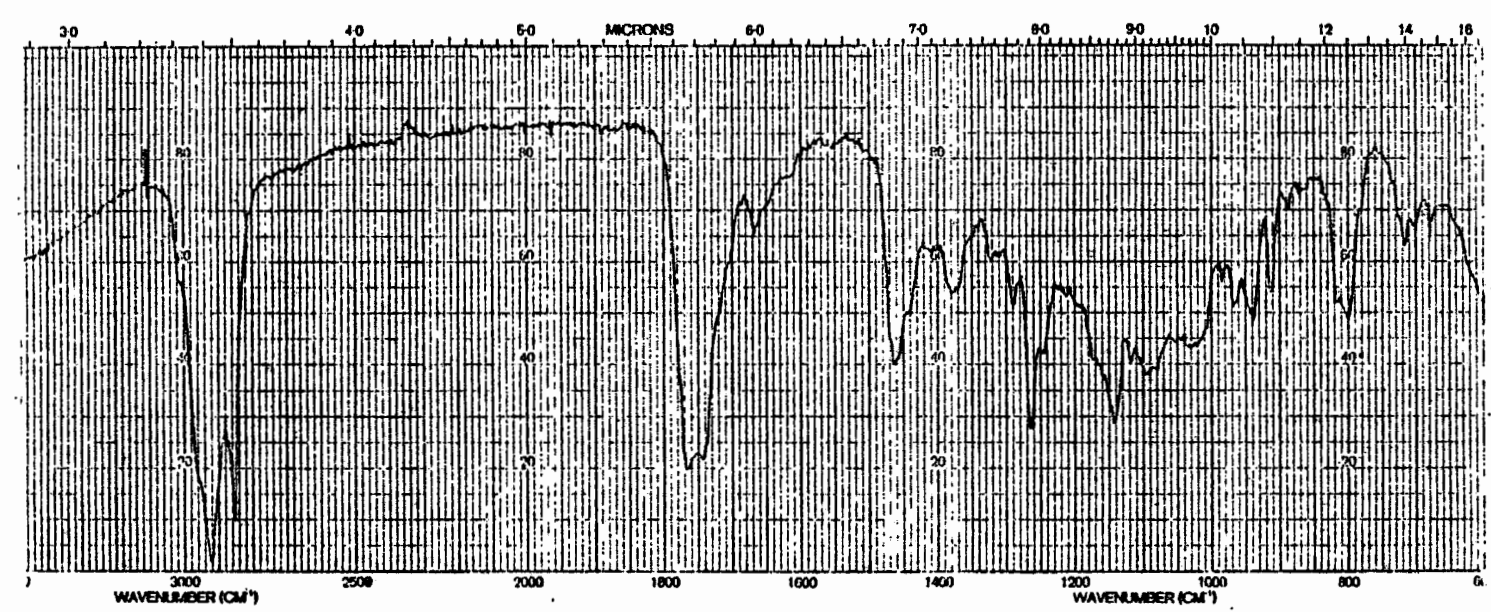

2. Infrared. Initial Chromatograph. F. franciscana (Howe) Fr. 4

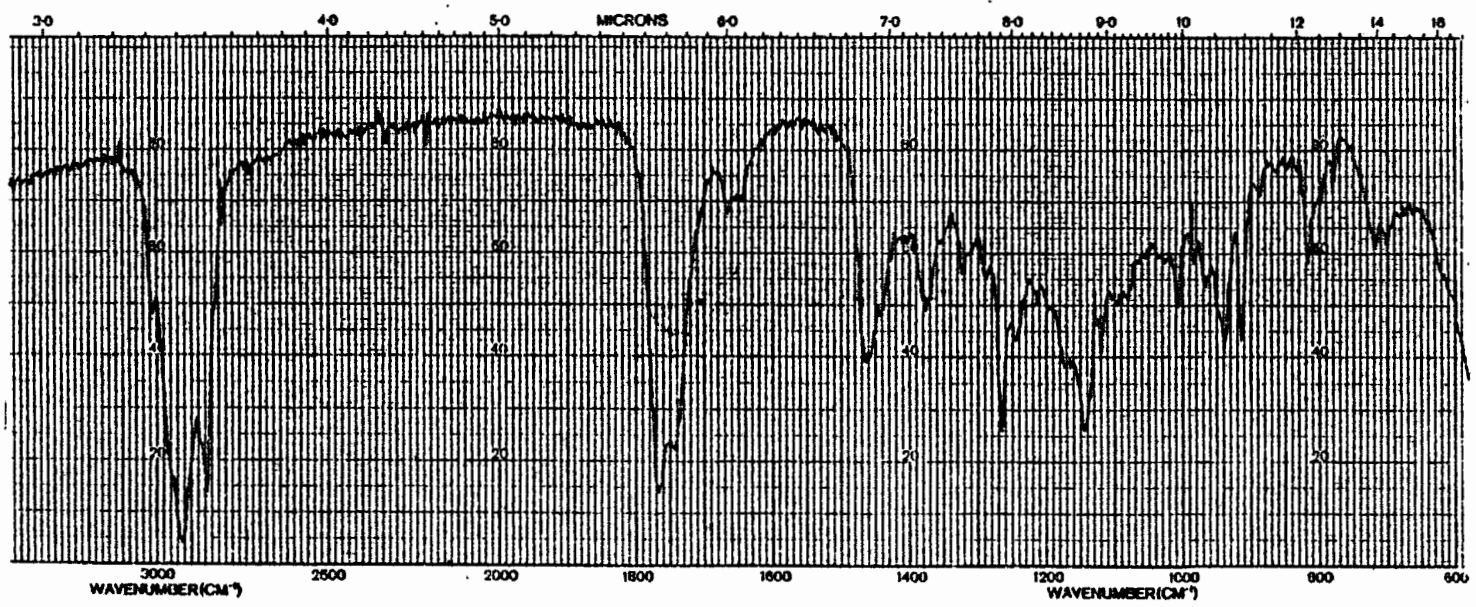

3. Infrared. Initial Chromatograph. F. franciscana (Howe) Fr. 6 


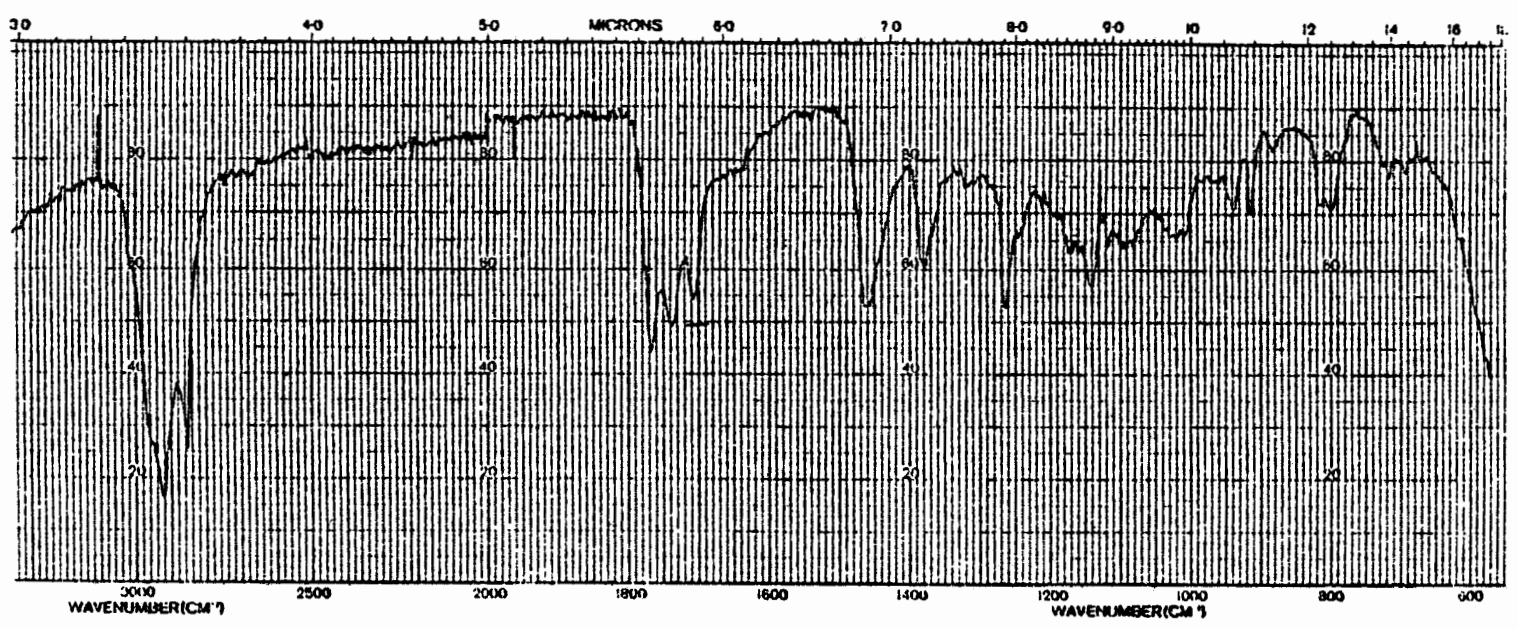

4. Infrared. Initial Chromatograph. F. franciscana (Howe) Fr. 4
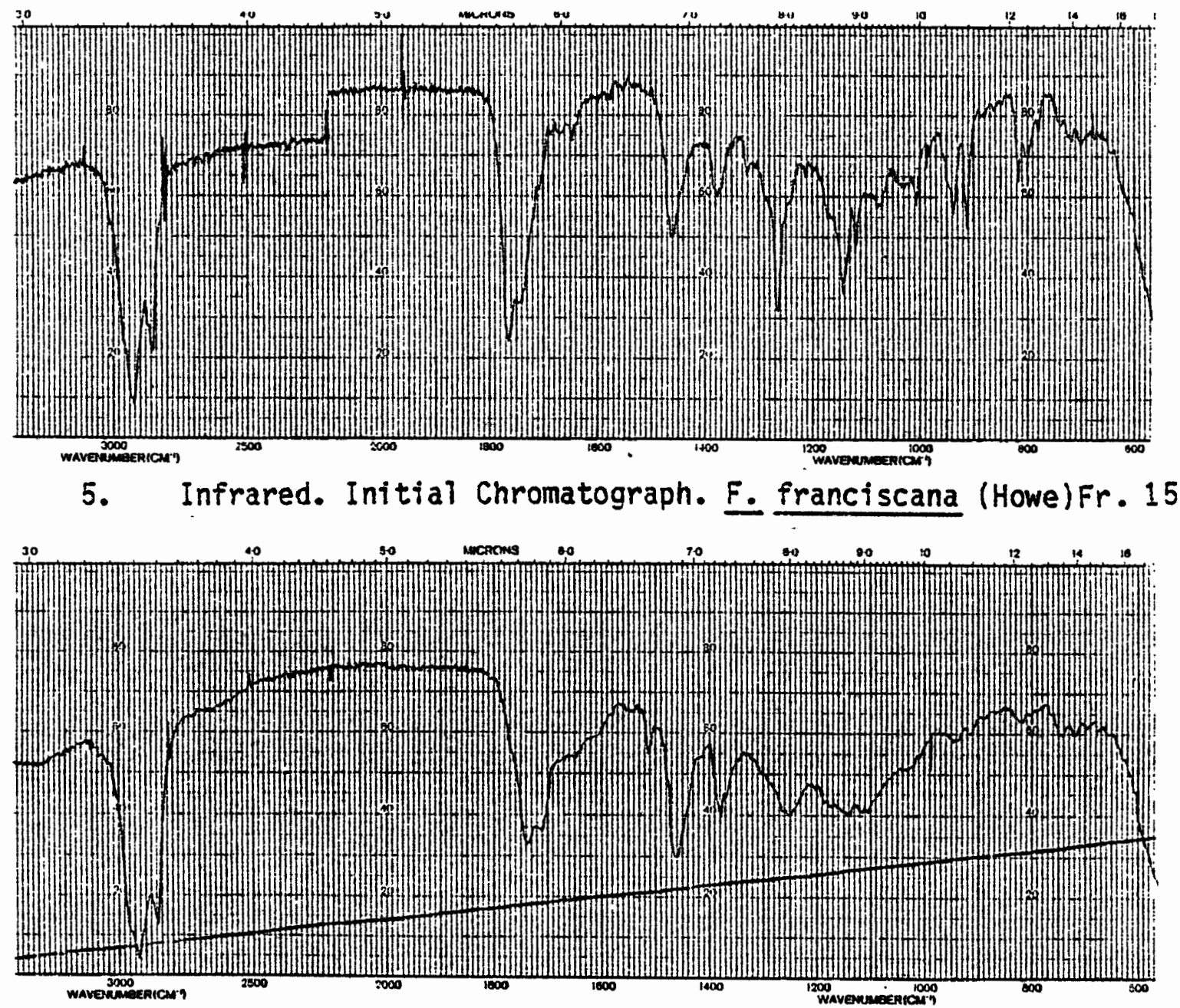

6. Infrared. Initial Chromatograph. F. nisquallensis (Sull) Fr. 12 


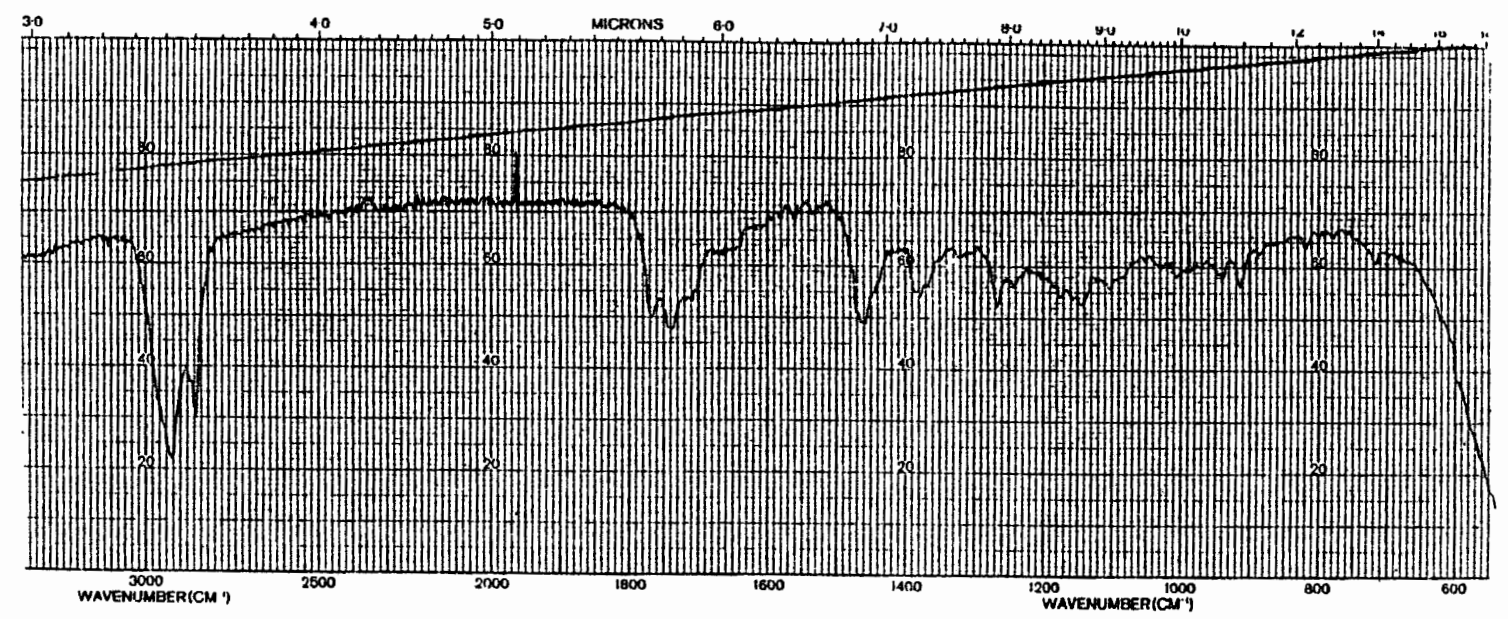

7. Infrared. Initial Chromatograph. F. nisquallensis (Sul1) Fr. 7

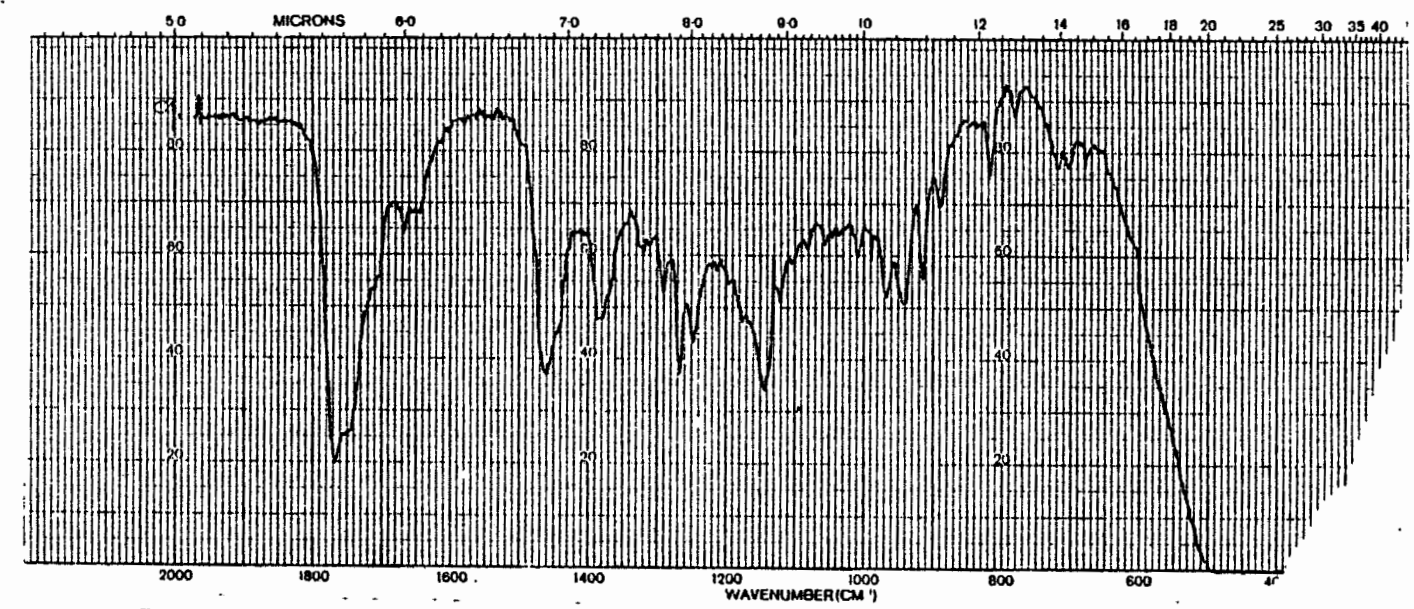

8. Infrared. Initial Chromatograph. F. nisquallensis (Sul1) Fr. 12

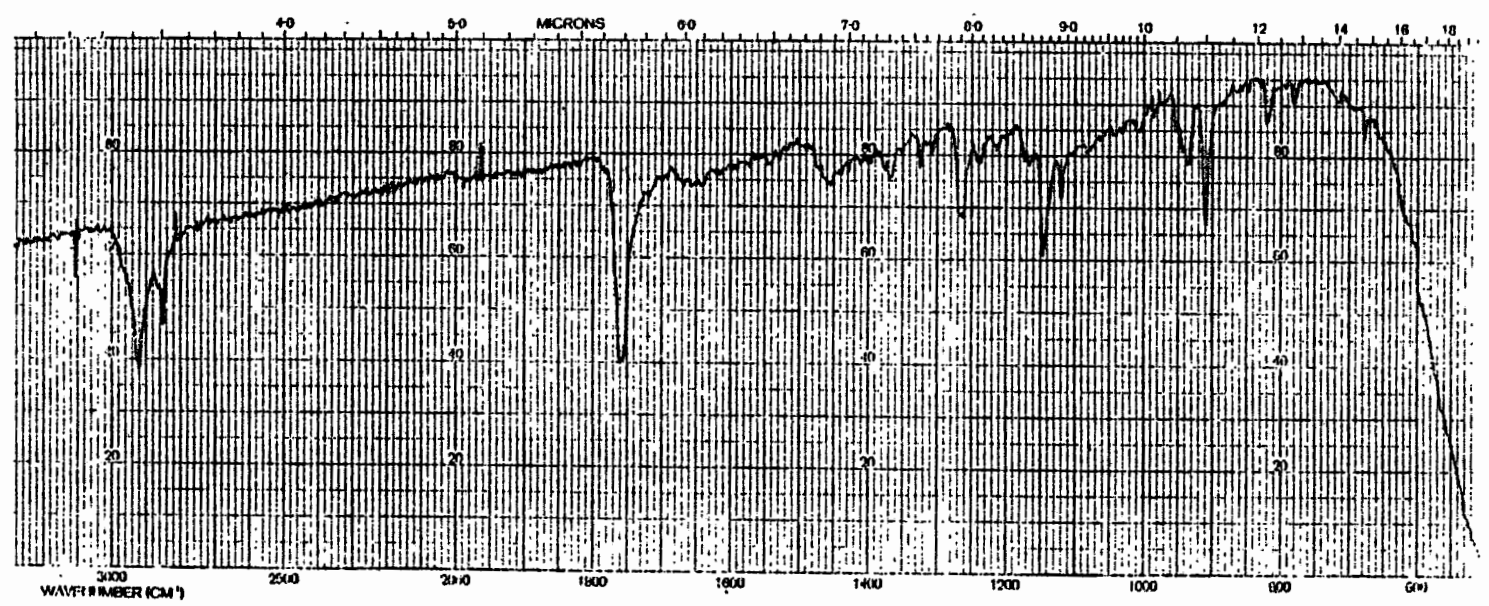

9. Infrared. First Rechromatograph. F. franciscana (Howe) Fr. 2 


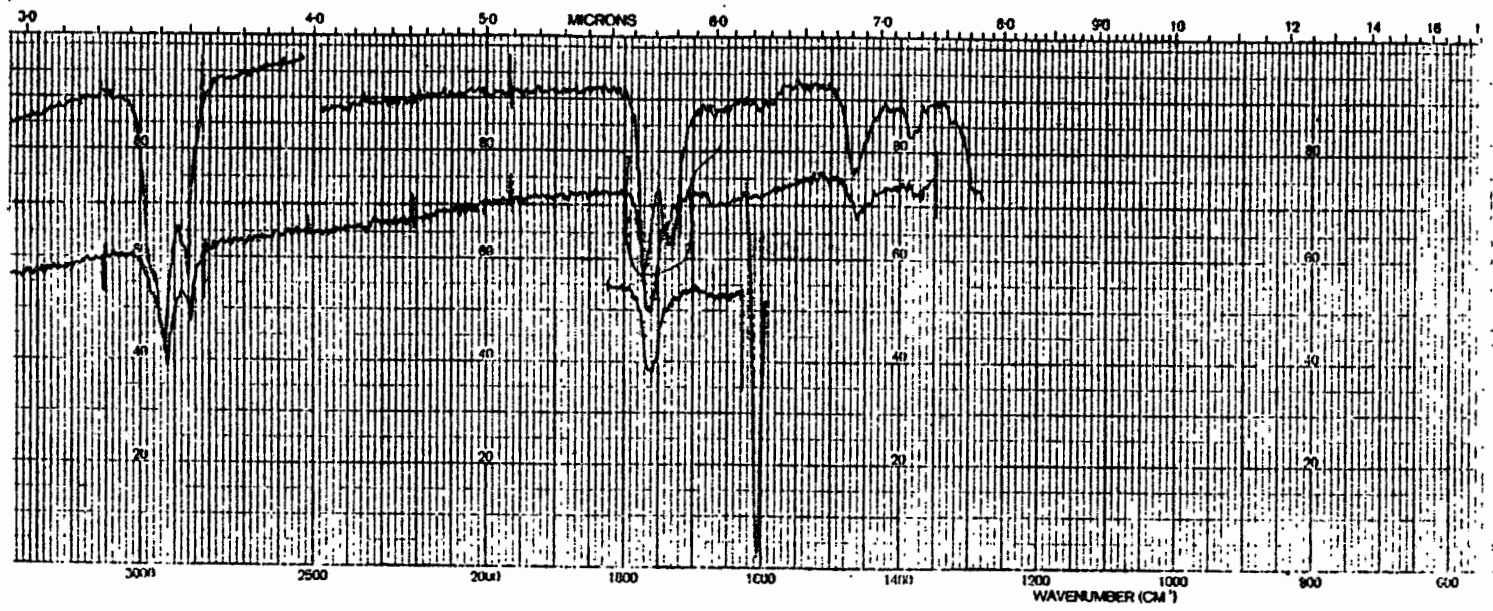

10. Infrared. First Rechromatograph. F. franciscana (Howe) Fr. 5

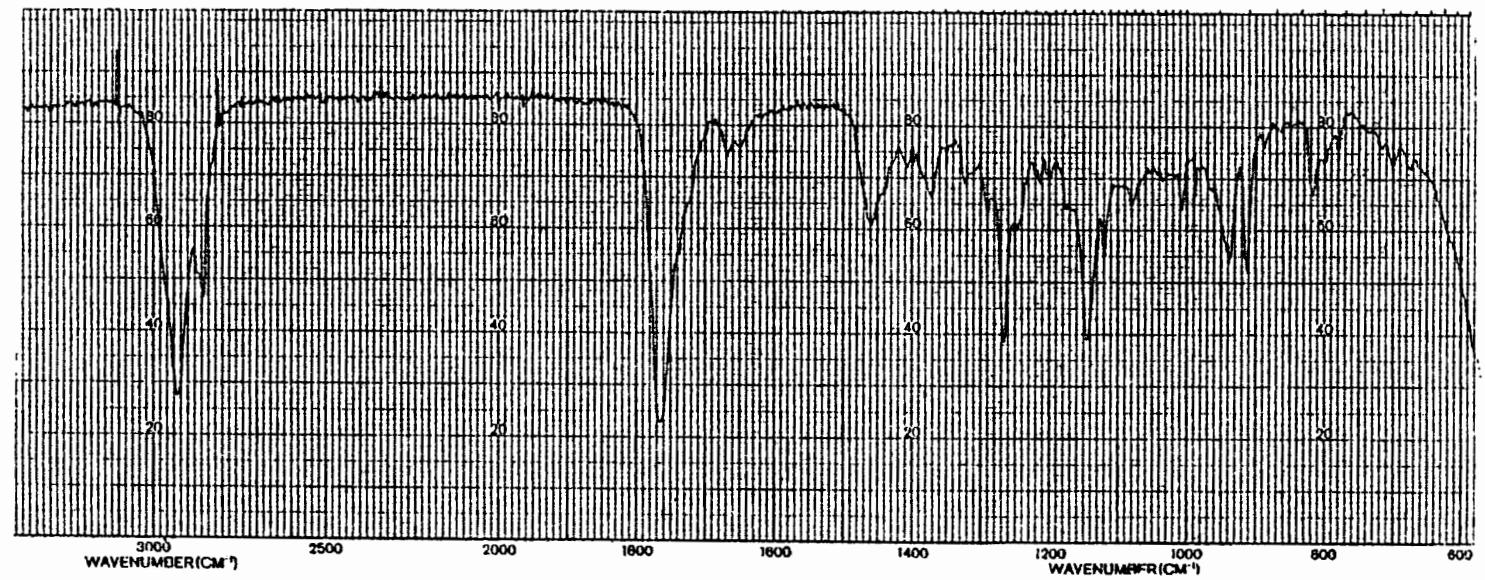

11. Infrared. First Rechromatograph. F. franciscana (Howe)Fr. 1

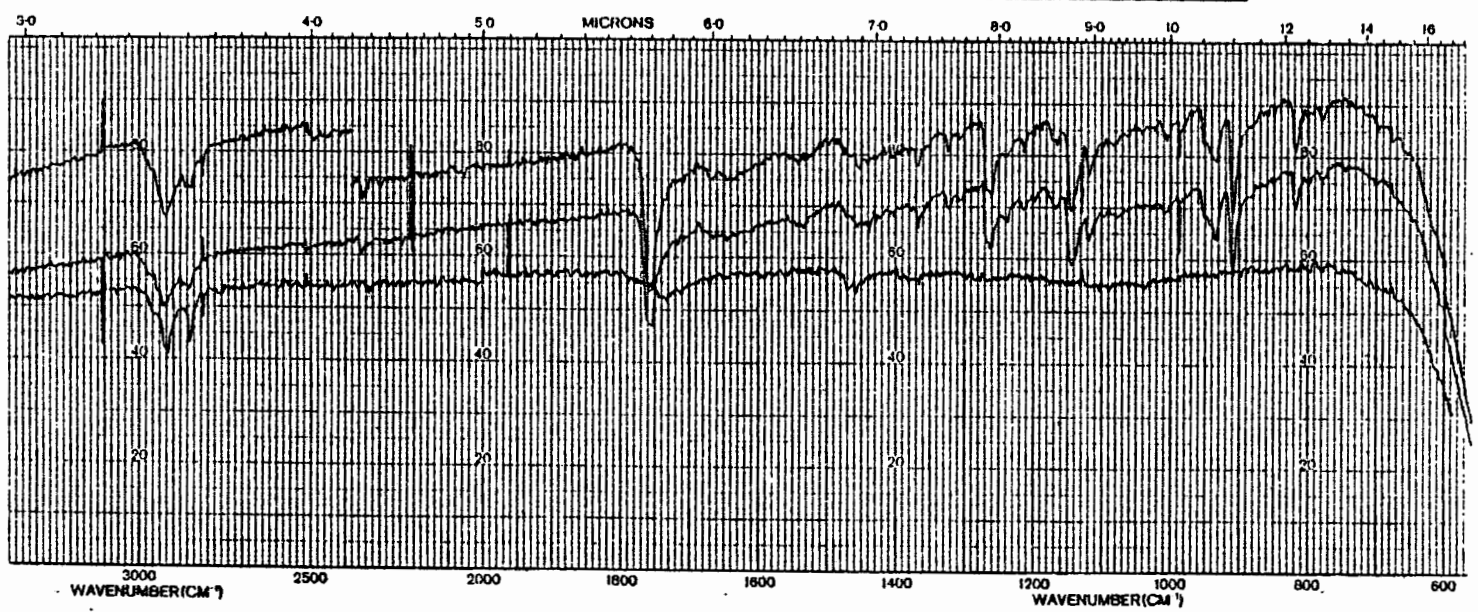

12. Infrared. First Rechromatograph. F. franciscana (Howe) Fr. 7 


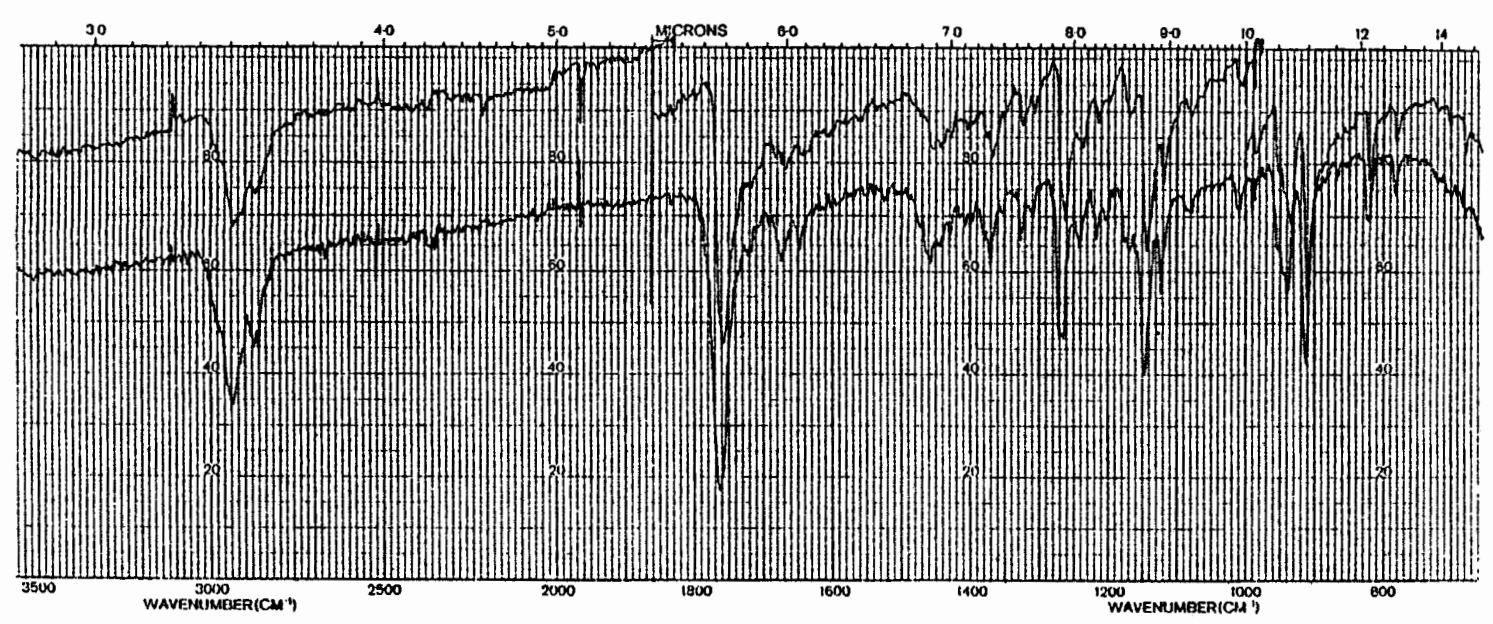

13. Infrared. First Rechromatograph. F. franciscana (Howe)Fr. 15,16

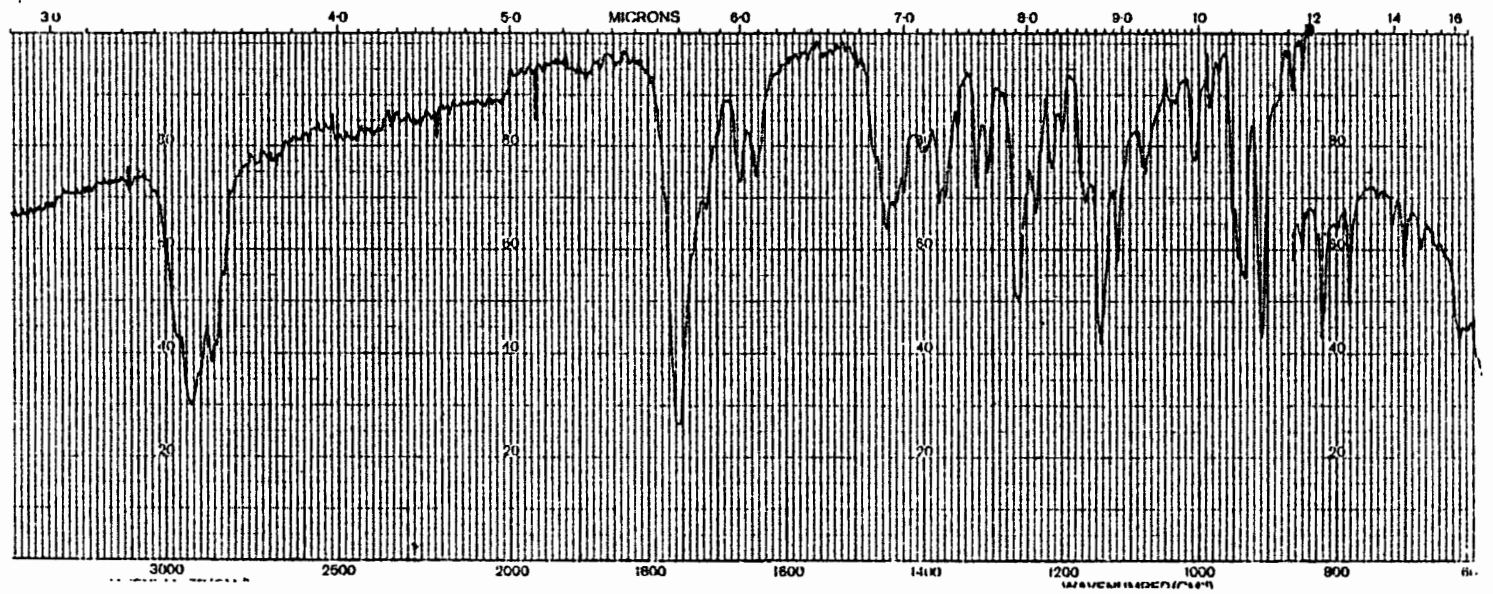

14. Infrared. First Rechromatograph. F. franciscana (Howe) Fr. 5

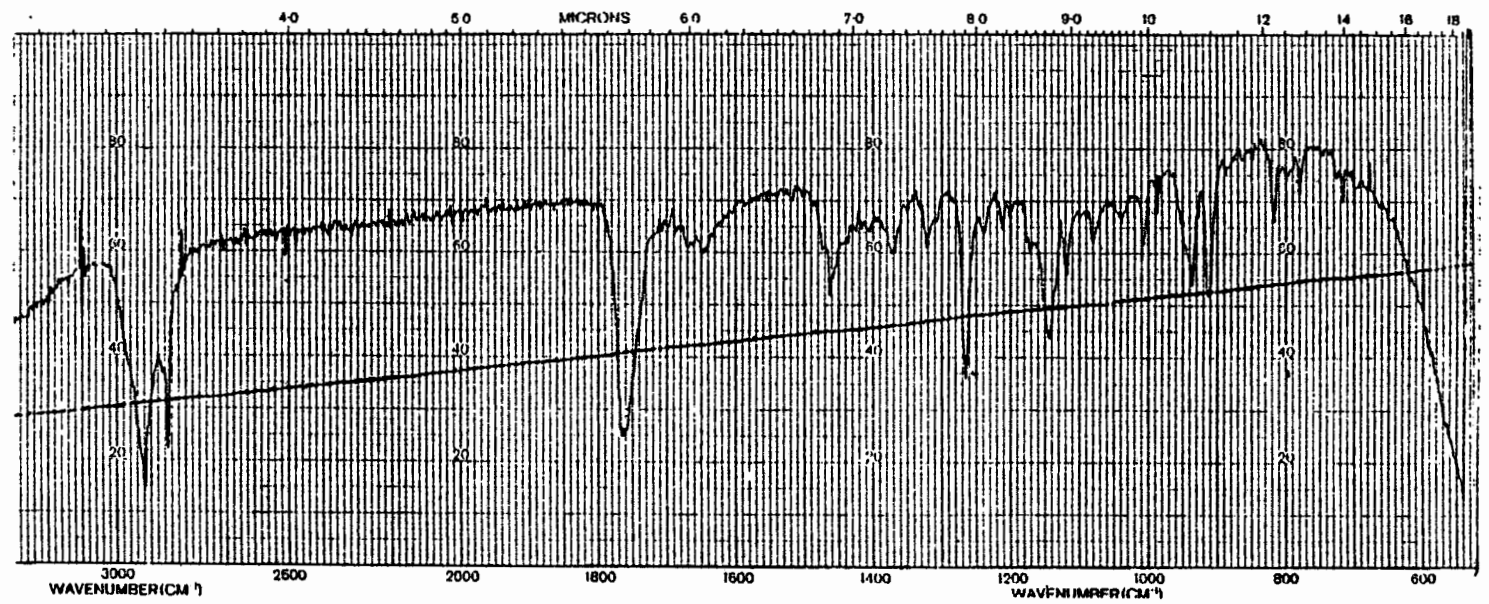

15. Infrared. First Rechromatograph. F. franciscana (Howe)Fr. 4 


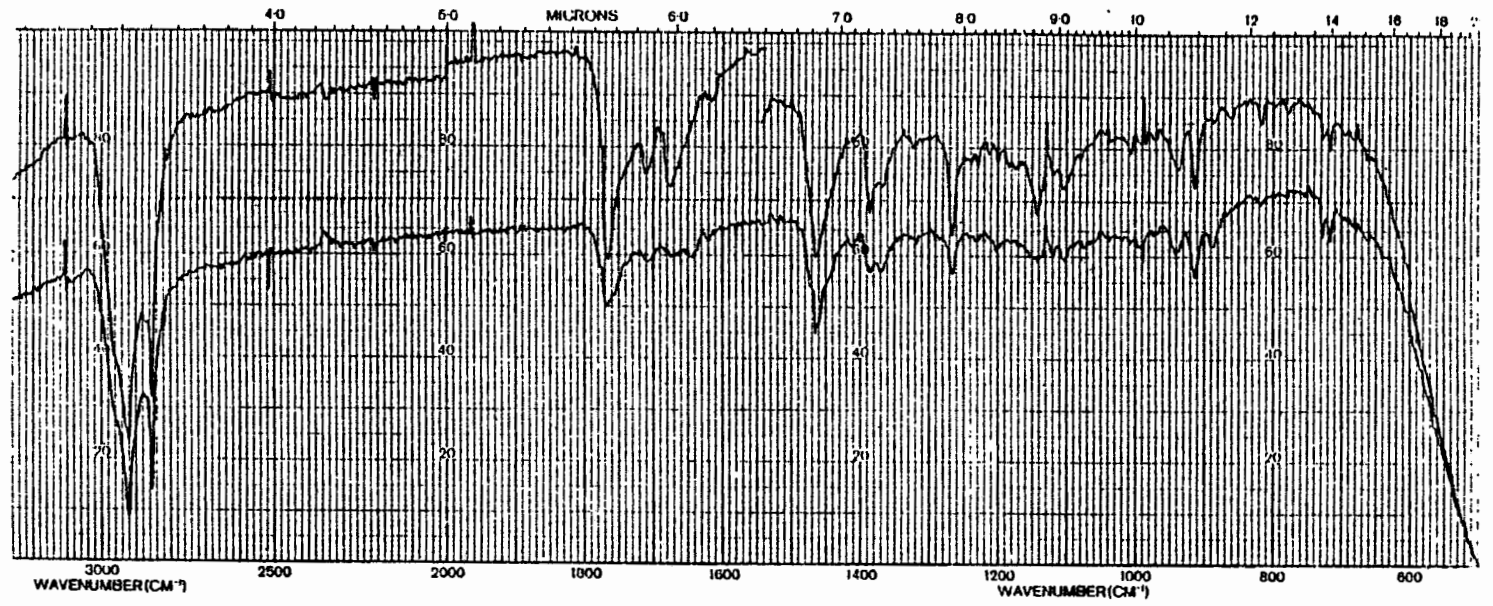

16. Infrared. First Rechromatograph. F. nisquallensis (Sull) Fr. 11

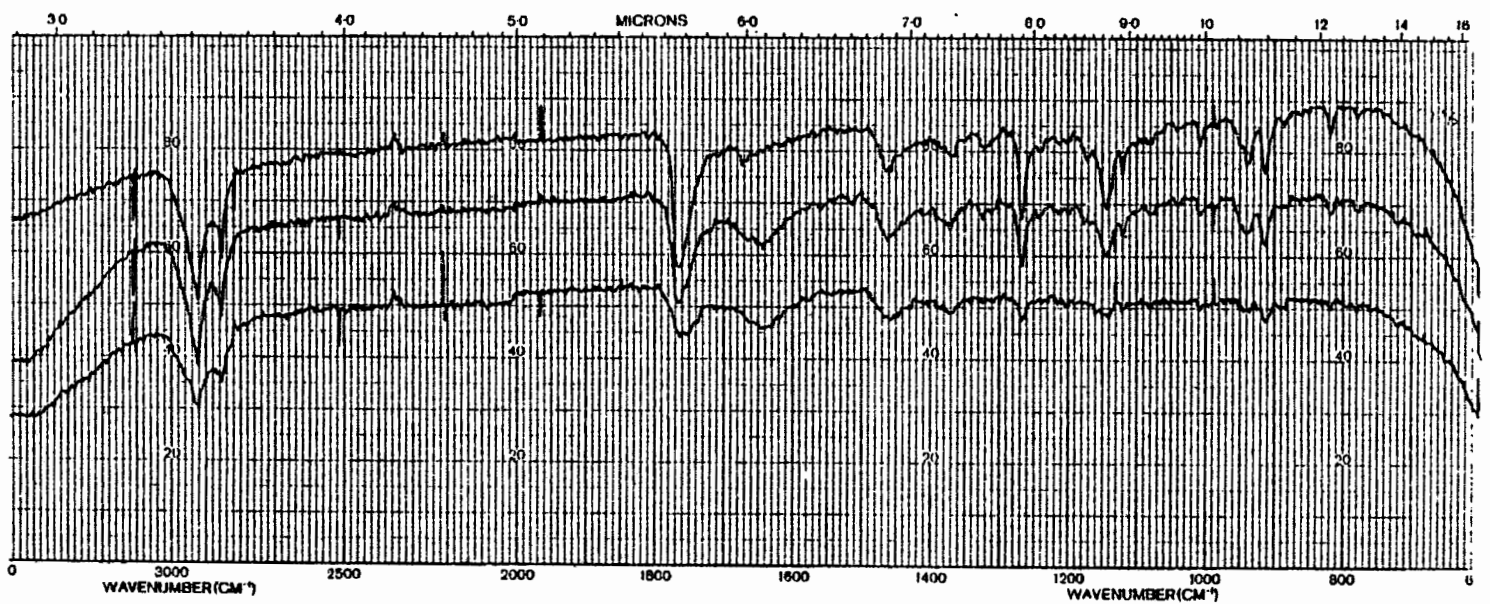

17. Infrared. First Rechromatograph. F. nisquallensis (Sul1) Fr. 7

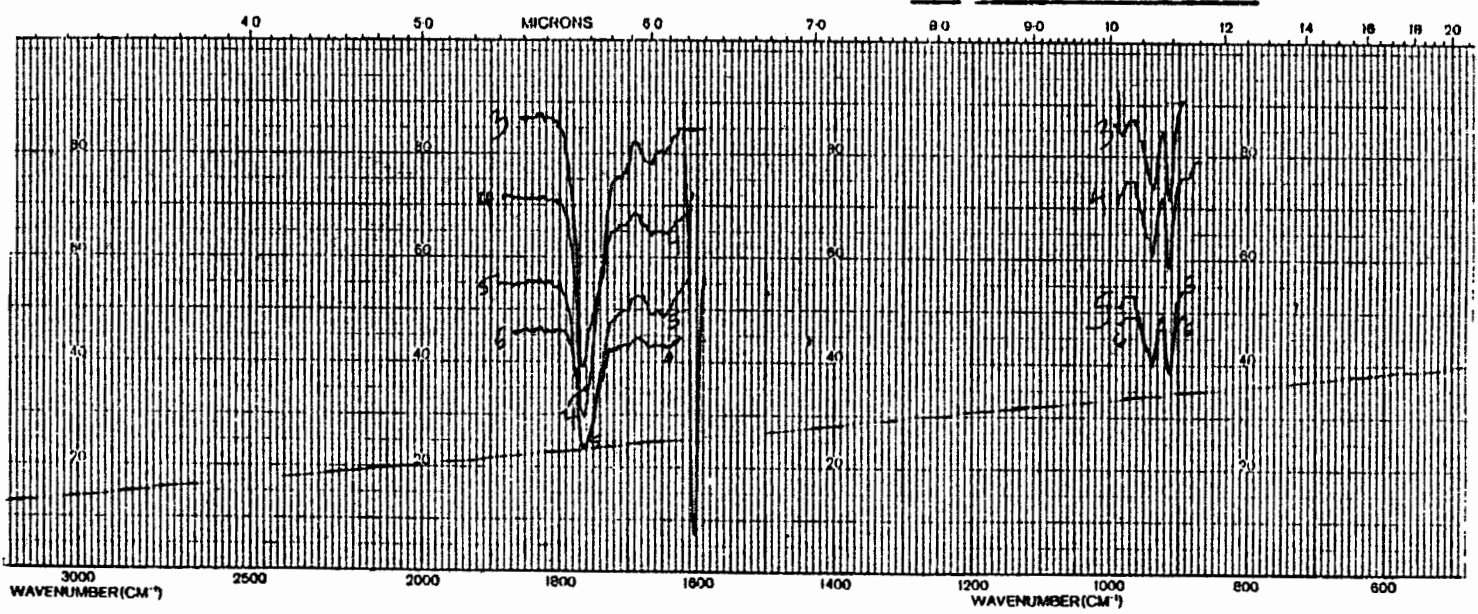

18. Infrared. First Rechromatograph. F. nisquallensis (Sull)Fr. 3 


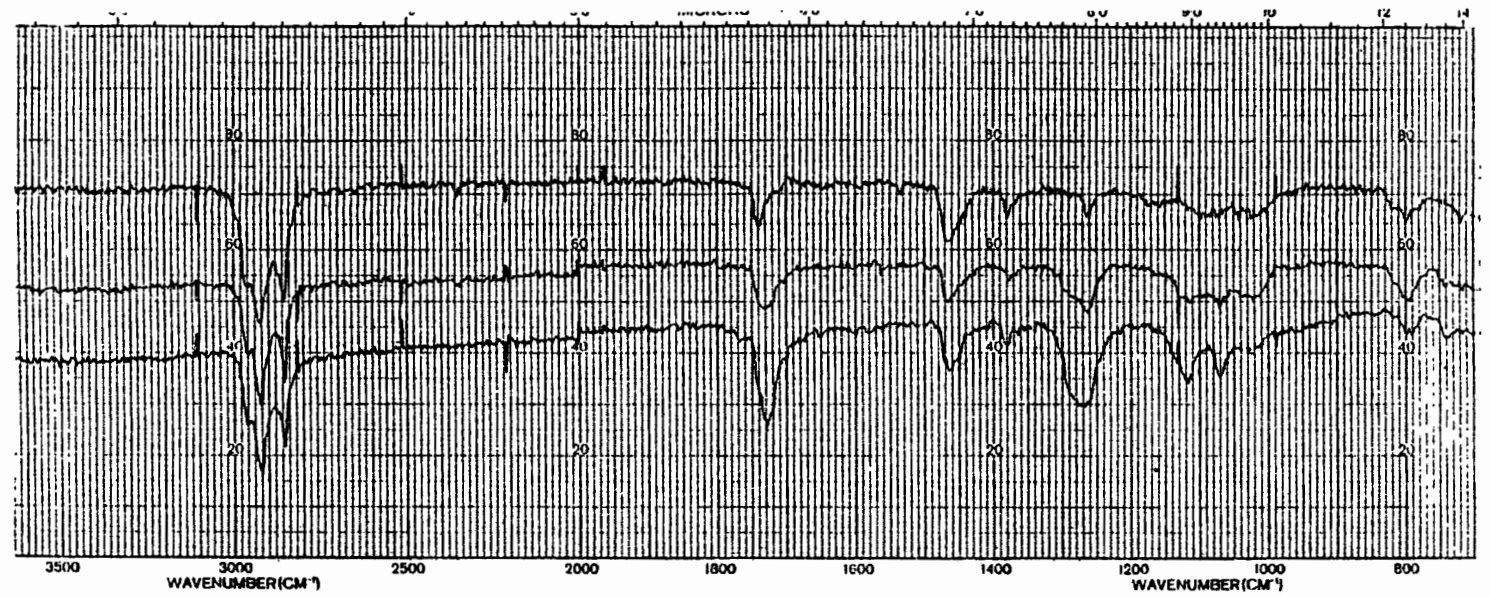

19. Infrared. Second Rechromatograph. F. franciscana (Howe) Fr. 1,2,4

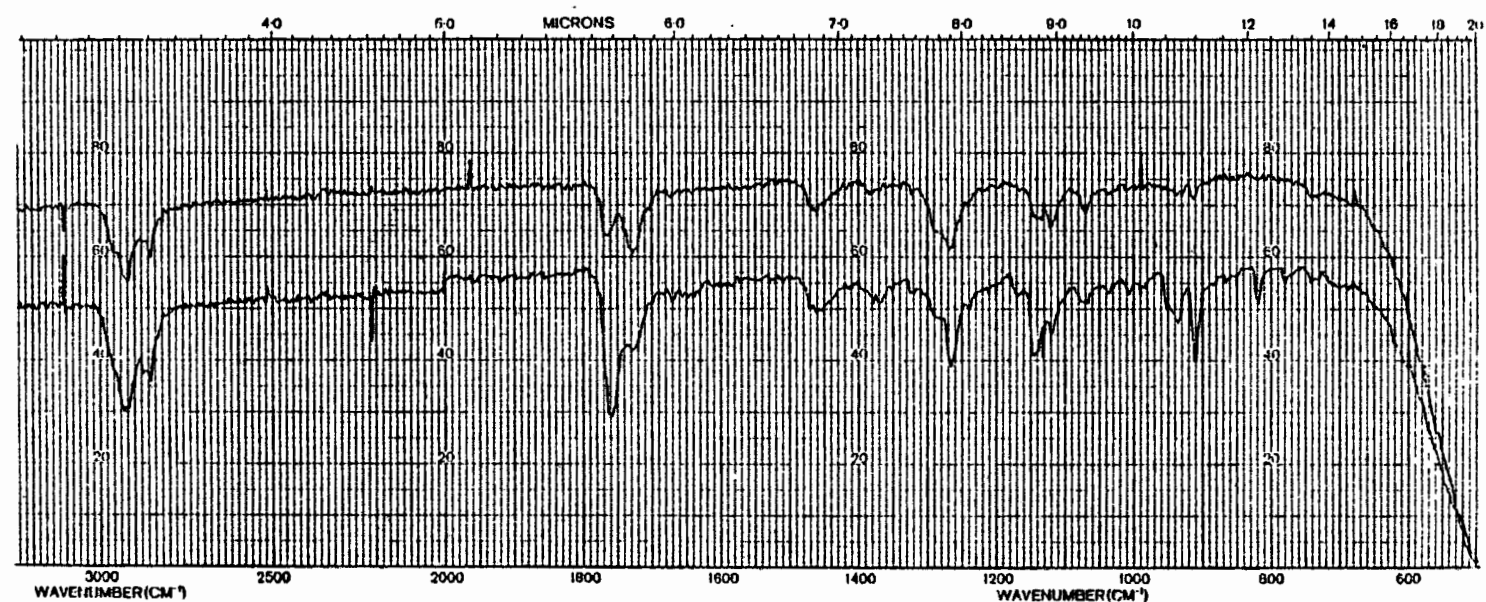

20. Infrared. Second Rechromatograph. F. franciscana (Howe) Fr. 6,7

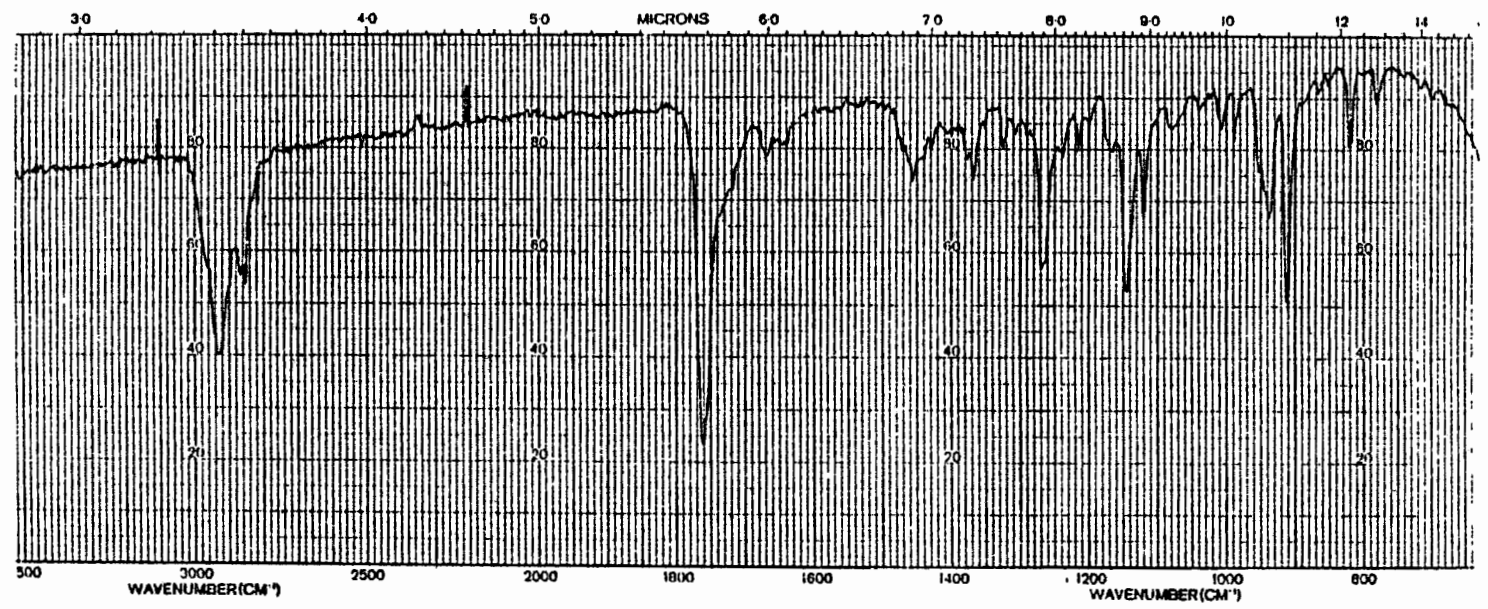

21. Infrared. Second Rechromatograph. F. franciscana (Howe)Fr. 8 


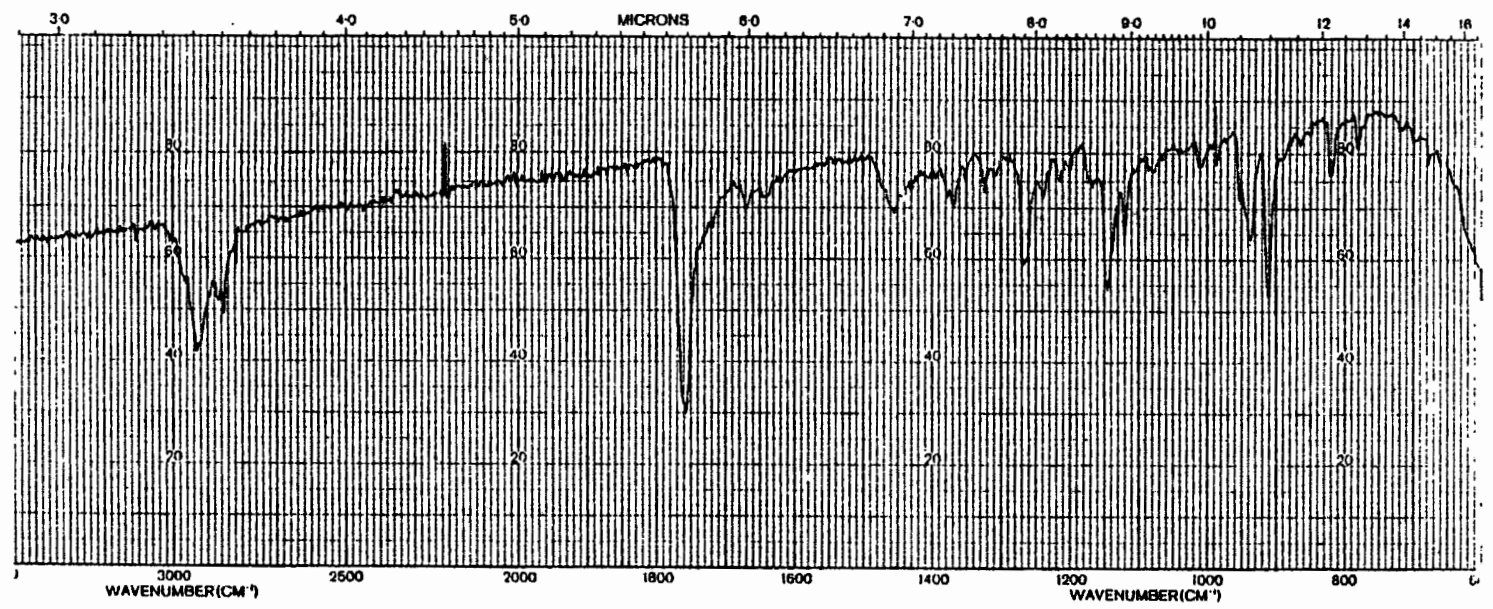

22. Infrared. Second Rechromatograph. F. franciscana (Howe)Fr. 9

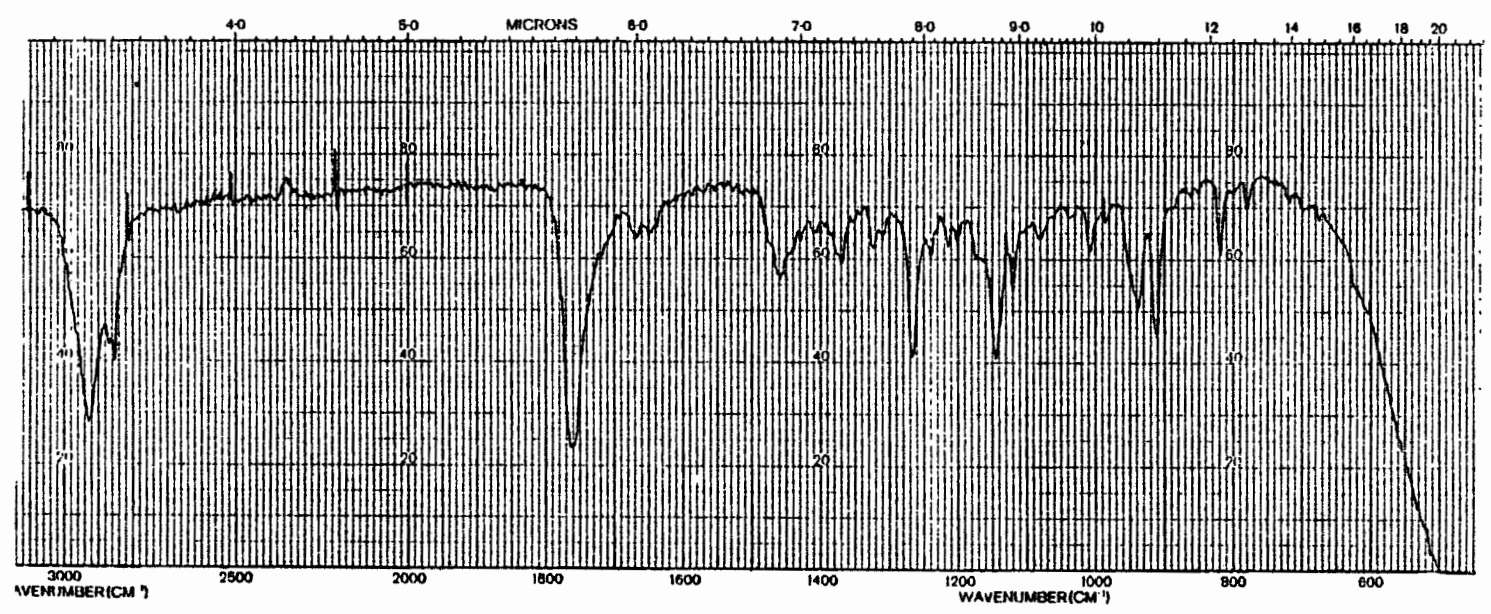

23. Infrared. Second Rechromatograph. F. franciscana (Howe)Fr. 10

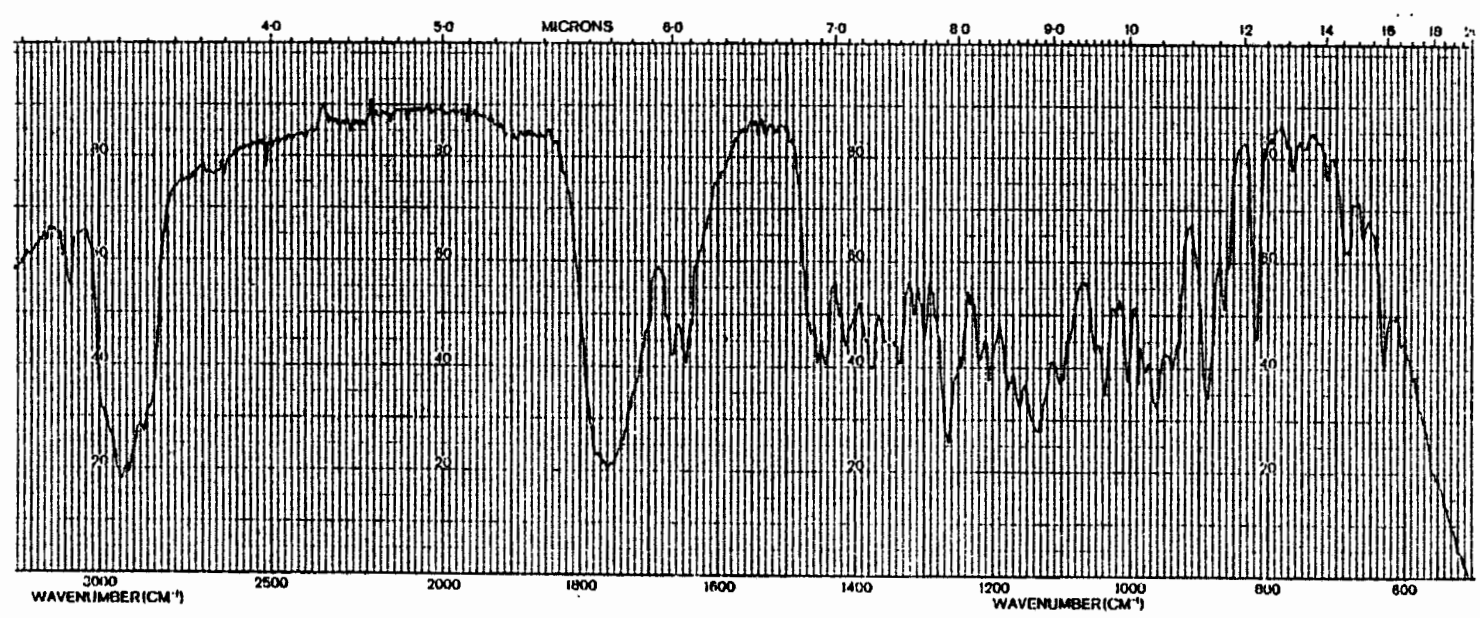

24. Infrared. Alantoiactone (Chemical Procurment Labs, Inc.) 


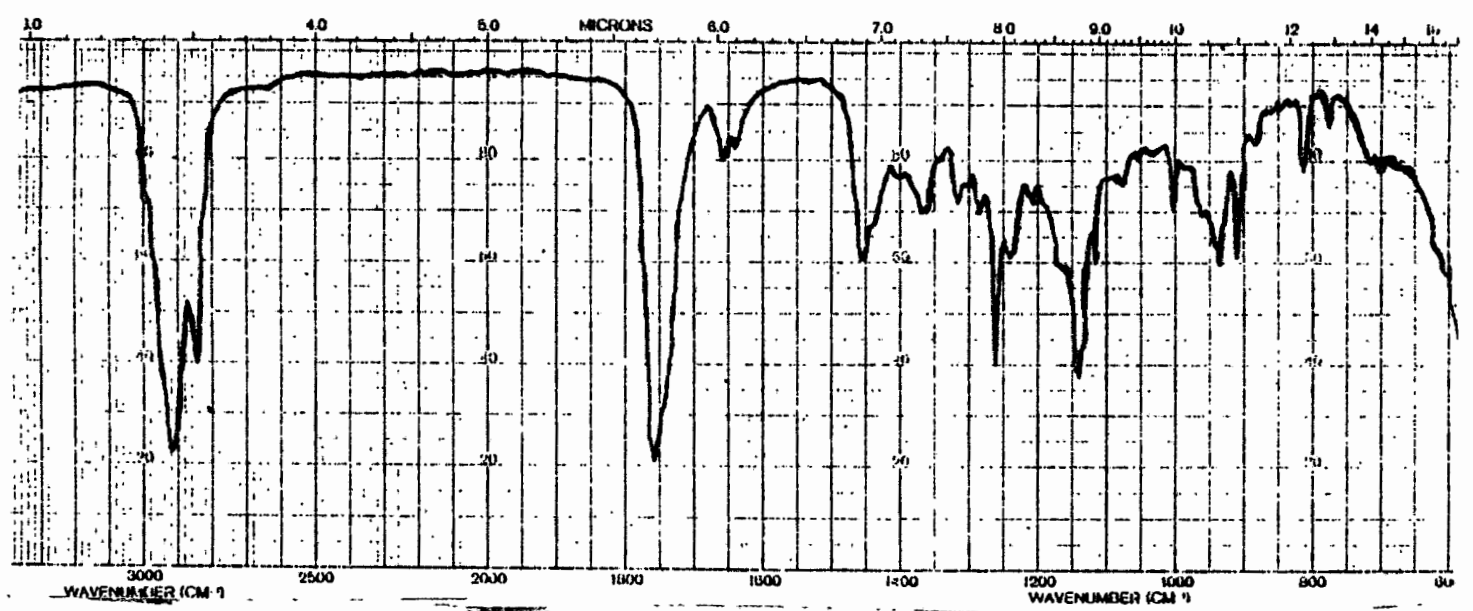

25. Infrared. Initial Chromatograph. F. franciscana (Howe)

(from Dr. Levinson)

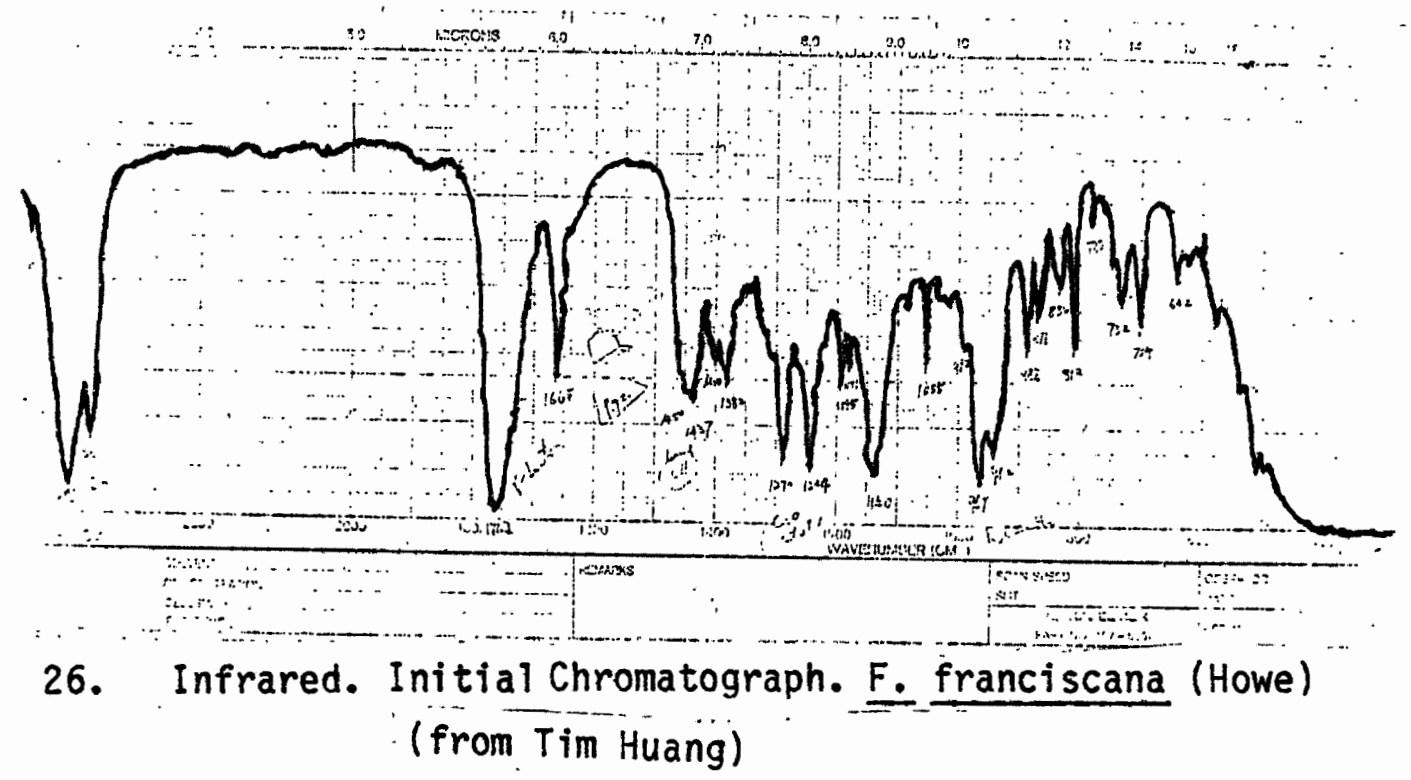




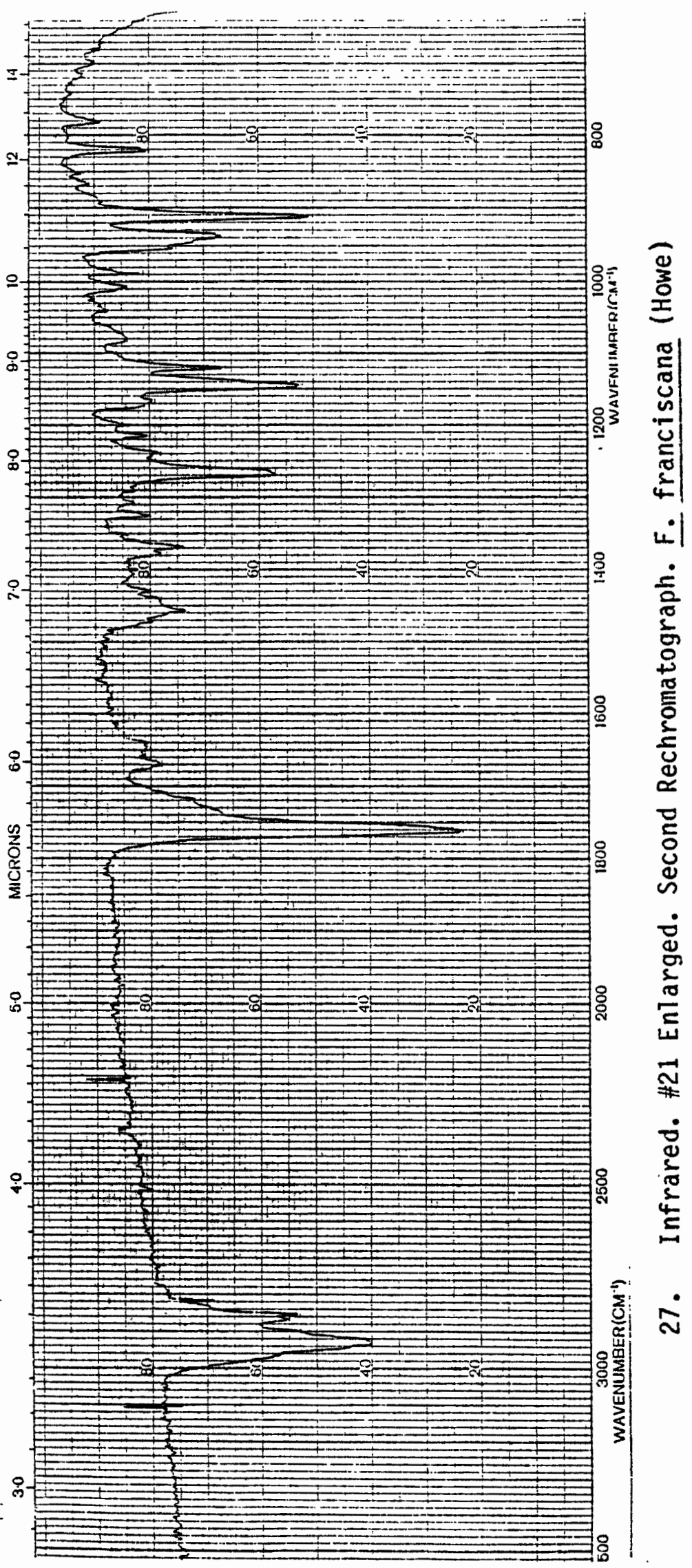




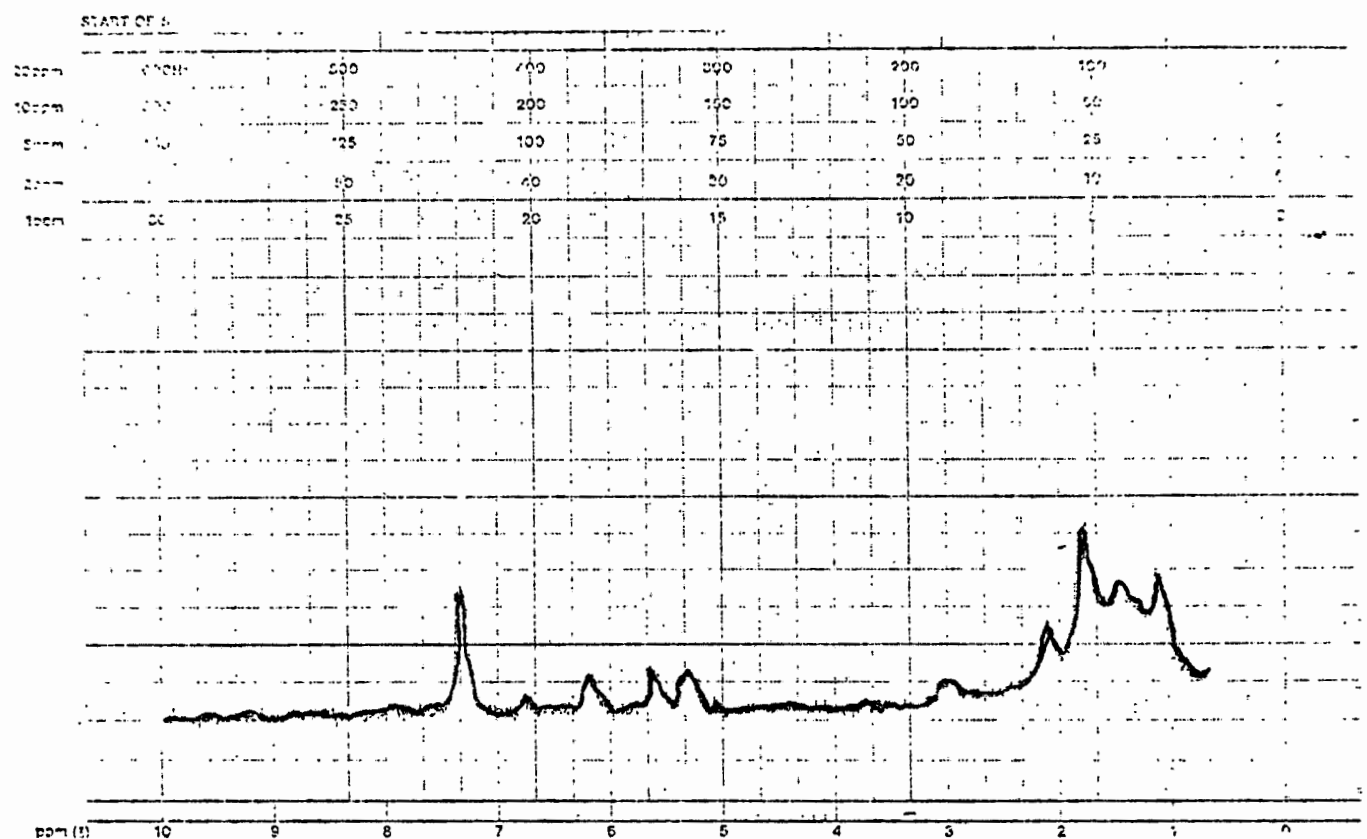

28. Nuctear Magnetic Resonance. Second Rechromatograph. F. franciscana (Howe). Low tuned

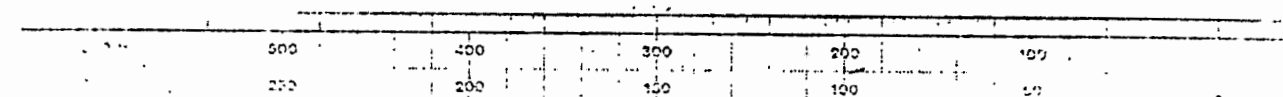

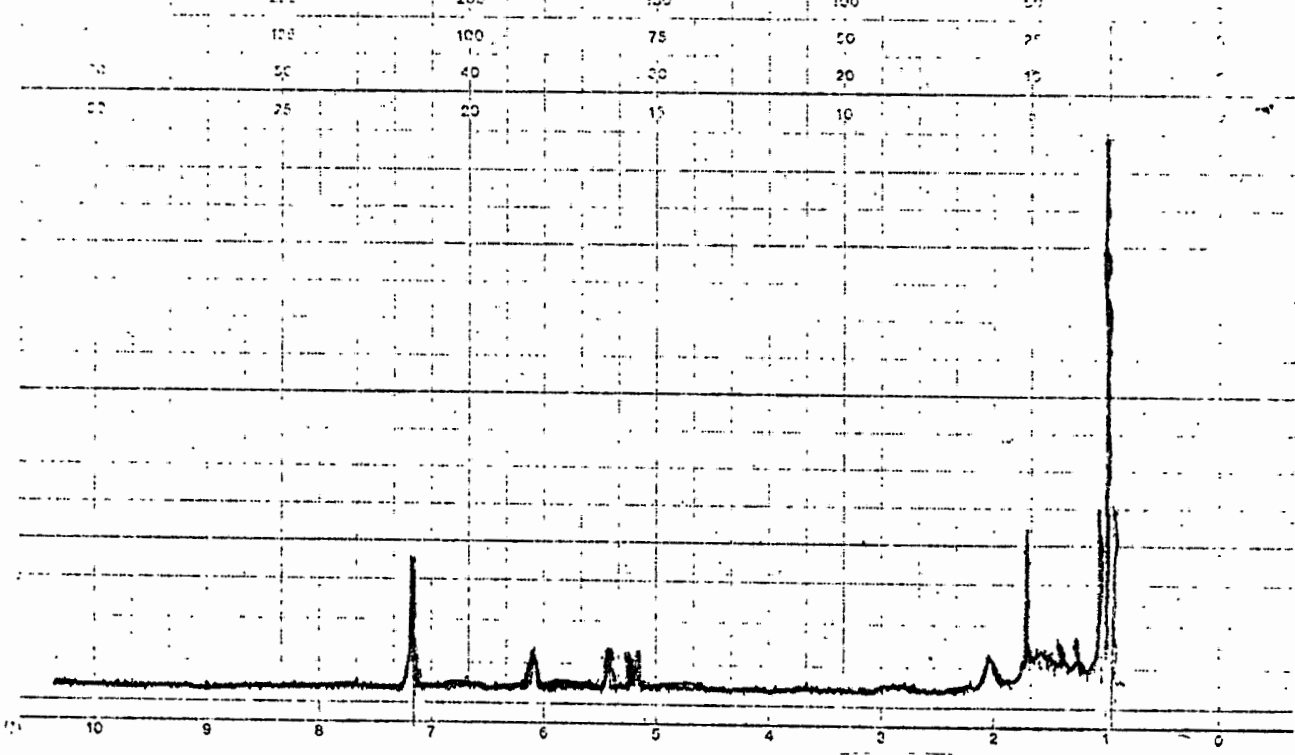

29. Nuclear Magnetic Resonance. Second Rechromatograph. F. franciscana (Howe). Hi tuned 


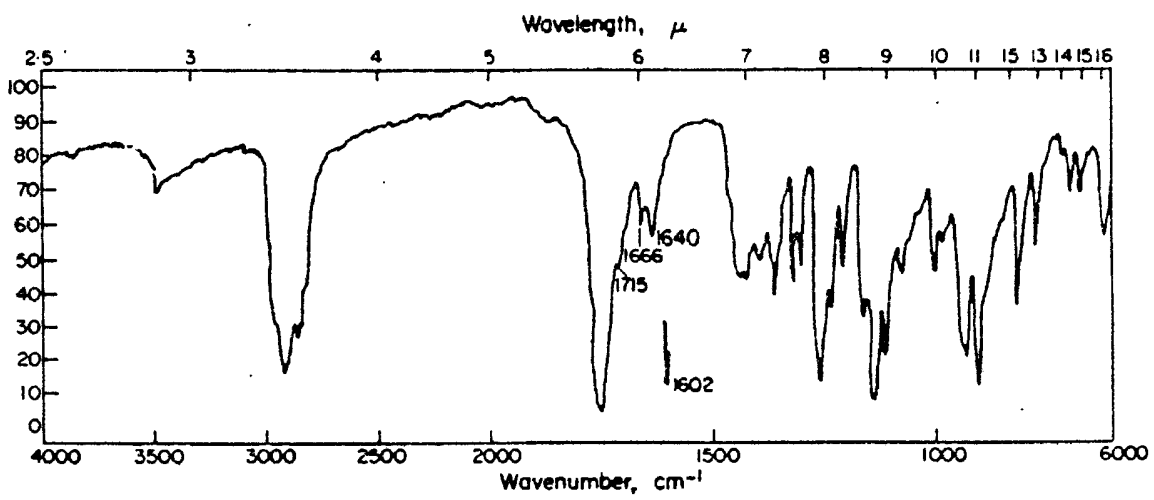

30. Infrared. Frullanolide. Published Spectrum (7)

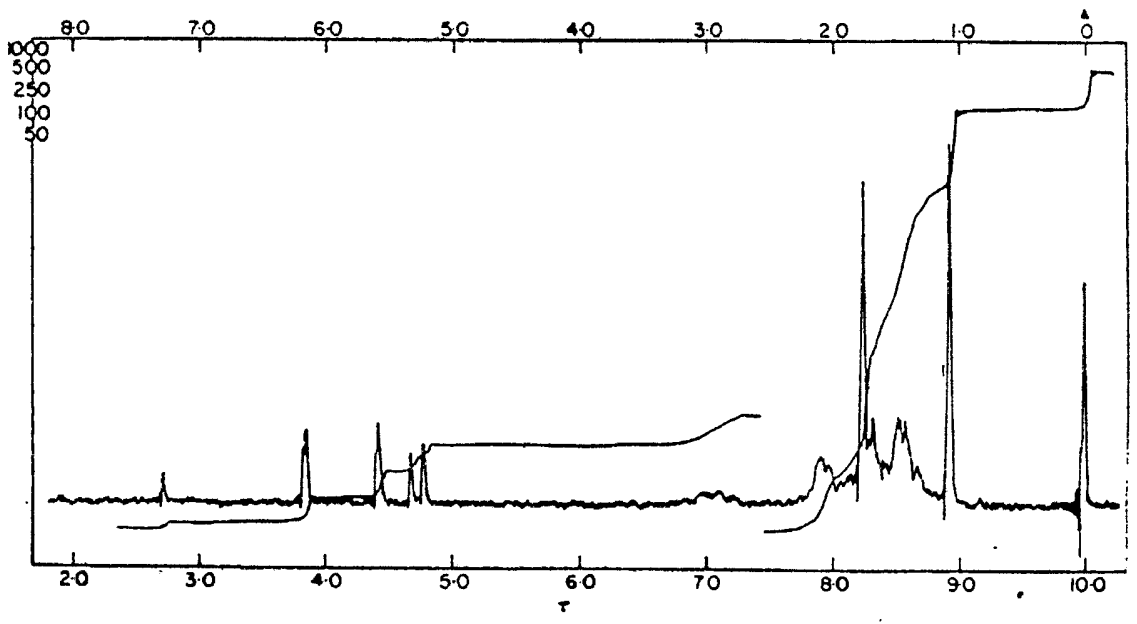

31. Nuclear Magnetic Resonance.

Frullanolide. Published Spectrum (7) 


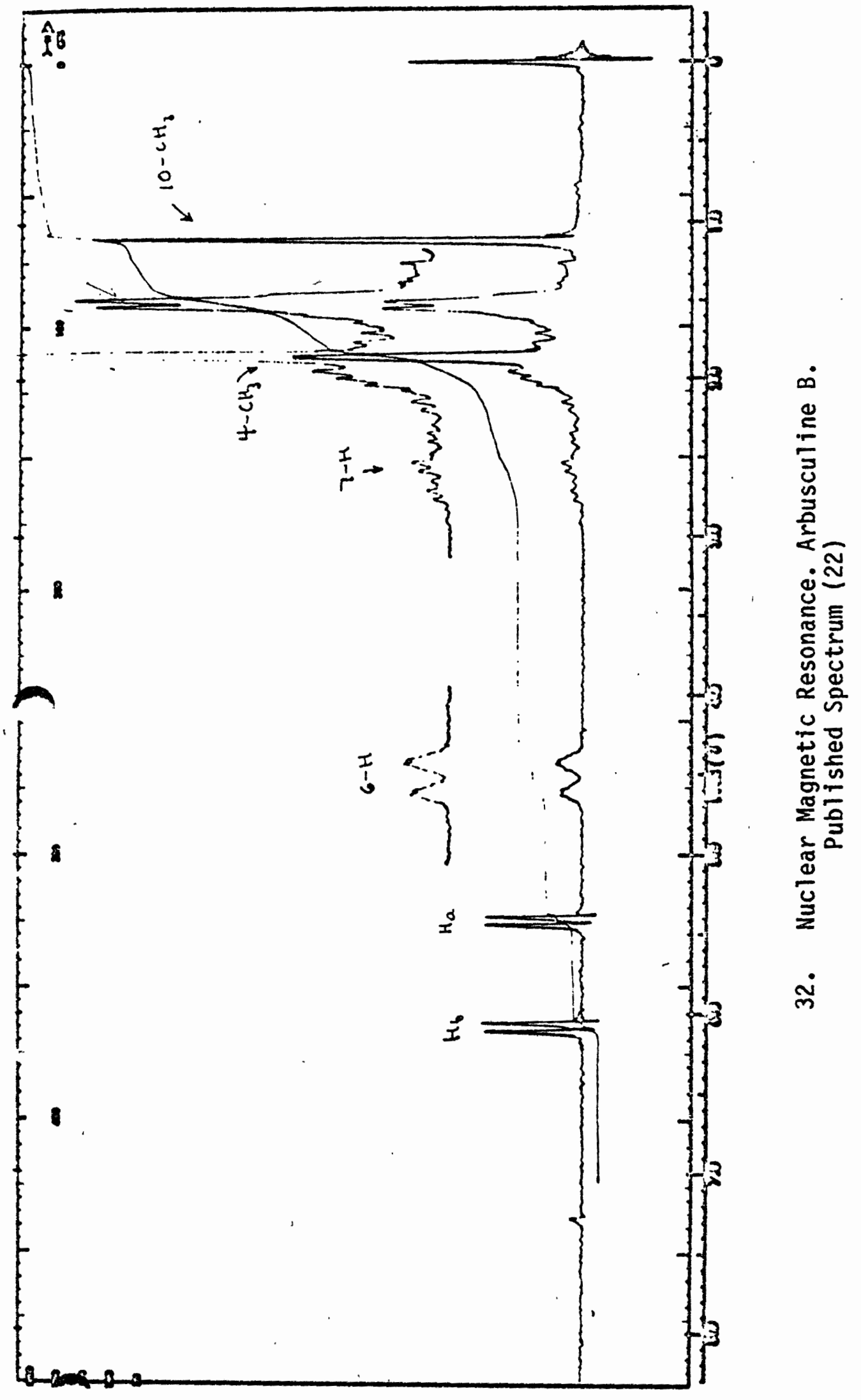




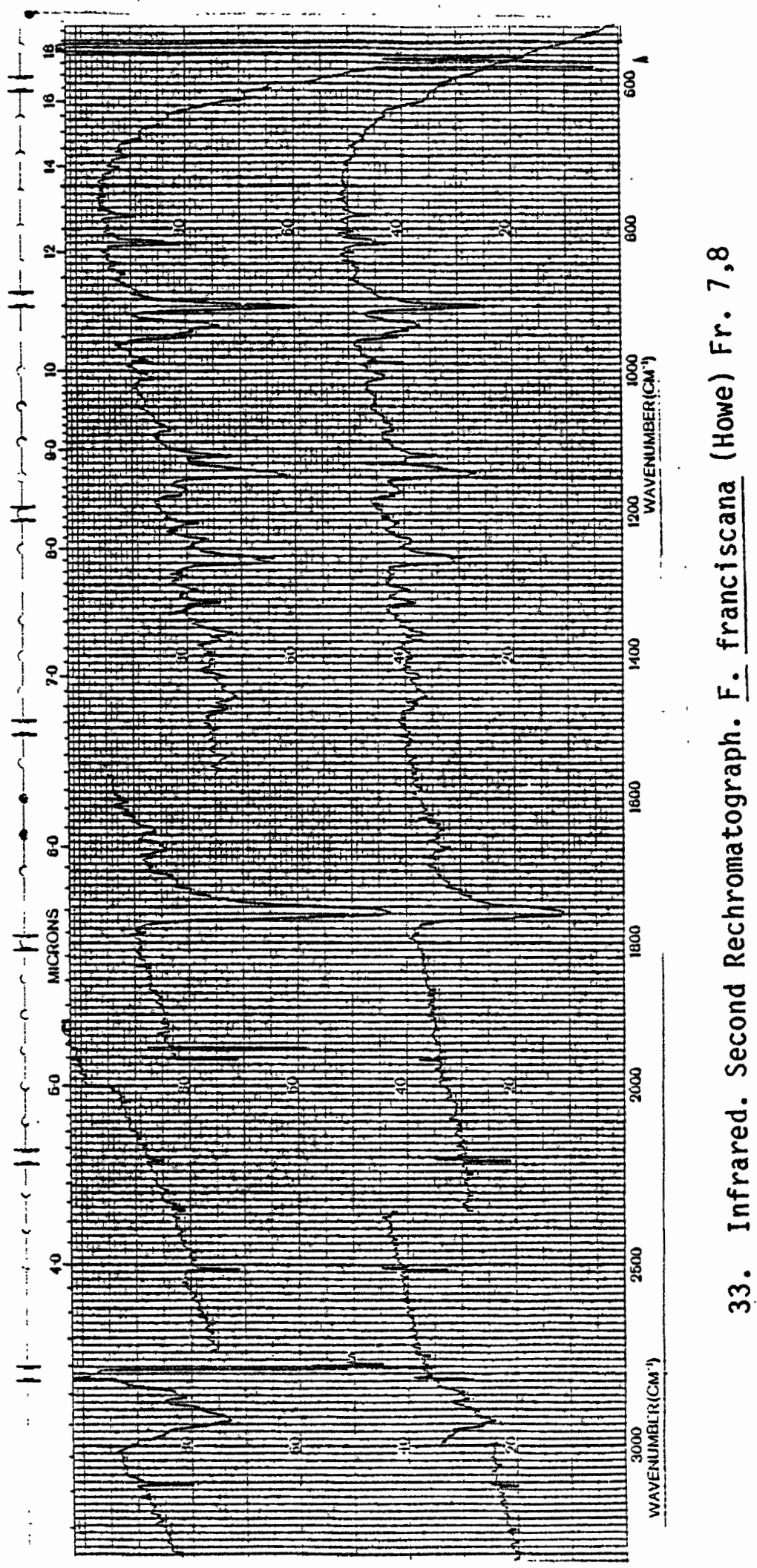

